\title{
Blood pressure control in hemodialysis patients
}

Citation for published version (APA):

Luik, A. J. (1998). Blood pressure control in hemodialysis patients. [Doctoral Thesis, Maastricht

University]. Universiteit Maastricht. https://doi.org/10.26481/dis.19980115al

Document status and date:

Published: 01/01/1998

DOI:

10.26481/dis.19980115al

Document Version:

Publisher's PDF, also known as Version of record

\section{Please check the document version of this publication:}

- A submitted manuscript is the version of the article upon submission and before peer-review. There can be important differences between the submitted version and the official published version of record.

People interested in the research are advised to contact the author for the final version of the publication, or visit the DOI to the publisher's website.

- The final author version and the galley proof are versions of the publication after peer review.

- The final published version features the final layout of the paper including the volume, issue and page numbers.

Link to publication

\footnotetext{
General rights rights.

- You may freely distribute the URL identifying the publication in the public portal. please follow below link for the End User Agreement:

www.umlib.nl/taverne-license

Take down policy

If you believe that this document breaches copyright please contact us at:

repository@maastrichtuniversity.nl

providing details and we will investigate your claim.
}

Copyright and moral rights for the publications made accessible in the public portal are retained by the authors and/or other copyright owners and it is a condition of accessing publications that users recognise and abide by the legal requirements associated with these

- Users may download and print one copy of any publication from the public portal for the purpose of private study or research.

- You may not further distribute the material or use it for any profit-making activity or commercial gain

If the publication is distributed under the terms of Article $25 \mathrm{fa}$ of the Dutch Copyright Act, indicated by the "Taverne" license above, 
Luik, Antinus, Johan

ISBN 90-9011205-7

Cover design: Max Gaasbeek

The scientific work was supported by The Dutch Kidney Foundation.

In addition, financial support of Baxter BV, Mark Sharp \& Dohme BV, Bayer BV, Jansen-Cilag BV. Fresenius BV, Gambro BV, and Hospal-Cobe BV, is gratefully acknowledged. 


\section{Blood pressure control in hemodialysis patients}

\section{PROEFSCHRIFT}

ter verkrijging van de graad van doctor aan de Universiteit Maastricht, op gezag van de Rector Magnificus, Prof. Dr. A.C. Nieuwenhuijzen Kruseman, volgens het besluit van bet College van Decanen, in het openbaar te verdedigen op 15 januari 1998 om 16.00 uur

door

\section{A J Luik}

geboren op 06-08-1959 te Steenwijk 
Promotor

Prof dr JP van Hooff

Co-promotor

Dr KML Leunissen

\section{Beoordelingscommissie}

Prof dr PJEHM Kitslaar, voorzitter

Dr LMAB van Bortel

Prof dr ir APG Hoeks

Prof dr GK van der Hem (Rijksuniversiteit Groningen)

Prof dr GM Londen (University of Fleury, France) 
Aan: Lucas, Sophie en Philine 



\section{Contents}

Chapter 1: Introduction 9

Chapter 2: Diurnal blood pressure variations in hemodialysis and CAPD patients 35

Chapter 3: Influence of inter-dialytic weight gain on blood pressure in hemodialysis patients $\mathbf{4 7}$

Chapter 4: The effects of hypervolemia on inter-dialytic hemodynamics and blood pressure control in hemodialysis patients $\mathbf{5 9}$

Chapter 5: Blood pressure control and hemodynamic changes in patients on long-treatment-time dialysis $\mathbf{7 5}$

Chapter 6: The influence of increasing dialysis treatment-time and reducing dry weight on blood pressure control in hemodialysis patients; A prospective study $\mathbf{9 5}$

Chapter 7: Arterial compliance in patients on long-treatment-time dialysis 111

Chapter 8: Summary and conclusions $\mathbf{1 2 1}$

Chapter 9: Samenvatting 129

Chapter 10: General discussion 137

Dankwoord 149

Curriculum vitae $\mathbf{1 5 3}$ 



\section{Chapter 1}

\section{Introduction}

\section{AJ Luik}

In part published: Dialysis regimens and myocardial hypertrophy. WHM van Kuijk, AJ Luik, KML Leunissen. In Pathogenetic and therapeutic aspects of chronic renal failure. Pp125-135. Editor KM Koch and $G$ Stein. Marcel Dekker, Inc. New York. Basel.Hong Kong. 1997 
Introduction 


\section{Introduction}

In the Netherlands, hemodialysis as a form of renal replacement therapy was for the first time practised in 1943 during World War II by Willem Kolff at the City Hospital of Kampen". Today, half a century later, hemodialysis has become a worldwide therapy for ten's of thousands of patients. In Europe alone, more than 10.000 patients are being treated with hemodialysis ${ }^{2}$. In Europe, the percentage of hemodialysis patients older than 60 years has risen profoundly in the last decade. Moreover, there is an increasing number of end stage renal failure patients due to diabetes mellitus and generalised vascular disease. As a result, the incidence of cardiovascular complications is high ${ }^{3}$. Ischaemic heart disease, cardiac failure and cerebrovascular disease are the main cause of mortality and morbidity in dialysis patients. Hypertension is the most important risk factor of cardiovascular complications $^{4}$. Also, disturbance of calcium/phosphate, glucose and lipid metabolism, anemia, and uremic toxins contribute to cardiovascular complications ${ }^{s}$.

Dialysis treatment-time has decreased during the past 30 years which could have a negative influence on morbidity and mortality. In Europe these days, most patients are dialyzed $12 \mathrm{~h}$ per week or less ${ }^{6}$. Less than $20 \%$ of the patients are dialyzed longer than $12 \mathrm{~h}$ a week. The average treatment-time in the USA is even shorter, probably contributing to the lower survival rate in the USA? ${ }^{7}$. Both the Japanese Registry of dialysis patients as well as the European EDTA registry demonstrate greater mortality rates in patients treated with less than $12 \mathrm{~h}$ dialysis a week as compared to patients with more than $12 \mathrm{~h}$ dialysis a week ${ }^{3,8.9}$. Also, a relationship has been found between weekly $\mathrm{Kt} / \mathrm{V}$ (small molecular weight clearance) and morbidity and mortality ${ }^{10}$.

The incidence of hypertension in hemodialysis patients is high. In Europe, $83 \%$ of the dialysis patients are reported to use antihypertensive drugs and $30 \%$ of the patients have pre-dialytic systolic blood pressure $>160 \mathrm{mmHg} "$. 30 Years ago, hypertension was less a problem and blood pressure could be controlled in most patients without antihypertensive drugs by reducing dry weight ${ }^{12}$. Apart from the change in dialysis population, the change in dialysis treatment also has influence on blood pressure control. Charra reports an excellent blood pressure control, with less than $5 \%$ of his patients having hypertension with long-treatment-time dialysis and a gradual reduction of dry weight ${ }^{13}$. They treat their patients with dialysis 3 times a week for 8 hours, mostly with cuprophane membranes and acetate as a buffer. Dry weight is determined by lowering body weight until a normotensive level is reached. The long dialysis makes it possible to ultra-filtrate fluid excess more gradual, with a better plasma volume preservation, which reduces the chance of intra-dialytic hypotension. They claim that a lower dry weight can be reached with this type of conventional dialysis as compared to short term dialysis. However, during the long dialysis sessions, patients are also more efficiently 
dialyzed in terms of removing small and midde nolecular toxins which could have an positive effect on blood pressure control as well ${ }^{4}$.

\section{Defining blood pressure control}

Defining hypertension in hemodialysis patients is difficult because blood pressure is usually measured during the dialysis session. Pre-dialytic blood pressure could be infuenced by flud excess and possibly by accumulation of vasoactive dialysable factors. Post-dialytic blood pressure could be infuenced by the dialysis treatment, ultra-filtration rate and the capacity to compensate for the decrease in circulatory volume. Many factors infuence vascular refilling rate ${ }^{15}$. Also structural changes, like a decreased venous compliance can impair effective circulatory volume during ultrafiltration and can lead to a steeper decline in central venous pressure by a change of plasma volume as compared to patients with a normal venous compliance $^{16}$. Autonomous neuropathy, end-organ resistance to the effect of vasoactive hormones, and the dialysis procedure itself can interfere with adequate vascular constricting response to a decline in circulatory volume, resulting in a blood pressure drop during hemodialysis and ultra-filtration ${ }^{17}$. When comparing pre-dialytic and post-dialytic blood pressure, post-dialytic blood pressure appears to be more representative for the average inter-dialytic blood pressure ${ }^{18}$. However, in general, post-dialytic blood pressure may lead to under estimation of average blood pressure control, whereas pre-dialytic blood pressure will over estimate average blood pressure.

A better way to determine blood pressure level in hemodialysis patients would be a continuous blood pressure recording between two dialysis sessions. Ambulatory blood pressure monitors, measuring blood pressure several times an hour, make it possible to obtain a full inter-dialytic blood pressure profile. In non-uremic patients, average 24 hour blood pressure, measured with ambulatory blood pressure monitors, have a greater predictive value on the incidence of cardiovascular morbidity and mortality than casual blood pressure ${ }^{19}$. Healthy volunteers as well as patients with essential hypertension, have circadian blood pressure and heart rate variation ${ }^{20}$. Blood pressure tends to be highest in the morning and lowest during the night, with a gradual decrease over the course of the day. In healthy subjects diurnal blood pressure variation seems to be particularly influenced by arousal and physical activity ${ }^{21}$. Fluctuations in arterial pressure and sympathetic activity over a 24 hour period are closely coupled and sympathetic activity seems to be the main determinant in diurnal blood pressure variation ${ }^{22,23}$. A blunted day-night blood pressure difference is associated with an increased incidence of left ventricular hypertrophy ${ }^{24}$. 
Few studies are available on ambulatory blood pressure measurements in hemodialysis patients ${ }^{18.25-28}$. Blood pressure in hemodialysis patients changes along the inter-dialytic period, and one would expect that the superiority of ambulatory blood pressure monitoring over casual pre- or post-dialytic blood pressure measurement in predicting cardiovascular morbidity and mortality, is especially true for hemodialysis patients. However, hard data are not yet available.

In dialysis patients, diurnal blood pressure drop is blunted with sometimes even an increase of blood pressures during the night instead of a blood pressure decline $e^{18,25-28}$. This can contribute to cardiovascular complications in dialysis patients and especially to the high incidence of left ventricular hypertrophy (LVH) in dialysis patients. Why diurnal blood pressure drop is blunted in dialysis patients is not clear. Autonomic failure ${ }^{29}$, increased neural sympathetic activity ${ }^{30}$ and elevated levels of catecholamines ${ }^{31}$, heart failure ${ }^{32}$, the use of erythropoietin ${ }^{33}$, and reduced daily activity could all play a role. It has been suggested that volume expansion and inter-dialytic volume changes could also contribute to the attenuated diurnal blood pressure rhythm ${ }^{25}$. Whether the more stable fluid status in CAPD patients compared to hemodialysis patients results in a better preserved diurnal blood pressure rhythm is not known.

\section{Blood pressure control and dialysis modality}

Comparing different dialytic modalities in the management of hypertension is a difficult and complicated matter. As will be discussed later, different pathogenetic factors play a role in hypertension in uremic patients, as fluid state, vasopressor systems and perhaps dialysis dose, which make standardized comparison not possible. Hemodialysis, peritoneall dialysis and hemofiltration have quite different clearance profiles and different possibilities to extract sodium and fluid. CAPD and hemofiltration have a relative better clearance of toxins in the middle molecular weight range as compared to hemodialysis which offers a relative better small molecular weight clearance. CAPD is a continuous process with daily controlled ultra-filtration, making it easier to lower dry weight as compared to hemodialysis. Also hemofiltration offers better possibilities to ultra-filtrate with less hemodynamic instability as compared to hemodialysis ${ }^{34}$. All three dialytic therapies are capable of improving blood pressure control in end stage renal failure $e^{12,35,36}$. Some authors find a superior blood pressure control in CAPD patients as compared to hemodialysis patients $^{35}$. When patients are shifted from hemodialysis to CAPD blood pressure is found to be better controlled ${ }^{37}$. This is associated with a significant weight loss and thus a reduction of extra-cellular fluid. Others failed to find a superior blood pressure control in CAPD patients as compared to hemodialysis patients ${ }^{38}$. However, the efficiency to control blood pressure in CAPD patients declines after one or more years ${ }^{39}$. This can be due to less disciplined sodjum and fluid regime, loss of residual renal function or structural changes of the peritoneal membrane, 
with as consequence a decreased ultra-filtration and/or clearing capacity.

Quelhorst found blood pressure to be better controlled in dialysis resistant hypertensive patients when they switched to hemofiltration ${ }^{36}$. Hemofiltration made it possible to lower dry weight. However, high renin activity was also lowered after switching to hemofiltration. A beneficial effect of hemofiltration on blood pressure control was especially found in patients with very high blood pressures at the start of the treatment.

A better blood pressure control was also found in patients who switched from conventional hemodialysis to hemodiafiltration ${ }^{40}$. This could not be explained by a reduced total body sodium or water content. These data on hemofiltration could be an indication of a favourable effect of convective clearance on blood pressure control.

\section{Pathogenetic factors in hypertension}

The etiology of hypertension in hemodialysis patients is multiple and not completely understood ${ }^{41}$. The frequency of hypertension varies with the type of primary renal disease although reported incidence of hypertension in renal diseases varies substantial in different studies ${ }^{42}$. Patients with diabetes, renal-vascular disease, focal glomerulosclerosis and adult polycystic disease have more often and more severe hypertension than patients with IgA nephropathy and chronic interstitial nephritis ${ }^{42,43}$. We discussed already the increasing portion of patients with renovascular disease and diabetes on renal replacement therapy.

A disturbed hormonal pattern with an activated renin-angiotensin system, increased catecholamines, and elevated arginine vasopressin concentrations could all increase blood pressure. Also local vascular factors as endothelin and NO could play a role. Neural sympathetic activity is found to be increased in dialysis patients. Other possible factors are autonomic neuropathy, the use of erythropoietin, and functional and structural vascular changes. However, hypervolemia has always been considered the most important factor in elevating blood pressure in dialysis patients ${ }^{44}$.

\section{Volume status}

Sodium and fluid retention play a major role in the pathogenesis of hypertension in renal failure. Optimalisation of fluid state and an accurate determination of ideal dry weight is the first step in the management of hypertension in dialysis patients. The definition of dry weight as can be found in the textbooks is "that weight below which a normo-albuminemic patient on dialysis will become hypotensive with fluid removal, and above which the same patient will either be hypertensive or show 
subtle signs of fluid expansion" ${ }^{\text {s45 }}$. However, a low blood pressure at the end of the dialysis procedure does not strictly mean that the patient is at his dry weight but merely reflects the inability to compensate the decrease in circulatory volume, and blood pressure can rise again a few hours after dialysis when intravascular refilling has been completed. More objective methods for the determination of dry weight have been developed ${ }^{45}$. Echographic measurement of the caval vein diameter is a good parameter for intravascular hydration state ${ }^{47}$. This measurement has been successfully validated against right atrial pressure, which may be considered the gold standard for the estimation of fluid state. Moreover there also appeared to be a strong correlation between caval vein diameter and total blood volume. Postdialytic measurement of the caval vein diameter should not be performed directly after dialysis when the refilling of fluid from the interstitium to the intravascular space has not been completed. This is especially evident after short and rapid ultrafiltration ${ }^{48}$. Conductivity measurements are also developed for the determination of intra- and extra-cellular volume $e^{49}$. By measuring conductivity of current at low and high frequencies evoked by electrodes positioned at the lower and upper extremities, intra-cellular and extra-cellular resistivity is measured. Extra-cellular and intra-cellular volume is calculated from the difference of resistivity between patients and healthy controls, which makes this method at the moment not reliable. Current studies are being performed to validate this method against extra-cellular volume measurements in dialysis patients using nuclear techniques.

Patients with severe renal failure starting with dialysis, are often hypervolemic and hypertensive. After institution of dialysis treatment, hypervolemia will be corrected and blood pressure is mostly better controlled ${ }^{12}$. However this does not necessarily mean that the normalisation of blood pressure can completely be explained by the reduction of fluid status.

The relationship fluid status - blood pressure control is explained by Guyton's concept of autoregulation of systemic blood flow ${ }^{50}$. According to this theory, blood flow to peripheral tissues is carefully regulated by changes in local vascular resistance. Any increase in cardiac output, induced by expansion of extracelluarand/or blood-volume, augments peripheral blood flow, which in turn elicits an increase in peripheral vascular resistance in order to restore blood flow towards baseline. However, in a study of 10 dialysis patients who underwent salt and water loadingst, only one of these patients followed the classic pattern of Guyton's autoregulation hypothesis. In two patients blood pressure did not change after increasing dry weight. Studies on the relationship between volume status and blood pressure are not conclusive. De Planque found a good correlation between blood pressure and extra-cellular volume in hypertensive patients with advanced renal failure who were not yet treated with dialysis ${ }^{52}$. Dathan failed to find a correlation between extra-cellular water and blood pressure in patients with chronic renal 
failure not yet on dialysis ${ }^{53}$. However, they found a relationship between blood pressure and exchangeable sodium and blood volume. Wilkinson could not find a relationship between blood pressure and exchangeable sodium in hemodialysis patients ${ }^{54}$. Only after nephrectomy in 14 patients, was he able to find a correlation between diastolic blood pressure and exchangeable sodium. Schultze studied normotensive and hypertensive hemodialysis patients in spite of efforts to reduce dry weight ${ }^{55}$. The hypertensive patients were found not to be more volume expanded as compared to the normotensive patients. Although it is clear that chronic fluid overload has an important impact on blood pressure control, the relationship between fluid state and blood pressure is rather complex in which also other factors are playing a role.

The effect of short term (inter-dialytic) fluid shifts on blood pressure are even less clear. Using ambulatory blood pressure monitors, Kooman could not find a relationship between inter-dialytic blood pressure changes and inter-dialytic weight changes ${ }^{18}$. Sherman measured pre-dialysis blood pressure and inter-dialytic weight gain in 19 hemodialysis patients during 17-25 treatments ${ }^{56}$. A significant MAP/ excess weight slope could be found in only 5 of the 19 patients, averaging 5.35 $\mathrm{mmHg} / \mathrm{kg}$. Leene studied the effect of inter-dialytic saline infusion in 7 hemodialysis patients ${ }^{57}$. Although he found a significant blood pressure rise after saline infusion, this blood pressure rise was not different from the usual interdialytic blood pressure rise, and pre-dialysis blood pressure was comparable to predialysis blood pressure in the previous inter-dialytic period.

Changes in body sodium content is mostly parallelled by changes in fluid state. Whether changes in sodium content apart from changes in fluid state can influence blood pressure is not clear. $\mathrm{Na}-\mathrm{K}$ ATPase inhibitor activity has been found to be increased in hemodialysis patients ${ }^{58}$. Intra-cellular sodium is found to be correlated with Na-K ATPase inhibitor activity and systolic blood pressure. Na-K ATPase inhibitor activity is probably influenced by dialysis ${ }^{59}$.

Changing dialysate sodium concentration does not seem to have significant impact on blood pressure regulation. Henrich increased exchangeable sodium in hemodialysis patients by elevating dialysate sodium concentration over a 6 weeks period $^{60}$. Inter-dialytic weight gain increased without an effect on blood pressure control. Barre compared the effect of dialysate concentration of $1.45 \mathrm{mmol} / \mathrm{l}$, $150 \mathrm{mmol} / 1$, and $155 \mathrm{mmol} / 1$ during two months $\mathrm{s}^{61}$. Inter-dialytic weight gain increased without a change in serum sodium concentration, while there was not an increased incidence of hypertension.

The severity of fluid overload could also play a role. It is possible that dialysis patients are able to compensate a moderate increase in extra-cellular fluid and 
circulating volume by reduction of vascular constriction as can be found in normotensive patients with slightly impaired renal failure ${ }^{62}$. When fluid excess becomes to high, compensatory mechanisms will fail and blood pressure will rise. Individual difference in capacity to compensate for a certain increase in extracellular volume and circulatory volume could explain the differences in blood pressure response in dialysis patients to fluid load. As we discussed above, chronic fluid changes probably have different effects on blood pressure compared to more short term inter-dialytic fluid changes.

The inconsistency in finding a relationship between volume parameters and blood pressure, and the often weak correlation when a relationship is found, points to the fact that other co-factors influence the relationship between volume status and blood pressure. Hormonal factors such as the renin-angiotensin and sympathetic system interfere with this relationship. Also cardiac and vascular alterations may influence the effect of fluid load on blood pressure. These relationships will be discussed later.

\section{Pressor systems}

An activated renin-angiotensin system is considered to be the major factor in elevating blood pressure in hemodialysis patients who do not respond to lowering dry weight in an effort to control blood pressure ${ }^{44}$. In these volume non-responders with uncontrollable hypertension, plasma renin activity is often found to be elevated $^{12,63}$. Bilateral nephrectomy produces a significant decrease in blood pressure in these patients. However, plasma renin is not always elevated in hypertensive normovolemic dialysis patients ${ }^{55,64}$. On the other hand plasma renin can also be elevated in normotensive normovolemic patients. The relationship of the renin-angiotensin system with blood pressure, volume status, and other hormonal axes is complex, and cannot be considered as a separate entity. In hemodialysis patients, the reciprocal relationship between volume and exchangeable sodium is disturbed ${ }^{65}$. Circulating levels of renin and angiotensin are inappropriate increased in relationship to sodium and volume state ${ }^{66}$. However, the response to saline infusion seems to be normal in lowering plasma renin activity ${ }^{57}$, whereas volume depletion during dialysis increases plasma renin activity ${ }^{67}$. The vascular reactivity after angiotensin II stimulation is found to be reduced in hemodialysis patients $^{68}$. The exact role of the renin-angiotensin system in blood pressure control in dialysis patients is not clear. Elevated renin and angiotensin concentrations in hypertensive patients could contribute to the elevated blood pressure. On the other hand modulation of the renin-angiotensin activity can possibly protect patients against blood pressure elevation after expanding extra-cellular volume. This could explain why some investigators find a positive correlation between blood pressure and plasma renin ${ }^{54}$, and others fail to find such a relationship ${ }^{55.64}$.

Norepinephrine is mostly found elevated in hypertensive as well as in normotensive 
hemodialysis patients, although normal norepinephrine concentrations can be found as wel1 ${ }^{6971}$. A decreased blood pressure response to norepinephrine infusion is found in experimental chronic uremia and in hemodialysis patients ${ }^{7,72}$. Decreasing sympathetic outflow with debrisoquine increases $\alpha$ and $\beta$-receptor sensitivity. The decreased responsiveness to norepinephrine is possible caused by down regulation of $\alpha$-adrenoreceptor by the increased norepineprine levels. Daul found decreased platelet $\alpha 2$-receptor density in hypotensive hemodialysis patients ${ }^{73}$. Platelet $\alpha 2$ receptor density and norepinephrine concentration are inversely correlated ${ }^{74}$.

Apart from elevated catecholamine levels, nervous sympathetic activity is increased in dialysis patients, contributing to peripheral vasoconstriction. Microelectrode recordings of postganglionic sympathetic action potentials in peroneal nerves of chronic hemodialysis patients have shown that the rate of sympathetic nerve discharge was 2.5 times higher in hemodialysis patients as compared to control subjects $^{17}$. Bilateral nephrectomy was associated with normalized sympathetic nerve firing, lower regional vascular resistance, and lower MAP, suggesting an afferent nervous input from the scarred kidney to the central nervous system. Sympathetic nerve discharge was not correlated with plasma norepinephrine levels. Both nephrectomized as non-nephrectomized hemodialysis patients had elevated norepinephrine levels as compared to normal controls.

Nitric Oxide (NO) an endothelial vasodilating substance, synthesized from l-arginine, contributes to blood pressure regulation. Vallance found asymmetric dimethylarginine (ADMA), an endogenous inhibitor of NO, to be 8-fold increased in hemodialysis patients as compared to normal controls ${ }^{75}$. Arginine, the endogenous substrate for NO synthase, was reduced in dialysis patients. An impaired NO synthesis in dialysis patients, could contribute to hypertension in these patients. ADMA concentration in uremic patients is reduced by hemodialysis treatment $^{76}$. A higher clearance of ADMA during long-treatment-time dialysis as compared to short-treatment-time dialysis, could be one factor in the good blood pressure control in patients on long-treatment-time dialysis ${ }^{14}$.

Apart from endothelial NO, neuronal NO probably also plays a role in blood pressure control in hemodialysis patients. Victor hypothized that neuronal NO could be an inhibitory neuromodulator involved in the tonic restraint of central sympathetic outflow ${ }^{77}$. In chronic renal failure, accumulation of endogenous NO inhibitors could lead to sympathetic overactivity. He found chronic inhibition but not acute inhibition of NO to increase MAP twice as much in control rats as compared to rats with sympathectomy. Whether these results can be extrapolated to humans is subject to further research.

Arginine vasopressin is increased in hemodialysis patients ${ }^{68}$. In healthy subjects 
vasopressin release is mainly regulated by serum osmolarity, although also hypovolemia can increase vasopressin release ${ }^{78}$. Besides antidiuretic effects in nonuremic subjects, AVP has also vasoconstricting properties. A normal increase in AVP concentration in uremic patients after hypertonic saline infusion is found, suggesting a normal function of the hypothalamic osmoreceptors ${ }^{79}$. Hegbrant found a decrease in AVP parallel with the decrease in plasma osmolality during isovolemic bicarbonate hemodialysis ${ }^{80}$. Heintz found an increase in AVP parallel with changes in blood volume during isolated ultra-filtration ${ }^{81}$. So, in hemodialysis patients osmolarity as well as volume status can influence AVP concentration. The effect of AVP on blood pressure control in dialysis patients is not clear.

Endothelin, a potent vasoconstricting peptide, is mostly found elevated in hemodialysis patients ${ }^{82}$. Whether the increased endothelin concentrations is caused by the reduced renal function itself or by local vascular factors, such as endothelial cell damage, shear stress, hypoxia or cytokines is not clear ${ }^{* 3}$. The plasma concentrations found in hemodialysis patients however, are much lower than necessary to elevate blood pressure. However, the main action of endothelin may be an autocrine or paracrine action.

$\alpha$-ANP is elevated in hemodialysis patients. $\alpha$-ANP decreases linear to weight loss during hemodialysis ${ }^{84}$. $\alpha$-ANP concentration in dialysis patients is mainly influenced by fluid status ${ }^{85}$. Measuring $\alpha$-ANP in non-uremic patients with heart disease, $\alpha$-ANP appeared to be correlated with mean right atrial pressure ${ }^{86}$. Also in hemodialysis patients $\alpha$-ANP is significantly correlated with right atrial pressure ${ }^{87}$. Changes in $\alpha$-ANP during ultra-filtration is also significantly correlated with changes in left atrial volume ${ }^{88}$. $\alpha$-ANP concentrations in hemodialysis patients must particullarly be seen as an index of overhydration. In a recent study $\alpha-$ ANP had no influence on hemodynamics in hemodialysis patients ${ }^{89}$.

\section{Uremic toxins and dialysis dose}

An adequate blood pressure control with an incidence of hypertension below $5 \%$ can be achieved by long-treatment-time dialysis ( 8 hours three times weekly) at the Tassin dialysis center ${ }^{13}$. In this dialysis center patients are dialyzed in a way which was custom 20 years ago. With shortening of dialysis treatment-time over the last two decades, hypertension has become an increasing problem. Today, bicarbonate buffer, biocompatible membranes, sodium profiling etc improves hemodynamic stability during dialysis, and makes it possible to ultra-filtrate a certain amount of fluid in shorter time. However, this has not prevented the increased incidence of hypertension. Patients today are less dialyzed in terms of clearance with short dialysis as compared with "old fassion" long dialysis, as practised in Tassin. This stresses the fact that dialysis dose can have influence on blood pressure control. 
Dialysis dose is quantified by $\mathrm{Kt} / \mathrm{V}^{90}$. However, $\mathrm{Kt} / \mathrm{V}$ only quantifies small molecular ureum clearance. CAPD and hemofiltration have a relative higher middle molecular clearance than small molecular (ureum) clearance as compared to hemodialysis. We already mentioned improving blood pressure control when hypertensive patients were switched from hemodialysis to hemofiltration ${ }^{36}$, and when patients were switched from hemodialysis to $\mathrm{CAPD}^{37}$. A higher clearance of small and middle molecular weight vasoactive substances probably contributes to the better blood pressure control.

Victor hypothized that neuronal NO could be an inhibitory neuromodulator involved in the tonic restraint of central sympathetic outflow, and that accumulation of uremic toxins can inhibit endothelial NO synthesis ${ }^{7}$. ADMA an endogenous inhibitor of vascular endothelial NO accumulates in dialysis patients and can be cleared by dialysis ${ }^{75}$. Also other, yet unknown uremic toxins possibly influence sympathetic outflow. The observation that $\mathrm{Na}-\mathrm{K}$ inhibitor is increased in diallysis patients, and that $\mathrm{Na}-\mathrm{K}$ inhibitor can be influenced by dialysis, is interesting when considering possible uremic vasoactive substances ${ }^{58.59}$.

\section{Other factors}

Hemodialysis patients often have autonomic dysfunction, resulting in a disturbed baroreceptor reflex arc. However there is a normal reaction to efferent sympathetic stimulation ${ }^{91,92}$. This depressed baroreceptor activity can influence hemodynamic stability during dialysis. If autonomic dysfunction contributes to hypertension in dialysis patients is not clear.

Hypertension is a common complication of erythropoietin (EPO) therapy ${ }^{93}$. The increase in systemic vascular resistance after EPO therapy has been attributed to the loss of hypoxic vasodilatation, to changes in humeral effects on resistance, and increased blood viscosity ${ }^{94,95}$. EPO stimulates vascular endothelial cells in culture to increase endothelin release ${ }^{96}$. A positive relationship between blood pressure and endothelin concentration has been found in patients treated with $\mathrm{EPO}^{97,98}$

A possible link exists between hyperparathyroidism, calcium metabolism and blood pressure control. Pizzarelli found a significant blood pressure reduction after parathyroidectomy in 7 of 11 hemodialysis patients ${ }^{99}$. The data on this subject is however still scarce and not unequivocal, and does not permit dogmatic statements ${ }^{100}$.

The pathogenetic factors of hypertension in dialysis patients are complex and not fully understood. Volume overload and vasopressor systems influence blood pressure control. Dialysis treatment can possibly influence blood pressure by decreasing fluid status and by clearing vasoactive substances. In this view, dry 
weight as well as dialysis dose could have their impact on blood pressure control.

\section{Cardiovascular changes}

\section{Left ventricular hypertrophy (LVH)}

Cardiac disease is the major cause of death in dialysis patients (2). Cardiac disease in hemodialysis patients usually results from systolic failure, LVH with diastolic dysfunction, or ischaemic disease ${ }^{101}$. The prevalence of LVH is high among hemodialysis patients and has shown the most predominant structural cardiac finding ${ }^{102-104}$. LVH appears to be an important, independent, determinant of survival in uremic patients ${ }^{105}$. $\mathrm{LVH}$ is a physiological adaptation in response to increased pressure or volume overload and is often a combination of concentric and eccentric hypertrophy. In concentric and septal hypertrophy, cardiac wall and septum are increased by chronic pressure overload due to hypertension or increased stiffening of the arterial systemic vasculature. Eccentric LVH results from chronic volume load due to hypervolemia, anemia, and arteriovenous fistula. Other factors contributing to LVH are age, hyperparathyroidism, and perhaps uremic toxins ${ }^{106}$. A diffuse interstitial fibrosis has been found in the myocardium of uremic patients. PTH might be recognized as a specific uremic toxin and has been found to correlate with the ratio: left ventricular radius/left ventricular wall thickness ${ }^{107}$.

Hypertension plays a central role in the occurrence of LVH. Harnett found age, hypertension, and alkaline phosphatase the most important factors independently related to LVH in dialysis patients ${ }^{102}$. Also others found hypertension to be an important independent risk factor for LVH in dialysis patients ${ }^{108,109}$. Harnett evaluated 51 patients without LVH at the start of dialysis treatment and had dialysis for at least two years ${ }^{110}$. 14 Patients developed LVH and 37 did not. Systolic blood pressure correlated significantly with final posterior left ventricular wal] thickness. Age and systolic blood pressure were significantly and independently associated with increased left ventricular mass. Cannella found a reduction in LVH in uremic patients after prolonged antihypertensive therapy ${ }^{11}$. This indicates the importance of a good blood pressure control, not only for the prevention of increasing $\mathrm{LVH}$ but also for treatment of LVH.

We already discussed the optimal blood pressure control in patients on longtreatment-time dialysis with less cardiovascular morbidity and mortality ${ }^{13}$. However, Hüting found still considerable LVH in long-treatment-time dialysis patients despite an adequate blood pressure control ${ }^{112}$. This emphasises other risk factors such as age, hypervolemia, fistula, decreased arterial compliance, anemia, or hyperparathyroidism, in these patients that influences left ventricular mass. The 
importance of anemia on $\mathrm{LVH}$ in dialysis patients has become more clear after the introduction of EPO therapy. Several sudies are showing partial reduction of left ventricular mass after EPO therapy ${ }^{11,113,114}$.

\section{Systolic and diastolic left ventricular dysfunction}

Left ventricular dysfunction is often found in hemodialysis patients ${ }^{\text {I15.5 }}$. Reduced myocardial contractility by myocardial infarction, carnitine deficiency, acetate dialysis, and perhaps uremic toxins and hyperparathyroidism can contribute to reduced systolic function ${ }^{101}$. Also hypercirculatory state with inadequate eccentric LVH induced by anemia, fluid overload, or dialysis fistulae can have a negative influence on left ventricular systolic performance.

Diastolic dysfunction in hemodialysis patients is often seen in combination with (concentric) $\mathrm{LVH}^{104,116}$. The compliance is reduced resulting in an impaired capacity of the ventricle to accept blood without a disproportionate increase in left ventricular enddiastolic pressure. Left atrial diameter is increased in hemodialysis patients most likely due to an increased atrial contribution to left ventricular filling caused by the noncompliant ventricular wall ${ }^{117}$. Diastolic function improves after dialysis treatment ${ }^{118}$. Whether uremic toxins have a deteriorating effect on ventricular compliance is still a matter of debate.

\section{Vascular compliance}

Arterial compliance is reduced in hemodialysis patients ${ }^{119,120}$. The consequence of the decreased arterial compliance is an increase in arterial pulse pressure resulting in a decrease in diastolic pressure and an increased systolic pressure ${ }^{121}$. Arterial compliance affects pulse pressure amplitude in two ways. First, a direct effect of the left ventricle when it has to eject into a stiff arterial system. Second, an indirect effect by an increased velocity of the pressure wave trough the stiffened arterial system, resulting in a change on the timing and incidence of reflected waves. It is not clear if the decreased arterial compliance in uremics is a passive consequence of an increased blood pressure or the consequence of altered arterial composition, i.e. smooth muscle hypertrophy and increased collagen content of the media ${ }^{122}$. London suggests arterial stiffness to be a pathogenetic factor in concentric LVH by increasing cardiac pressure load ${ }^{104}$. A decreased arterial compliance could be a factor in the presence of LVH despite optimal blood pressure control in patients on long-treatment-time dialysis ${ }^{112}$.

Another point of interest is the possible modulation of arterial compliance on the effect of fluid overload on blood pressure. Fluid overload can increase stroke volume. A higher stroke volume could possible increase systolic blood pressure more in a stiffened arterial system than in a more compliant arterial system, thus having more impact on blood pressure control. 
Also venous compliance is reduced in hemodialysis patients ${ }^{91}$. Hypertension, not renal failure itself, seems to be the cause of the reduced venous compliance. A reduced venous compliance is an important factor in hemodynamic instability during hemodialysis ${ }^{16}$. Whether venous compliance has any impact on inter-dialytic blood pressure control through an effect on venous return after changes in extracellular and intravascular volume, is not clear.

LVH and a decreased vascular compliance is often found in dialysis patients. Hypertension is a major pathogenetic factor of LVH and a decreased vascular compliance. On the other hand, a decreased arterial compliance can also induce LVH. Normalizing blood pressure could possibly restore vascular compliance with a regression of $L V H$. 


\section{Aims of the study}

The main goal of this study is to investigate possible pathogenetic mechanisms that influence inter-dialytic blood pressure regulation with special focus on fluid status and dialysis dose.

In chapter 2 we studied diurnal blood pressure variation in normotensive and hypertensive hemodialysis patients, CAPD patients, and non-uremic controls without the use of antilhypertensive drugs. The influence of inter-dialytic weight gain on diurnal blood pressure pattern was analyzed. Furthermore it was studied whether the more stable fluid state in CAPD patients as compared to hemodialysis patients, resulted in better preservation of day-night blood pressure differences.

The influence of short-term inter-dialytic weight gain on blood pressure control in normotensive and hypertensive hemodialysis patients is described in chapter 3 . Blood pressure changes during a 2-day inter-dialytic period were compared to blood pressure changes during a 3-day inter-dialytic period with a concomitant higher inter-dialytic weight gain.

In chapter 4 the influence of short-term hypervolemia on inter-dialytic blood pressure control and hemodynamics was prospectively studied. The effect of $3 \mathrm{~L}$ fluid load on cardiac output, systemic vascular resistance, and blood pressure was evaluated also in relationship to the arterial- and venous compliance and hormonal changes.

Chapter 5 describes our study in Tassin where we evaluated hemodynamics and inter-dialytic blood pressure control in patients on long-treatment-time dialysis $24 \mathrm{~h}$ a week. We studied whether the good blood pressure control in patients on longtreatment-time dialysis was associated with a lower fluid state or a higher dialysis dose. Inter-dialytic blood pressure was evaluated in relationship to inferior caval vein diameter, cardiac output, systemic vascular resistance and compared to patients on short-treatment-time dialysis. Furthermore we analyzed whether the better blood pressure control in patients on long-treatment-time dialysis is associated with less activation of the renin-angiotensin or sympathetic system, and whether the better blood pressure control in Tassin was associated with less LVH as compared to short-treatment-time dialysis.

In chapter 6 the effect of long-term reduction of fluid state and increasing dialysis treatment-time on hemodynamics and blood pressure control was prospectively studied during a three months period in hypertensive hemodialysis patients. 
Whether uremic patients on long-treatment-time dialysis with a good blood pressure control have stiffening of the arterial vascular system, contributing to LVH despite adequate blood pressure control, was examined in chapter 7 . Arterial vascular compliance in patients on long-treatment-time dialysis was compared with healthy controls matched for blood pressure level. 


\section{References}

1. Kolff WJ, Berk HTHJ. De kunstmatige nier: een djalysator met een groot oppervlak. Ned Tijdschr v Geneesk 1943;97:1684-1688.

2. Valderrábano $F$, Jones EHP, Mallick NP. Report on the management of renal fäilure in europe, XXIV, 1993. Nephrol Dial Transpl 1995;10 (supp 5).

3. Valderrabano $F$, Berthoux $F C$, Jones $E H P$, Mehls $O$. Report on management of renal failure in europe, XXV, 1994. Nephrol Dial Transpl 1996;11 (supp 1).

4. Fermandez JM, Carbonell ME, Mazzuchi N, Petruccelli D. Simultanous analysis of morbidity and mortality factors in chronic hemodialysis patients. Kidneyt Int 1992;41:1029-1034.

5. Foley RN, Parfrey PS. Risk factors for cardiac morbidity and mortality in dialysis patients. Curr Opinion Nephr Hypert 1994;3:608-614.

6. Geerlings W, Tufveson G, Ehrich JHH, Jones EHP, Landais P, Loirat C, Mallick NP, Margreiter R, Raine AEG, Salmela $K$, Selwood NH, Valderrabano F. Report on management of renal failure in europe, XXIII, 1992. Nephrol Dial Transpl $1994 ; 9$ (supp 1).

7. Held PJ, Blagg CR, Liska DW, Port FK, Hakim R, Levin N. The dose of hemodialysis according to dialysis prescription in Europe and the United states. Kidney Int Suppl 1992;-/38:S16-S21.

8. Kramer P, Broyer M, Brunner FP, et all. Combined report on Regular Dialysis and Transplantation In Europe XII, 1981. Proceedings of European Dialysis and Transplant association 1982;19:4-59.

9. Teraoka S, Toma H, Nihei H, Ota K, Babazono T, Ishikawa I, Shinoda A, Maeda $K$, Koshikawa $S$, Takahashi $T$, Sonoda $T$. Current status of renal replacement therapy in Japan. Am J Kidney Dis 1995;25:151-164.

10. Held PJ, Port FK, Wolfe RA, Stannard DC, Carroll CE, Daugirdas JT, Bloembergen WE, Greer JW, Hakim RM. The dose of hemodialysis and patient mortality . Kidney Int 1996;50:550-556.

11. Raine AEG, Margreiter $\mathbf{R}$, Brunner FP, Ehrich JHH, Geerlings W, Landais $P_{\text {, }}$ Loirat C, Mallick NP, Selwood NH, Tufveson G, Valderrabano F. Report on the management of renal failure in europe, XXII, 1991. Nephrol Dial Transpl 1992;7 (supp 2).

12. Vertes V, Cangiano JL, Berman LB: Hypertension in end stage renal disease. $N$ Eringl J Med 1969;280:978-981.

13. Charra B, Calemard E, Ruffet M, Chazot C, Terrat JC, Vanel T, Laurent G. Survival as an index of adequacy of dialysis. Kidney Int 1992;41:1286-1291.

14. Ritz $E$, Vallance $P$, Nowicki $M$. The effect of malnutrition on cardiovascular mortality in dialysis patients: is L-arginine the answer. Nephr Dial Transpl 1994:9:129 130.

15. Leunissen KML, Kooman JP, van Kuijk W, van der Sande F, Luik AJ, van Hooff JP. Preventing laemodynamic instability in patients at risk for intra-dialytic hypotension. Nephrol Dial Transpl 1996;11 suppl 2:11-15. 
16. Kooman JP, Gladziwa U, Böcker $G$, van Bortel LMAB, van Hooff JP, Leunissen KML. Role of the venous sytem in hemodynamics during ultrafiltration and bicarbonate dialysis. Kidney Int 1992;42:718-726.

17. Daugirdas JT. Dialysis hypotension: A hemodynamic analysis. Kidney Int 1991;39:233-246.

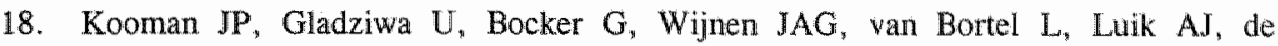
Leeuw PW, van Hooff JP, Leunissen KML. Representative blood pressure in haemodialysis patients by 48 -hour ambulatory blood pressure monitoring. Nephrol Dial Transpl 1992;7:917-923.

19. Perloff $D$, Sokolow $M$, Cowan $R$. The prognostic value of ambulatory blood pressures. JAMA 1983;249:2792-2798.

20. Mancia G, Ferrari A, Gregorini L, Parati G, Pomidossi G, Bertinieri G, Grassi G, di Rienzo M, Pedotti A, Znchetti A. Blood pressure and heart rate variabilities in normotensive and hypertensive human beings. Circ Res 1983;53:96-104.

21. Pickering TG. Ambulatory monitoring and blood pressure variability. Science Press. London, 1991.

22. Richards AM, Nicholls MG, Espiner EA, lkram H, Cullens M, Hinton D. Diurnal patterns of blood pressure, heart rate and vasoactive hormones in normal man. Clin Exp Hypertens 1986; [A] 8:153-166.

23. Kawano $\mathrm{Y}$, Tochikubo $\mathrm{O}$, Minamisawa $\mathrm{K}$, Miyajima $\mathrm{E}$, Ishii $\mathrm{M}$. Circadian variation of haemodynamics in patients with essential hypertension: Comparison between early morning and evening. J Hypertens 1994;12:1405-1412.

24. Verdecchia $P$, Schillaci G, Guerrieri $M$, Gatteschi $C$, Benemio G, Boldrini F, Porcellati C. Circadian blood pressure changes and left ventricular hypertrophy in essential hypertension. Circulation 1990;81:528-536.

25. Baumgart $P$, Walger $P$, Gemen $S$, von Eiff $M$, Raidt $H$, Rahn KH. Blood pressure elevation during the night in chronic renal failure, hemodialysis and renal transplantation. Nephron 1991;57:293-298.

26. Battistella P, De Cornelissen F, De Gaudemaris R, Contard S, Janin G. Profill tensionnel ambulatoire de 48 heures chez l'hemodialyse chronique. Arch Mal Coeur 1990;83:1223-1227.

27. Rosansky SJ. Nocturnal hypertension in patients recieving chronic hemodialysis. Letter. Ann Int Med 1991;114:96.

28. Cheigh JS, Milite C, Sullivan JF, Rubin AL, Stenzel KH. Hypertension is not adequately controlled in hemodialysis patients. Am J Kidney Dis 1992;19:453-459.

29. Mann S, Altman G, Raftery EB, Bannister E. Circadian variation of blood pressure in autonomic failure. Circulation 1983;68:477-483.

30. Converse RL, Jacobsen TN, Toto RD, Jost CJ, Cosentino F, Fouad-Tarazi DOF, Victor RG. Sympathetic overactivity in patients with chronic renal failure. New Eng J Med 1992;327:1912-1918.

31. McGrath BP, Ledingham JGG, Benedict CR. Catecholamines in peripheral venous plasma in patients on chronic haemodialysis. Clin Sci Mol Med 1978;55:89-96. 
32. Caruana M, Lahiri A, Cashman PMM, Alman DG, Raftery EB. Effects of chronic congestive heart falure secondary to coronary artery disease on the circadian rhythm of blood pressure and heart rate. Am J Cardiol 1988;62:755-759.

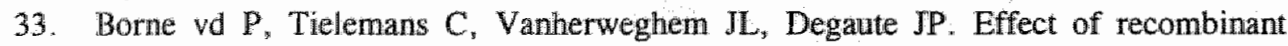
human erythropoietin therapy on ambulatory blood pressure and heart rate in chronic haemodialysis patients. Nephrol Dial Transpl $1992 ; 7: 45-49$.

34. Quellhorst E, Rieger J, Doht B, Beckmann H, Jacob I, Kraft B, Mietzsch G, Scheler $F$. Treatment of chronic uremia by an ultra-filtration kidney. First clinical experiences. Proc Eur Diall Transplant Assoc 1976;13:314-321.

35. Hamburger RJ, Christ PG, Morris PA, Luft FC. Hypertension in dialysis patients: Does CAPD provide an advantage? Adv Perit Dial 1989;5:91-96.

36. Quelhorst E, Schuenemann B, Doht $\mathbb{B}$. Treatment of severe hypertension in chronic renall failure by haemofiltration. Proc Eur Dial Transplant Assoc 1977;14:129-135.

37. Sadanha LF, Weiler EW, Gonick HC. Effect of continuous ambulatory peritoneal dialysis on blood pressure control Am J Kidney Dis 1993;21:184-188.

38. Youmbissi $J$, Sellars L, Shore AC, Poon T, Wilkinson R. Blood pressure on CAPD: Relationship to sodium status, renin and aldosterone, compared with hemodialysis. In Maher JF, Winchester JF eds. Frontiers in peritoneal dialysis. New York: Field, Rich and asssociates Inc. 1986:450-456.

39. Gimour J, Wu G, Khanna R, Schilling H, Mitwalli A, Dreopulos DG. Long-term continuous ambulatory peritoneal dialysis. Perit Dial Bull 1985;5:112-118.

40. Henderson LW, Lilley JJ, Ford CA, Stone RA. Hemodiafiltration. Journ of Dial 1977; 1:211-238.

41. de Leeww PW. Pathophysiology of hypertension in patients on renal replacement therapy. Blood Purif 1994;12:245-251.

42. Brown MA, Whitworth JA. Hypertension in renal disease. J Hypert 1992;10:701712.

43. Guidi E, Magni M, di Belgiojoso GB, Minetti L, Bianchi G. Blood pressure in patients with four different primary glomerulopathies. Clin Exp Theory Pract $1984 ; A 6: 1357-1366$

44. Dorhout Mees EJ. Volaemia and blood pressure in renal failure: have old truths been forgotten?. Nephr Dial Transpl 1995;10:1297-1298.

45. Malher JF. Replacement of renal function by dialysis. Boston. Kluwer Academic Publishers 1989;776-777.

46. Leunissen KML, Kouw P, Kooman JP, Cherieux EC, deVries PMJM, Donker ALM, van Hooff JP. New techniques to determine fluid status in hemodialyzed patients. Kidney Int 1993;43 suppl 41:S50-S56.

47. Cheriex EC, Leunissen KML, Janssen JHA, Mooy JMV, van Hooff JP. Echography of the vena cava inferior is a simple and reliable tool for estimation of dry weight in hemo-dialysis patients. Nephrol Dial Transpl 1989;4:563-568.

48. Katzarski KS, Nisell J, Bergstrom J. Relationship between blood volume and inferior vena cava diameter during and after hemodialysis. JASN 1994;5:518. 
49. Kouw PM, Olthof CG, Ter Wee PM, Oe LP, Donker AMM, Schneider H, De Vries PMJM. Assessment of post-dialysis dry weight: An application of the conductivity measurement method Kidny Int 1992;41:440-444.

50. Coleman TG, Bower JD, Langford HG, Guyton AC. Regulation of arterial pressure in the anephric state. Circulation 1970;42:509-514.

51. Kim KE, Onesti G, Del Guerico ET, Fernandes M, Eidelson B, Swartz C. Sequential hemodynamic changes in end-stage renall disease and the anephric state during volume expansion. Hypertension 1980;2:102-110.

52. Planque BA de, Mulder E, Dorhout Mees EJ. The behaviour of blood and extracellular volume in hypertensive patients with renal insufficiency. Acta Med Scand $1969 ; 186: 75-81$.

53. Dathan JRE, Johnson DB, Goodwin FJ. The relation between body fluid compartment volumes, renin activity and blood pressure in chronic renal failure. Clin Science Mol Med 1973;45:77-88.

54. Wilkinson $R$, Scott DF, Uldall PR, Kerr DNS, Swinney J. Plasma renin and exchangeable sodium in the hypertension of chronic renal faillure. Q I Med $1969 ; 39: 377-394$.

55. Schultze G, Piefke $S$, Molzahn M. Blood pressure in terminal renal failure. Nephron $1980 ; 25: 15-24$.

56. Sherman RA, Daniel A, Cody RP. The effect of inter-dialytic weight gain on predialysis blood pressure. Artif Organs 1993;17:770-774.

57. Leenen FHH, Galla SJ, Geyskes GG, Murdaugh HV, Shapiro AP. Effects of hemodialysis and saline loading on body fluid compartments, plasma renin activity, and blood pressure in patients on chronic hemodialysis. Nephron 1977;18:93-100.

58. Krzesinski JM, Du F, Pequeux ML, Rorive GL. Plasma Na-K ATPase inhibitor activity and intracellular ions during hemodialysis. Int $J$ Artif Organs $1993 ; 16: 23-30$.

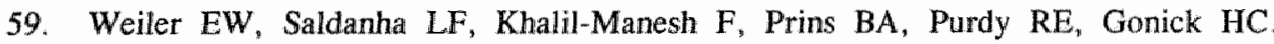
Relationship of $\mathrm{Na}-\mathrm{K}$-ATPase inhibitors to blood pressure regulation in contiruous ambulatory peritoneal dialysis and hemodialysis. JASN 1996;7:454-463.

60. Henrich WL, Woodard 'TD, McPhaul JJ. The chronic efficacy and safety of high sodium dialysate: Double-blind, crossover study. Am J Kidney Dis 1982;2:349-353.

61. Barre PE, Brunelle $G$, Gascon-Barre M. A randomized double blind trial of dialysate sodiums $05145 \mathrm{mEq} / 1,150 \mathrm{mEq} / 1$, and $155 \mathrm{mEq} / \mathrm{l}$. ASAlO Trans $1988 ; 34: 338-341$.

62. Brod J, Bahlman FRCP, Cachovan M, Hubrich W. Mechanisms for the elevation of blood pressure in human renal disease. Hypertension 1982;4:839-844.

63. Del Greco $F$, Simon NM, Renin activity and peripheral resistance in hypertensive uremics on chronic dialysis. Trans Amer Soc Artif Int Organs 1973;19:293-297.

64. Boer P, Koomans HA, Dorhout Mees. Renin and blood volume in chronic renal failure: a comparison with essential hypertension. Nepron 1987;45:7-15. 
65. Schalenkamp MA, Beevers DG, Briggs JD, Brown JJ, Davies DL, Fraser R, Lebel M, Lever AF, Medina A, Morton J\}, Robertson JLS, Tree M. Hypertension in chronic renal failure: An abnormal relation between sodium and the renin-angiotensin system. Am J Med 1973;55:379-390.

66. Weidman P, Baretta-Piccoli $C$, Steffen $F$, Blumberg $A$, Reubi FC. Hypertension in terminal renal failure. Kidney Int 1976,9:294-301.

67. Brown JJ, Curtis JR, Lever AF, Robertson JIS, de Wardener HE, Wing AJ. Plasma renin concentration and the control of blood pressure in patients on maintenance haemodialysis. Nephron 1969;6:329-349.

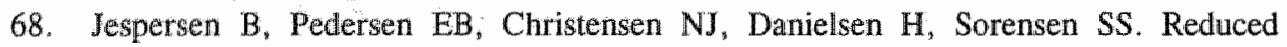
angiotensin II induced vascular reactivity in chronic renal failure. Scand J Clin Lab Invest 1988; $49: 705-713$.

69. Campese VM, Romoff MS, Levitan D, Lane K, Massry S. Mechanisms of autonomic nervous system dysfunction in uremia. Kidney Int 1981;20:246-253.

70. Cuche JL, Prinseau J, Selz F, Ruget G, Baglin A. Plasma free, sulfo- and glucuroconjugated catecholamines in uremic patients. Kidney Int 1986;30:566-572.

71. Schohn D, Weidmann P, Jahn H, Baretta-Piccoli C. Norepinephrine-related mecharism in hypertension accompanying renal failure. Kidney Int $1985 ; 28: 814-822$.

72. Rascher W, Schomig A, Kreye VA, Ritz E. Diminished vascular response to noradrenaline in experimental chronic uremia. Kidney Int 1982;21:20-27.

73. Brodde OE, Daul A. Impaired regulation of alpha and betha-adrenoreceptor function in chronic renal insufficientcy. Contr Nephrol 1986;50:29-35.

74. Daul AE: Wang XL, Michel MC, Brodde OE. Arterial hypotension in chronic hemodialyzed patients. Kidney Int 1987;32:728-735.

75. Vallance $\mathrm{P}$, Leone A, Calver A, Collier $\mathrm{J}$, Moncada $\mathrm{S}$. Accumulation of an endogenous inhibitor of nitric oxide synthesis in chronic renal failure. Lancet 1992:339:572-575.

76. Arese M, Strasly M. Ruva C, Costamagna C, Ghigo D, MacAllister R, Verzetti G, Tetta C, Bosia A, Bussolino F. Regulation of nitric oxide synthesis in uraemia. Nephrol Dial Transpl 1995;10:1386-1397.

77. Victor RG. Reflex control of synpathetic nerve discharge in uremia. Blood purif $1997 ; 15$ suppl 1:43-45.

78. Rose BD. Clinical physiology of acid-base and electrolyte disorders, 4th edition. McGraw-Hill, Inc 1994:155-164.

79. Argent NB, Burrell LM, Goodship THJ, Wilkinson R, Baylis PH. Osmoregularion of thirs and vasopressin release in sewere chronic renal failure. Kidney Int $1991 ; 39: 295-300$.

80. Hegbrant $\mathrm{J}$, Thysell $\mathrm{H}$, Mårtensson $\mathrm{L}$, Ekman $\mathrm{R}$, Boberg $\mathrm{U}$. Changes in plasma levels of vasoactive peptides during sequential bicarbonate hemodialysis. Nephron $1993 ; 63: 309-313$. 
81. Heintz B, Königs F, Dakshinamurty KV, Kierdorf H, Gladłiwa U, Kirsten R, Nelson $\mathrm{K}$, Wieland D, Riehl J, Mann $\mathrm{H}$, Sieberth HG. Response of vasoactive substances ti intermittent ultrafiltration in normotensive hemodialysis patients. Nephron $1993 ; 65: 266-272$.

82. Warrens AN, Cassidy MJD, Takahashi K, Ghatei MA, Bloom SR. Endothelin in renal failure. Nephrol Dial Transpl 1990,5:418-422.

83. Takahashi $K$, Totsune $K$, Mouri $T$. Endothelin in chronic renal failure. Nephron 1994;66:373-379.

84. Hasegawa $\mathbb{K}$, Matsuhita $Y$, Inoue $T$, Morii $H$, Ishibashi $M$, Yamaji T, Plasma levels of atrial natriuretic peptide in patients with chronic renal failure. $\mathrm{J} \mathrm{Clin}$ Endocrinol Metab 1986;63:819-822.

85. Leunissen KML, Menheere PPCA, Cheriex EC, van den Berg BW, Noordzij TC, van Hooff JP. Plasma alpha-human atrial natriuretic peptide and dry weight in chronic hemodialysis. Nephrol Dial Transpl 1989;4:382-386.

86. Hirata $Y$, Ishii $M$, Matsuoka $H$, Sugimoto $T$, Iizuka $M$, Uchida $Y$, Serizawa $T$, Sato H, Kohmoto O, Mochizuki T, Sugimoto T, Miyata A, Kangawa K, Matsuo H. Plasma concentrations of $\alpha$-human atrial natriuretic polypepticle and cyclic GMP in patients with heart disease. Am Heart J 1987;113:1463-1469.

87. Tan SY, Nolan J, Craig K, Swainson CP. Changes in atrial natriuretic peptide and plasma renin activity following changes in right atrial pressure in patients with chronic renal failure. Am J Nephrol 1995; 15:18-23.

88. Corboy JC, Walker RJ, Simmonds MB, Wilkins GT, Richards AM, Espiner EA. Plasma natriuretic peptides and cardiac volume during acute changes in intravascular volume in haemodialysis patients. Clin Science 1994;87:679-684.

89. Mallamaci F, Postorino M, Zoccali C. Influence of ANP on the cardiovascular reponse to volume expansion in haemodialysis patients. Nephrol Dial. Transpl 1994;9;1279-1282.

90. Gotch FA, Yarians S, Keen M. A kinetic survey of hemodialysis prescriptions. Am J Kidney Dis 1990;15:511-515.

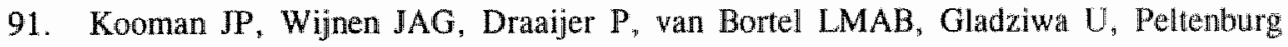
HG, Struyker Boudier HAJ, van Hooff JP, Leunissen KML. Compliance and reactivity of the peripheral venous system in chronic intermittent hemodialysis. Kidney Int 1992;41:1041-1048.

92. Lazerus JM, Hampers CL, Lowrie EG, Meril JP. Baroreceptor activity in normotensive and hypertensive uraemic patients. Circulation 1973:47:1015-1021.

93. Eschbach JW, Egrie JC, Downing MR, Browne JK, Adamson JW. Correction of anemia of end-stage renal disease with recombinant human erythropoietin. $N$ Eng J Med 1987;316:73-78.

94. Wirtz JJM, Leunissen KML, van Esser JWJ, Cheriex EC, Slaaf DW, Reneman RS, van Hooff JP. Recombinant human erythropoitin and its effects on macro- and micro-circulation during normovolemia. Blood Purif 1990;8:285-294.

95. London GM, Zins B, Pannier B, Naret C, Bertelot JM, Jacquot C, Safar M, Drueke TB. Vascular changes in hemodialysis patients in response to recombinant human erythropoitin. Kidney Int 1989;36:878-882. 
96. Carlini RG, Dusso AS, Obialo IC, Alvarez UM, Rothstein M. Recombinant human erythropoitin increases endothelin-1 release by endothelial cells. Kidney Int $1993: 43: 1010-1014$.

97. Carlini $R$, Obialo $\mathbb{C}$, Rothstein $M$. Intravenous erythropoietin daministration increases plasma endothelin and blood pressure in hemodialysis patients. Am I Hypert $1993 ; 6: 103-107$.

98. Takahashi $K$, Totsune $\mathbf{K}$, Imai $\mathbf{X}$, Sone $\mathbf{M}$, Nozuki $\mathbf{M}$, Murakami $O$, Sekino $H$, Mouri T. Plasma concentrations of immunoreactive-endothelin in patients with chronic renal fallure treated with recombinant human erythropoietin. Clin Science $1993 ; 84: 47-50$.

99. Pizzarelli F, Fabrizi F, Pastorino M, Curatola G, Zoccali, Maggiore Q. Parathyroidectomy and blood pressure in hemodialysis patients. Nephron $1993 ; 63: 384-389$.

100. Lind $L$, Ljunghall $S$. Parathyroid hormone and blood pressure-is there a relationship?. Nephrol Dial Transpl 1995;10:450-451.

101. Kooman JP, Leunissen KML. Cardiovascular aspects in renal disease. Curr Opinion Nephr Hypert 1993;2:791-797.

102. Harnett ID, Parfrey PS, Griffith SM, Gault MH, Barre P, Guttmann RD. Left ventricular hypertrophy in end-stage renal disease. Nephron $1988 ; 48: 107-115$.

103. Hüting $J$, Kramer $W$, Schütterlle $G$, Wizemann V. Analysis of left ventricular changes associated with chronic hemodialysis: A noninvasive follow-up study. Nephron 1988;49:284-290.

104. London GM, Marchais SJ, Guerin AP, Metivier F, Pannier B. Cardiac hypertrophy and arterial alterations in end-stage renal disease: Hemodynamic factors. Kidney Int 1993;43 suppl 41:S42-S49.

105. Silberberg JS, Barre PE, Prichard SS, Sniderman AD. Impact of left ventricular hypertrophy on survival in end-stage renal disease. Kidney Int 1989;36:286-290.

106. London GM, Guerin AP, Marchais SJ. Pathophysiology of left ventricular hypertrophy in dialysis patients. Blood purif 1994;12:277-283.

107. London, GM, De Vernejoul MC, Fabiani F, Marchais SJ, Guerin AP, Metivier F, London $\mathrm{AM}$, Llach $\mathrm{F}$. Secondary hyperparathyreoidism and cardiac hypertrophy in hemodialysis patients. Kidney Int 1987;32:900-907.

108. Lima JJG, Abensur H, Bernardes-Silva H, Bellotti G, Pileggi F. Role of arterial hypertension in left ventricular hypertrophy in hemodiallysis patients: an echocardiographic study. Cardiology 1992;80:161-167.

109. Greaves SC, Gamble GD, Collins JF, Whalley GA, Sharpe DN. Determinants of left ventricular hypertrophy and systolic dysfunction in chronic renal failure. Am J Kidney Dis 1994;24:768 776 .

110. Harnett JD, Kent GM, Barre PE, Taylor R, Parfrey PS. Risk factors for the development of left ventricular hypertrophy in a prospectively followed cohort of dialysis patients. JASN 1994;4:1486-1490. 
111. Cannella G, La Canna G, Sandrini $M$, Gaggioti $M$, Nordio G, Movilli E, Mombelloni S, Visioli O, Maiorca R. Reversal of left ventricular hypertrophy following recombinant human erythropoitin treatment of anaemic dialysed uraemic patients. Nephrol Dial Transpl 1991;6:31-37.

112. Hüting J, Kramer $W$, Charra B, Laurent G, Wizemann $V$, Schütterle G. Assymmetric septal hypertrophy and left atrial dilatation in patients with end-stage renal disease on long-term dialysis. Clin Nephrol 1989;32:276-283.

113. Goldberg N, Lundin AP, Delano B, Friedman EA, Stein RA. Changes in left ventricualr size, wall thickness, and function in anemic patients treated with recombinant human erythropoietin. Am Heart J 1992;124:424-427.

114. Wirtz JJMM, Leunissen KML, van Kuijk W, Cheriex EC, Slaaf DW, Reneman RS, van Hooff JP. Long-term effects of recombinant human erythropoitin on macro- and microcirculation in chronic hemodialysis patients. Blood Purif 1993;11:237-247.

115. Greaves SC, Gamble GD, Collins JF, Whalley GA, Sharpe DN. Determinants of left ventricular hypertrophy and systolic dysfunction in chronic renal tailure. Am J Kidney Dis 1994;24:768-776.

116. Fujimoto S, Koghoshima T, Hashimoto T, Nakajima T, Dohi K. Left ventricular diastolic function in patients on maintenance hemodialysis: comparison with hypertensive heart disease and hypertrophic cardiomyopathy. Clin Nephrol 1994:42:109-116.

117. Miyaguchi K, Iwase M, Yokota M, Hayashi H, Tsuzuki J, Katoh M. Influence of left ventricular preload reduction by hemodialysis on the doppler-derived left ventricular filling profile. Am J noninvas Cardiol 1990;4:345-351.

118. Gupta S, Dev V, Kumar MV, Dash SC. Left ventricular diastolic functiom in endstage renal disease and the impact of hemodialysis. Am J Cardiol $1993 ; 71: 1427-1430$.

119. London GM, Marchais SJ, Safar ME, Genest AF, Guerin AP, Metivier F, Chedid $\mathrm{K}$, London AM. Aortic and large artery compliance in end-stage renal failure. Kidney Int 1990;37:137-142.

120. Barenbrock M, Spieker C, Laske V, Heidenreich S, Hohage H, Bachmann J, Hoeks APG, Rahn KH. Studies of the vessell wall properties in hemodialysis patients. Kidney Int 1994;45:1397-1400.

121. London GM, Guerin A, Pannier B, Marchais S, Benetos A, Safar M. Increased systolic pressure in chronic uremia: Role of arterial wave reflections. Hypertension 1992;20:10-19.

122. London GM. Increased arterial stiffness in end stage renal failure: why is it of interest to the clinical nephrologist? Nephrol Dial Transpl 1994;9:1790-1712. 


\section{Chapter 2}

\section{Diurnal blood pressure variations in hemodialysis and CAPD patients}

AJ Luik, Struijk DG, U Gladziwa, RW v Olden, JP v Hooff, PW de Leeuw, KML Leunissen

Nephr Dial Transpl 1994;9:1616-1621 


\section{Abstract}

The influence of variations in fluid state on diurnal blood pressure was studied by measuring day-time and night-time blood pressure during a 3-day inter-dialytic period in 10 normotensive and 10 hypertensive hemodialysis patients using Spacelabs 90207 monitors. Ambulatory blood pressure was also measured during $24 \mathrm{~h}$ in 11 normotensive- and, 9 hypertensive CAPD patients, and in 9 mormotensive- and 11 hypertensive control patients with a normal renal function. Antihypertensive drugs had been discontinued for at least 3 weeks before the study period. Optimal dry weight in the hemodialysis patients was estimated by echography of the inferior vena cava, and in the CAPD patients on clinical grounds.

Although in the dialysis patients and controls a significant nocturnal blood pressure reduction was found, day-night blood pressure difference in the dialysis patients was blunted when compared with the control patients. No significant differences in diurnal blood pressure variation was found between the normotensive and the hypertensive patients. Day-night blood pressure differences in the hemodialysis patients did not change during the 3-day inter-dialytic period. Also the more stable fluid state of the CAPD patients was not associated with significant different diurnal blood pressure variation compared to the hemodialysis patients. We conclude that factors other than changes in extra-cellular fluid volume, are responsible for a blunted day-night difference in blood pressure in dialysis patients. 


\section{Introduction}

Healthy volunteers as well as patients with essential hypertension with a normal renal. function have a circadian blood pressure and heart rate variation". Blood pressure tends to be highest in the morning, with a gradual decrease over the course of the day, and lowest during the night. A blunted day-night blood pressure difference is associated with an increased incidence of left ventricular hypertrophy ${ }^{2}$, and hence could lead to more cardiovascular complications.

Ischemic heart disease, cardiac failure and cerebrovascular disease are the main cause of death and morbidity in hemodialysis patients, with hypertension being the most important risk factor ${ }^{3,4}$. We have found that circadian blood pressure variation is blunted in normotensive and hypertensive hemodialysis patients compared to normotensive and hypertensive controls ${ }^{5}$. This blunted diurnal blood pressure variation could contribute to the left ventricular hypertrophy and left ventricular dysfunction found in dialysis patients ${ }^{6}$. In this and most other studies dealing with diurnal blood-pressure differences in hemodialysis patients, the influence of medication on blood pressure variation cannot be ruled out because antihypertensive medication had been continued during the study ${ }^{5,7,8}$.

Volume expansion and continuous changes in volume status could be major determinants in the pathogenesis of blunted day-night blood pressure differences in dialysis patients. The slow daily adjustable ultra-filtration achieved with continuous ambulatory peritoneal dialysis (CAPD) provides a more stable fluid state than hemodialysis. However, it is not known whether CAPD patients actually display less blunted diurnal blood pressure variations than hemodialysis patients.

In this study we determined day-night blood pressure differences in relationship to fluid state in hypertensive and normotensive hemodialysis patients without the use of antihypertensive medication. Furthermore day-night blood pressure differences in normotensive and hypertensive CAPD patients without antihypertensive medication were compared to hemodialysis patients and control patients.

\section{Subject and methods}

20 chronic hemodialysis (10 hypertensive: post-dialytic systolic blood pressure $\geq 140 \mathrm{mmHg}$ and/or diastolic blood pressure $\geq 90 \mathrm{mmHg}$, and 10 normotensive: post-dialytic blood pressure $<140 / 90 \mathrm{mmHg}$ ) patients on a thrice-weekly dialysis scheme, and 20 CAPD patients ( 9 hypertensive and 11 normotensive patients) were studied. All patients had a stable hemoglobin concentration (Ht: $0.30 \pm 0.05 \%$ ). As a control group 20 patients (11 hypertensive and 9 normotensive) with a normal renal function were included. Patients with diabetes mellitus, severe valvular disease, cardiac failure or clinically evident autonomic neuropathy defined as an 
orthostatic blood pressure fall of more than $20 \mathrm{mmHg}$ with no change in heart rate, were excluded. Antihypertensive medication was discontinued at least 3 weeks prior to the start of the study. Optimal dry weight in the hemodialysis patients was estimated by echographic measurement of the inferior caval vein diameter ${ }^{9}$. In the CAPD patients dry weight was estimated by clinical criteria (no edema, no congestion on chest X-ray, no hypotension) because the method of echography of the inferior caval vein has not been validated for CAPD patients. The hemodialysis patients were dialyzed in the afternoon with a Gambro AK-100 or a Fresenius 2008 dialysis module with bicarbonate as dialysate buffer. Biocompatible polysulphone or polyacrylonitrile membranes were used. The CAPD patients were treated with a glucose peritoneal dialysis solution, 2 litres three or four times a day. Day-time (7.00 a.m. -23.00 p.m.) and night-time (23.00 p.m.-7.00 a.m.) blood pressure was monitored throughout a 3-day inter-dialytic period in the hemodialysis patients, and during $24 \mathrm{~h}$ in the CAPD and control patients. Spacelabs 90207 Ambulatory Blood pressure Monitors, specially recommended for this purpose, were used ${ }^{10}$. Blood pressure and heart rate were measured every $20 \mathrm{~min}$ during day-time and every 30 min during the night. All patients and controls were instructed to continue their actual daily activities during the study period.

Individual day-time and night-time blood pressures were calculated from the individual hourly average values. Day-time minus night-time blood pressure was calculated for each patient. In the hemodialysis patients blood pressures on the second inter-dialytic day were compared with the $24 \mathrm{~h}$ blood pressure registration of the CAPD and control patients. For studying the influence of inter-dialytic weight gain on diurnal blood pressure variation in the hemodialysis patients, blood pressure registration on the first day of the inter-dialytic period was compared with the blood pressure registration on the second and on the third day of the interdialytic period. Echography of the inferior caval vein was performed just before (post-dialytic) and just after (pre-dialytic) the ambulatory blood pressure monitoring. Indexed inferior caval vein diameter was calculated by dividing caval vein diameter by body-surface area. Statistical analysis was performed using nonparametric tests. Diurnal blood pressure rhythm was considered to be lost (nondippers) when day-night mean arterial pressure (MAP) was less than $5 \mathrm{mmHg}$. Significance of differences between the groups was calculated by the Kruskal Wallis Anova and the Mann-Whitney $U$ test. The Wilcoxon test for paired data was used for calculating the significance of differences between day-time and night-time blood pressure and heart rate. A Friedman two-way Anova was used to analyze the differences in diurnal blood pressure variation on the three inter-dialytic days in the hemodialysis patients. Pearsons two-tails linear correlation was used for calculating the correlation coefficient between age, diuresis and time on dialysis and day-night blood pressure differences. Differences were considered significant when $\mathrm{p}$ values were $<0.05$. 


\section{Results}

The patient characteristics are shown in table 2.1. There were no significant differences between the patients groups with respect to age and sex. The time patients had been on renal replacement therapy and residual diuresis were comparable in the hemodialysis and CAPD patients. No significant differences in (post-dialytic) blood pressure were found between the hemodialysis $(139 \pm 14 /$ $82 \pm 8 \mathrm{mmHg}), \mathrm{CAPD}(141 \pm 24 / 86 \pm 15 \mathrm{mmHg})$, and control patients $(146 \pm 19 /$ $89 \pm 11 \mathrm{mmHg}$.

Table 2.1 Patient characteristics (unean $\pm S D)$ for sex $(m=$ male, $f=$ female), age, total time on dialysis treatment postdialytic systolic and diastolic blood pressure, and risidual diuresis

\begin{tabular}{|c|c|c|c|c|c|c|}
\hline & \multicolumn{2}{|c|}{ Henumbialysis } & \multicolumn{2}{|c|}{ CAPD } & \multicolumn{2}{|c|}{ Control } \\
\hline & normotensive & Whypertentive & normotensive & hypertensive & normotensive & hypertensive \\
\hline $\mathbb{N}$ & 10 & 10 & 11 & 9 & 9 & 11 \\
\hline $\operatorname{Sex}(\mathrm{m} / \mathrm{f})$ & $4 \mathrm{~m} / 6 \mathrm{f}$ & $7 \mathrm{~m} / 3 \mathrm{f}$ & $3 \mathrm{~m} / 8 \mathrm{c}$ & $6 \mathrm{nn} 13 \mathrm{r}$ & $5 \mathrm{~m} / 4 \mathrm{l}$ & $7 \mathrm{~min} 4 \mathrm{f}$ \\
\hline Age (years) & $44 \pm 17$ & $47 \pm 14$ & $51 \pm 1.5$ & $55 \pm 2 \mathbb{1}$ & $49 \pm 10$ & $55 \pm 11$ \\
\hline Time an dialysis (years) & $4.9 \pm 3.7$ & $3.7 \pm 3.4$ & $3.2 \pm 3.5$ & $3.7 \pm 3.7$ & - & - \\
\hline Prostdial syst. BP. (mullig) & $128+7$ & $150 \pm 10$ & $125 \pm 10$ & $1.61 \pm 21$ & $130 \pm 7$ & $15 \pm 16$ \\
\hline Prosudial.diast.BP.(mmHig) & $78 \pm 7$ & $86 \pm 7$ & $75 \pm 6$ & $99 \pm 10$ & $81 \pm 5$ & $96 \pm 11$ \\
\hline Diuresis (L/day) & $0.4 \pm 0.6$ & $0.7 \pm 0.6$ & $0.3 \pm 0.3$ & $0.2+0.3$ & . & 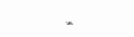 \\
\hline
\end{tabular}

Control patients as well as the hemodialysis and CAPD patients displayed a significant day-night blood pressure difference (figure 2.1). However, diastolic daynight blood pressure variation was significantly less in the hemodialysis and CAPD patients as compared to control patients $(9 \pm 6 \mathrm{mmHg}$ and $9 \pm 7 \mathrm{mmHg}$ versus $15 \pm 4 \mathrm{mmHg} ; \mathrm{p}=0.003$ and $\mathrm{p}=0.010$; figure 2.2 ). Systolic day-night blood pressure differences tended to be lower in the hemodialysis and CAPD patients as compared to control patients $(12 \pm 8 \mathrm{mmHg}$ and $13 \pm 11 \mathrm{mmHg}$ versus $16 \pm 7$ $\mathrm{mmHg}$ ), but failed to reach a significant level. MAP day-night blood pressure variation was only significantly less in the hemodialysis patients as compared to control patients $(10 \pm 6 \mathrm{mmHg}$ versus $15 \pm 5 \mathrm{mmHg} ; \mathrm{p}=0.019)$ but not in the CAPD patients $(11 \pm 9 \mathrm{mmHg} ; \mathrm{p}=0.088) .4$ Hemodialysis patients ( 1 normotensive and 3 hypertensive), had a day-night MAP variation of less than $5 \mathrm{mmHg}$. Of the CAPD patients, 5 patients ( 4 normotensive and 1 hypertensive) appeared to be nondippers. None of the control patients were non-dippers.

When comparing the hypertensive and the normotensive patients, the hypertensive hemodialysis, CAPD and control patients did not have a more blunted day-night blood pressure difference than the normotensive hemodialysis (systolic/diastolic: 
$10 \pm 8 / 9 \pm 7 \mathrm{mmHg}$ and $13 \pm 8 / 10 \pm 5 \mathrm{mmHg}), \mathrm{CAPD}(17 \pm 11 / 10 \pm 8 \mathrm{mmHg}$ and $10 \pm 9 / 8 \pm 7 \mathrm{mmHg}$ ), and control patients $(17 \pm 8 / 15 \pm 5 \mathrm{mmHg}$ and $16 \pm 6 /$ $15 \pm 5 \mathrm{mmHg}$ ). KW-ANOVA did not show significant differences in MAP, systolic or diastolic day-night blood pressure variation between the different normotensive patient groups (figure 2.2). The same was true for the hypertensive patient groups.

Comparing CAPD and hemodialysis patients, the more stable fluid state in CAPD patients did not result in significant different systolic $(12 \pm 8$ versus $13 \pm 11 \mathrm{mmHg}$ ) or diastolic day-night blood pressure differences $(9 \pm 6$ versus $9 \pm 7 \mathrm{mmHg}$ ) as compared to hemodialysis patients.
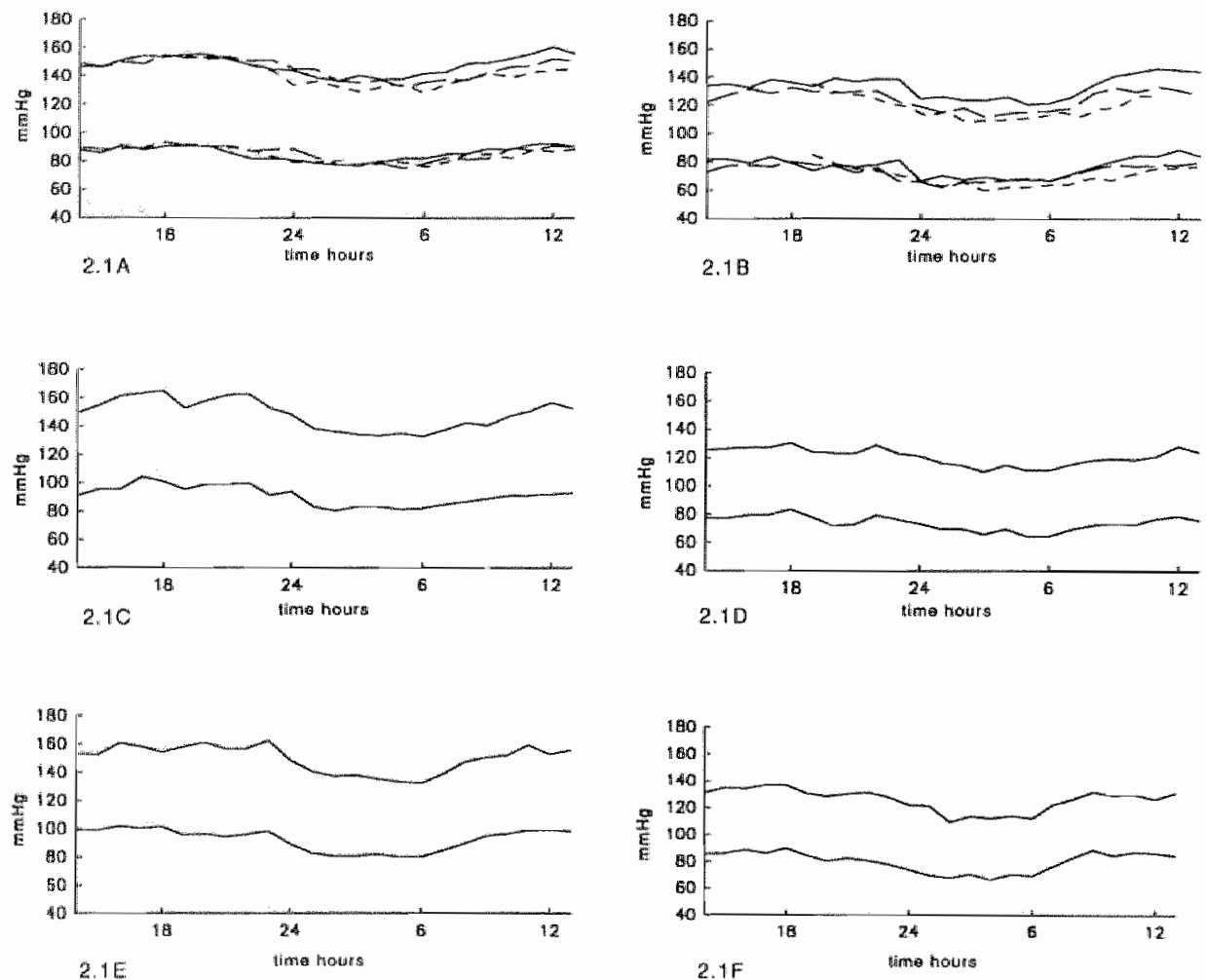

Figure 2.1 Hood pressure coutses. A. Hypertensive hemodialysis patients, $\mathrm{N}=10,3-\mathrm{day}$ : 1 st interdialytic day, - - - 2nd interdialytic day, _- 3th interdialytic day. B. Normotensive hemodialysis patients $\mathrm{N}=10,3$-day. C. Hypertensive CAPD patients, $\mathrm{N}=9$, 1-day. D. Normotensive CAPD patients, $N=11,1 \times d a y, E$. Hypertensive controls, $N=11,1-$ day. F. Normotensive controls, $N=9,1 \sim$ day. 


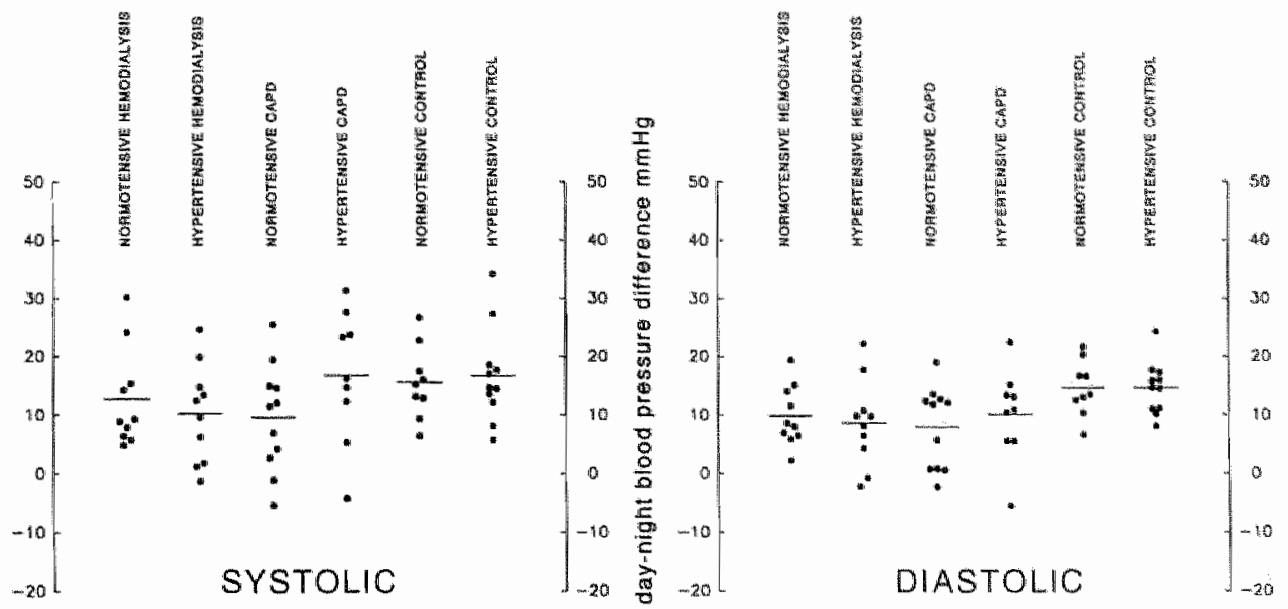

Figure 2.2 Day-night blood pressure differences in mormotensive and hypertensive hemedialysis, CA.PD, and control patients

In the hemodialysis patients day-night blood pressure differences did not change significantly during the inter-dialytic period (figure 2.1 , table 2.2 ), although interdialytic weight gain was $2.9 \pm 1.6 \mathrm{~kg}$ in the hypertensive and $2.7 \pm 1.7 \mathrm{~kg}$ in the normotensive patients. Indexed caval vein diameter increased significantly from $8.0 \pm 0.7 \mathrm{~mm} / \mathrm{m}^{2}$ post-dialytic to $10.7 \pm 2.1 \mathrm{~mm} / \mathrm{m}^{2}$ pre-dialytic $(p<0.01)$ in the hypertensive hemodialysis patients, and from $8.1 \pm 0.9 \mathrm{~mm} / \mathrm{m}^{2}$ post-dialytic to $10.8 \pm 2.3 \mathrm{~mm} / \mathrm{m}^{2}$ pre-dialytic $(\mathrm{p}<0.01)$ in the normotensive hemodialysis patients.

Table 2.2 Mean ( \pm SD) day-night blood pressure differences on the first, second, and third day of a $3 \times$ day ifuterdiallytic pertiod of 10 normotensive and 10 hypertens dwe hemodivalysis patientus

\begin{tabular}{lcccc}
\hline & \multicolumn{2}{c}{ Normotensive } & \multicolumn{2}{c}{ Hypertensive } \\
& systolic (mmHg) & diasiolic (mmHg) & systolic (mmHg) & diastolic (mmHg) \\
\hline $11 \pm 6$ & $10 \pm 4$ & $13 \pm 6$ & $8 \pm 6$ \\
2th day & $13 \pm 8$ & $10 \pm 5$ & $10 \pm 8$ & $9 \pm 7$ \\
3th day & $14 \pm 6$ & $12 \pm 5$ & $12 \pm 7$ & $9 \pm 6$ \\
\hline
\end{tabular}

No significant correlation was found between day-night blood pressure differences and residual diuresis, inter-dialytic weight gain, caval vein diameter or age. Weak inverse correlations were found between day-night systolic or diastolic blood pressure differences and total time on renal replacement therapy $(r=-0.31$; $\mathrm{p}=0.054$, and $\mathrm{r}=-0.38 ; \mathrm{p}=0.017$ ). 
Day-time heart rate was slightly higher in the hemodialysis and CAPD patients as compared to control patients ( $87 \pm 12$ and $84 \pm 10$ versus $79 \pm 11$ b.p.m.), however these differences did not reach a significant level $(p=0.055)$. Night-time heart rate was significantly higher in the hemodialysis and CAPD patients as compared to the control patients ( $74 \pm 9$ and $78 \pm 9$ versus $66 \pm 9$ b.p.m.; $p=0.004$ and $p<0.001$ ). Night-time heart rate in the hemodialysis patients was not significantly different from nightime heart rate in CAPD patients $(p=0.105)$. CAPD patients showed a significantly blunted day-night heart rate variation as compared to the hemodialysis and the control patients $(6 \pm 5$ versus $13 \pm 8$ and $13 \pm 7$ b.p.m.; $p=0.004$ and $\mathrm{p}=0.001$ ).

When comparing hypertensive and normotensive hemodialysis patients, no significant differences were found in day-time $(84 \pm 15$ and $90 \pm 8$ b.p.m.), nighttime ( $75 \pm 11$ and $73 \pm 6$ b.p.m.), and day-night heart rate variation $(13 \pm 7$ and $13 \pm 8$ b.p.m.). In the CAPD patients night-time heart rate was significantly lower in the hypertensive patients as compared to the normotensive patients $(74 \pm 6$ and $81 \pm 11$ b.p.m., $p=0.033)$. No differences in day-time ( $82 \pm 8$ and $86 \pm 11$ b.p.m.) and day-night heart rate $(7 \pm 5$ and $5 \pm 5$ b.p.m.) were found. Also between the hypertensive and normotensive control patients no significant differences in daytime $(81 \pm 9$ and $78 \pm 13$ b.p.m.), night-time $(67 \pm 9$ and $64 \pm 10$ b.p.m.) and daynight heart rate ( $13 \pm 7$ and $13 \pm 8$ b.p.m.) were found.

\section{Discussion}

In order to evaluate the influence of fluid excess and variations in fluid state on day-night blood pressure differences, we performed ambulatory blood pressure monitoring in normovolemic normotensive and hypertensive hemodialysis, CAPD and control patients without antihypertensive medication.

Our data show a significant blunted mocturnal blood pressure fall in hemodialysis and CAPD patients as compared to control patients, which is in accordance with other studies ${ }^{3,7,8,11}$. However, in most of the dialysis patients a clear nocturnal blood pressure reduction was preserved. The average nocturnal blood pressure in the control patients fell only about $5 \mathrm{mmHg}$ more than in the dialysis patients. Moreover no more than $20 \%$ of the hemodialysis patients and $25 \%$ of the CAPD patients appeared to be non-dippers. Finally, hypertensive hemodialysis and CAPD patients did not exhibit more blunting of their day-night blood pressure variation than normotensive hemodialysis and CAPD patients.

Most other studies show a much more blunted day-night blood pressure difference in dialysis patients, especially in hypertensive hemodialysis patients, than we did in the present study $y^{5,7,8,11}$. In contrast to most other studies however, we stopped all antihypertensive medication 3 weeks prior to the study. Although antihypertensive 
medication is thought to have only minimal effect on diumal blood pressure variation $^{12}$, the influence of these drugs on blood pressure variation in most studies can never be fully assessed. Apart from the specific influence of the various antihypertensive drugs on diumal blood pressure variation, also the time of drug intake can have some impact on blood pressure variations. Another factor in finding less blunting of day-night blood pressure difference in our study compared with other studies could be the relatively mild elevated blood pressure in our hypertensive patients. Only hypertensive patients with few antihypertensive medications were selected for our study because we had to stop these elrugs safely before the study period.

The causes of the attenuated diurnal blood pressure variation in dialysis patients is not clear. Autonomic failure ${ }^{13}$, increased neural sympathetic activity ${ }^{14}$ and elevated levels of catacholamines ${ }^{15}$, heart failure ${ }^{16}$, the use of erythropoietin ${ }^{17}$, and reduced daily activity could all play a role. Also, volume expansion has been suggested as playing a role in the blunted diurnal blood pressure variation?

We did not find a change in day-night blood pressure variation in hemodialysis patients during a 3-day inter-dialytic period. In particular diurnal blood pressure variation was not more attenuated on the 3 rd inter-dialytic day compared with the 1st inter-dialytic day. So inter-dialytic weight gain did not influence diumal blood pressure variations. CAPD patients have a more stable fluid state than hemodialysis patients. However, the day-night blood pressure difference in CAPD patients was similar to that in hemodialysis patients. Hence, it seems unlikely that volume expansion or variations in extra-cellular fluid, plays a major role in the disturbed blood pressure rhythm in dialysis patients.

A weak inverse correlation was found between day-night blood pressure differences and total time on renal replacement therapy. That renal replacement therapy itself influences diurnal blood pressure variation seems unlikely, for no signilicant differences were found between hemodialysis and CAPD patients. More probably the duration of renal insufficiency is the factor that influences the diurnal blood pressure variation. This could be explained by the development of cardiovascular changes or the development of autonomic neuropathy in patients with renal failure. Dialysis patients show a disturbed Valsalva ratio and normal efferent sympathetic activity ${ }^{18}$. Although patients with clinically evident autonomic neuropathy and patients with diabetes mellitus were excluded from the study, a mild autonomic dysfunction cannot be excluded in our patients.

Also elevated sympathetic activity could explain the disturbed diurnal blood pressure rhythm in dialysis patients. In healthy subjects diurnal blood pressure variation seems to be particularly influenced by arousal and physical activity ${ }^{12}$. It is hypothesized that sympathetic activity is the main determinant in blood pressure variation. Catecholamine levels parallel diurnal blood pressure variation with high 
levels during the day and a decrease during the night ${ }^{19}$. In dialysis patients catecholamine levels are found to be elevated and end-organ response to be impaired, probably due to down-regulation of the effector receptors ${ }^{15.20}$. Dialysis patients could by their high basal level of sympathetic neural and humoral activity have an impaired response on day-time sympathetic activation, resulting in a blunted diurnal blood pressure profile.

No significant changes in day-night heart rate variation was found in the hemodialysis patients as compared to the control patients. However, in the CAPD patients diurnal heart rate variation was significantly blunted in comparison to control and hemodialysis patients. This is surprising because it is not likely that CAPD treatment is associated with more autonomic dysfunction than hemodialysis treatment. An explanation for this can be the nocturnal presence of fluid in the abdomen. Night rest in CAPD patients could be more disturbed in CAPD patients by the presence of fluid in the abdomen, although no differences in blood pressure variation were found between the CAPD and hemodialysis patients. It is more likely that the nocturnal increase in parasympathetic activity is disturbed in CAPD patients. Especially in the lying position, the CAPD fluid could induce pressure on the vena cava and thereby reducing venous return and cardiac output during the night. Due to baroreceptor stimulation a lesser increase in parasympathetic tone and hence an attenuated fall in nocturnal heart rate could be the result ${ }^{21}$.

We conclude that the diurnal blood pressure variation is attenuated to the same extent in hypertensive and normotensive hemodialysis and CAPD patients, although in most patients a day-night blood pressure difference can be found. Diurnal blood pressure variations are not modified by inter-dialytic fluid changes. Although volume status is less stable in hemodialysis than in CAPD patients, this does not seem to affect day-night blood pressure differences when both groups of patients are compared. It may be hypothesized that in patients on dialysis, factors other than changes in extra-cellular fluid volumes, are responsible for a blunted day-night difference in blood pressure. 


\section{References}

1. Mancia G, Ferrari A, Gregorini L, Parati G, Pomidossi G, Bertinieri G, Grassi G, di Rienzo M, Pedotti A, Znchetti A. Blood pressure and heart rate variabilities in normotensive and hypertensive human beings. Circ Res 1983;53:96-104.

2. Verdecchia P, Schillaci G, Guerrieri $M$, Gatteschi $C$, Benemio G, Boldrini F, Porcellati C. Circadian blood pressure changes and left ventricular hypertrophy in essential hypertension. Circulation 1990;81:528-536.

3. Fassbinder W, Brunner FP, Brynger H, Ehrich JHH, Geerlings W, Raine AEG, Rizzoni G, Selwood NH, Tufveson G, Wing AJ. Combined report on regular dialysis and transplantation in Europe, XX, 1989. Nephrol Dial Transpl 1991;6 (supp 1).

4. Degoulet P, Legrain M, Reach I, Aime F, Devries C, Rojas P, Jacobs C. Mortality risk factors in patients treated by chronic haemodialysis. Nephron 1982;31:103-110.

5. Kooman JP, Gladziwa U, Bocker G, Wijnen JAG, van Bortel L, Luik AJ, de Leeuw PW, van Hooff JP, Leunissen KML. Representative blood pressure in haemodialysis patients by 48 -hour ambulatory blood pressure monitoring. Nephrol Dial Transpl 1992;7:917-923.

6. London GM, Marchais SJ, Guerin AP, Metivier F, Pannier B. Cardiac hypertrophy and arterial alteriations in end-stage renal disease. Hemodynamic factors. Kidney Int 1993;43 supp1.41:S42-S49.

7. Baumgart $\mathbf{P}$, Walger $\mathrm{P}$, Gemen $\mathrm{S}$, von Eiff $\mathbf{M}$, Raidt H, Rahn KH. Blood pressure elevation during the night in chronic renal failure, hemodialysis and renal transplantation. Nephron 1991;57:293-298.

8. Battistella P, De Cornelissen F, De Gaudemaris R, Contard S, Janin G. Profil tensionnel ambulatoire de 48 heures chez l'hemodialyse chronique. Arch Mal Coeur 1990;83:1223-1227.

9. Leunissen KML, Cheriex EC, Janssen JHA, Mooy JMV, van Hooff JP. Echography of the inferior caval vein is a simple and reliable tool for estimation of dry weight in haemodialysis partients. Nephrol Dial Transpl 1989;4:563-568.

10. O'Brien E, Mee F, Atkins N, O'Malley K. Accuracy of the SpaceLabs 90207 determined by the British Hypertension Society Protocol. J Hypert 1991;9:573-574.

11. Rosansky SJ. Nocturnal hypertension in patients recieving chronic hemodialysis. Letter. Ann Int Med 1991;114:96.

12. Pickering TG. Ambulatory monitoring and blood pressure variability. Science Press. London, 1991.

13. Mann S, Altman G, Raftery EB, Bannister E. Circadian variation of blood pressure in autonomic failure. Circulation 1983;68:477-483.

14. Converse RL, Jacobsen TN, Toto RD, Jost CJ, Cosentino F, Fouad-Tarazi DOF, Victor RG. Sympathetic overactivity in patients with chronic renal failure. New Eng J Med 1992;327:1912-1918.

15. McGrath BP, Ledingham JGG, Benedict CR. Catecholamines in peripheral venous plasma in patients on chronic haemodialysis. Clin Sci Mol Med 1978;55:89-96. 
16. Caruana $\mathrm{M}$, Lahin $\mathrm{A}$, Cashman PMM, Altman DG, Raftery EB. Effects of chronic congestive heart fallure secondary to coronary artery disease on the circadian thythm of blood pressure and heart rate. Am J Cardiol 1988;62:755-759.

17. Borne vd $P$, Tielemans $C$, Vanherweghem $\Omega$, Degaute JP. Effect of recombinant human erythropoietin therapy on ambulatory blood pressure and heart rate in chronic haemodialysis patients. Nephrol Dial Transpl $1992 ; 7: 45-49$.

18. Campese VM, Romoff MS, Levitan D, Lane K, Massry S. Mechanisms of autonomous nervous system dysfunction in uremia. Kidney Int 1981;20:246 253.

19. De Leeuw PW, van Leeuwen SJ, Willemse PJ, Tchang PT, Birkenhäger WH. Spontaneous and induced variations in adrenergic activity. Neth $J$ Med $1984: 27: 136-139$.

20. Bergström $\pi$. Catechoamines and control of blood pressure in hemodialysis and hemofiltration. Kidney Int 1988;34 suppl.25:S110-S114.

21. Berne RM. Handbook of physiology. section 2 The cardiovascular system. American Physiologicall Society 1979. 


\section{Chapter 3}

\section{Influence of inter-dialytic weight gain on blood pressure in hemodialysis patients}

AJ Luik, U Gladziwa, JP Kooman, JP v Hooff, PW de Leeuw, LMAB v Bortel, KML Leunissen 


\begin{abstract}
The role of fluid overload in the pathogenesis of hypertension in hemodialysis patients is not clear. One problem is the lack of techniques to determine the fluid state. Recently new noninvasive techniques have become available which make it possible to accurately determine the dry weight in these patients. Therefore, we studied the influence of interdialytic weight gain on inter-dialytic blood pressure in 10 normotensive and 10 hypertensive hemodialysis patients without antihypertensive medication. The dry weight was determined with echography of the vena cava. The blood pressure was measured during 2-day and 3-day inter-dialytic periods using Spacelabs 90207 ambulatory blood pressure monitors. Mean systolic and diastolic blood pressures of the last day of the interdialytic period were compared with mean systolic and diastolic blood pressures of the 1 st day of the inter-dialytic period. Although the inter-dialytic weight gain in the normotensive and hypertensive patients was greater during the 3-day than during the 2 day inter-dialytic period, the inter-dialytic systolic and diastolic blood pressure changes were not greater during the 3-day period. Also the inter-dialytic blood pressure rise did not correlate significantly with weight gain, neither in the normotensive nor in hypertensive patients. No significant inter-dialytic blood pressure changes were found between the normotensive and the hypertensive patients. We conclude that fluid overload does not seem to play a major role in inter-dialytic blood pressure control in normotensive and hypertensive hemodialysis patients.
\end{abstract}




\section{Introduction}

Cardiovascular complications are the main cause of morbidity and mortality in patients on renal replacement therapy ${ }^{1}$. Hypertension is considered the most important risk factor ${ }^{2}$. The pathogenesis of an elevated blood pressure in dialysis patients is multifactorial and not completely understood. High levels of circulating catecholamines, an activated sympathetic nervous system, an activated reninangiotensin system, and structural vascular changes have all been found in dialysis patients $^{3-7}$. The importance of fluid overload, always regarded as the major pathogenetic factor, is nowadays a matter of debate. Historically, the dry weight in dialysis patients was estimated clinically by the absence of edema and pulmonary congestion and a post-dialytic blood pressure in the normotensive range. The dry weight was considered to be reached at the moment the patient tended to become hypotensive $^{8}$. The concept of this treatment mode was that hypertension in hemodialysis patients is exclusively related to volume overload, ruling out all other pathogenetic mechanisms that could be involved. Furthermore, in this concept one assumes that the post-dialytic blood pressure is only related to the total fluid state of the patients, whereas it is known that many other dialysis related factors can influence post-dialytic blood pressure.

Today we have the tools for a more accurate determination of the ideal dry weight ${ }^{9}$. Especially ultrasonography of the vena cava inferior has proven to be a reliable and clinically useful method for accurate determination of the dry weight in hemodialysis patients ${ }^{10}$. Although nowadays the ideal dry weight is achieved in most patients on hemodialysis, many of them still appear to have hypertension. Therefore, it is less likely that fluid overload per se is a major determinant of hypertension in these patients.

Moreover, it seems to be more reliable to study the inter-dialytic blood pressure rather than the pre- and post-dialytic blood pressures ${ }^{\sharp 1}$. In order to analyze the influence of inter-dialytic weight gain on inter-dialytic blood pressure, we performed ambulatory blood pressure monitoring during a 2-day and 3-day interdialytic period in normotensive and hypertensive hemodialysis patients who were without antihypertensive medication.

\section{Materials and methods}

Ten hypertensive (post-dialytic blood pressure $\geq 140 / 90 \mathrm{mmHg}$ ) and 10 normotensive (post-dialytic blood pressure $<140 / 90 \mathrm{mmHg}$ ) hemodialysis patients on a three times weekly chronic dialysis scheme with a stable hemoglobin concentration were studied. Patients with diabetes mellitus, severe valvular disease, cardiac failure, or clinically evident autonomic neuropathy, defined as an ortho- 
static blood pressure fall of more than $20 \mathrm{mmHg}$ with no change in heart rate, were excluded. Antihypertensive medication was discontinued at least 3 weeks prior to the start of the study. Optimal dry weight in the hemodialysis patients was estimated by echographic measurement of the inferior caval vein diameter ${ }^{10}$. The patients were dialyzed in the afternoon with a Gambro AK-100 or a Fresenius 2008 dialysis apparatus with bicarbonate as dialysate buffer. Biocompatible polysulfone or polyacrylonitrile membranes were used. The individual inter-dialytic weight gain was measured.

Day-time (from 7.00 to $23.00 \mathrm{~h}$ ) and night-time (from 23.00 to $7.00 \mathrm{~h}$ ) blood pressures were measured during a 2-day and a 3-day inter-dialytic period, using Spacelabs 90207 ambulatory blood pressure monitors ${ }^{12}$. The blood pressure was measured every $20 \mathrm{~min}$ during day-time and every $30 \mathrm{~min}$ during the night. Individual day-time and night-time systolic and diastolic blood pressures were calculated from the individual hourly mean values. The day-time and night-time inter-dialytic blood pressure rises were calculated by subtracting average systolic or diastolic blood pressures on the 1st day of the inter-dialytic period from their respective counterparts on the last day of the inter-dialytic period.

Statistical analysis was performed using the non parametric Wilcoxon matchedpairs signed-rank test for paired data, the Wilcoxon rank sum test for testing differences between the normotensive and hypertensive patient groups, and the linear Pearson correlation for testing the relationship between inter-dialytic weight gain and blood pressure. A $p$ value $<0.05$ was taken as the level of significance.

Table 3.1 Patients characteristics (mean $\pm S D)$ for $\operatorname{sex}(\mathrm{m}=$ male, $\mathrm{f}=$ fernale), age, total time on dialysis, post-dialytic blood pressure, residual diuresis and 2-day and 3-daly inter-dialytic weight gain

\begin{tabular}{lcc}
\hline & $\begin{array}{c}\text { Normotensive } \\
\mathbf{n}=10\end{array}$ & $\begin{array}{c}\text { Hypertensive } \\
\mathbf{n}=10\end{array}$ \\
\hline Sex. (m/n) & $4 \mathrm{~m} / 6 \mathrm{f}$ & $7 \mathrm{~m} / 3 \mathrm{f}$ \\
Age (years) & $44 \pm 17$ & $47 \pm 14$ \\
Time on dialysis (years) & $4.9 \pm 3.7$ & $3.7 \pm 3.4$ \\
Postdial.syst.BP. (mmHg) & $128 \pm 7$ & $150 \pm 10$ \\
Posidial.diasc.BP. (mmHg) & $78 \pm 7$ & $86 \pm 7$ \\
Diuresis (Lday) & $0.4 \pm 0.6$ & $0.7 \pm 0.6$ \\
2-Day weight gain (kg) & $1.7 \pm 1.1$ & $2.3 \pm 1.2$ \\
3-Day weigh gain $(\mathrm{kg})$ & $2.7 \pm 1.7$ & $2.9 \pm 1.6$ \\
\hline
\end{tabular}




\section{Results}

The normotensive and the hypertensive patients were comparable with respect to sex, age, total time on renal replacement therapy, and residual diuresis (table 3.1). The inter-dialytic weight gain was significantly higher during the 3-day interdialytic period as compared with the 2 -day inter-dialytic period. The mean ( \pm SD) post-dialytic systolic and diastolic blood pressures were $128 \pm 7$ and $78 \pm 7 \mathrm{mmHg}$, respectively, in the normotensive patients and $150 \pm 10$ and $86 \pm 7 \mathrm{mmHg}$, respectively, in the hypertensive patients. A significant day-night blood pressure difference was found in the normotensive as well as in the hypertensive patients (figure 3.1). The average systolic and diastolic day-night blood pressure differences on the $2 \mathrm{~d}$ day of the 3 -day inter-dialytic period in the normotensive patients were $13 \pm 8$ and $10 \pm 5 \mathrm{mmHg} \quad(\mathrm{p}=005$ and $\mathrm{p}=0.005)$, respectively, and in the hypertensive patients $10 \pm 8$ and $9 \pm 7 \mathrm{mmHg}(\mathrm{p}=0.009$ and $\mathrm{p}=0.012)$, respectively.

Normotensive hemodialysis patients

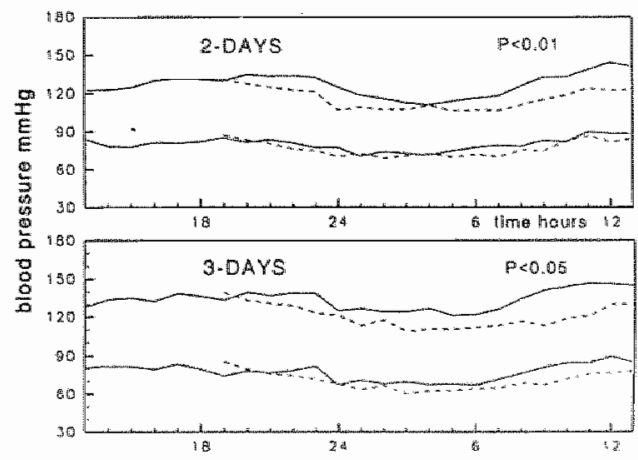

Hypertensive hemodialysis patients

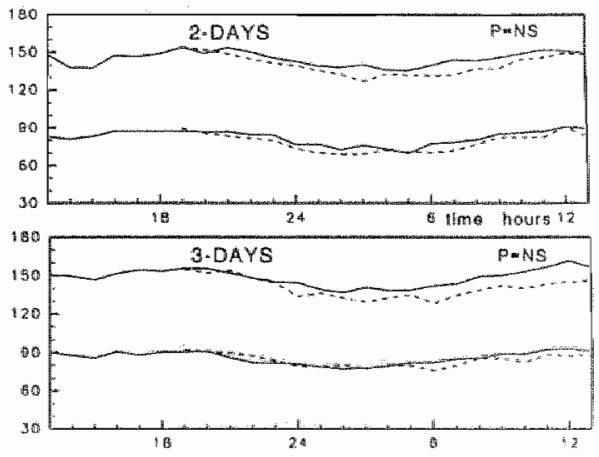

Figure 3.1 Interdialytic blood pressure changes in 10 normotensiwe (left box), and 10 hypertensiwe (righ box)

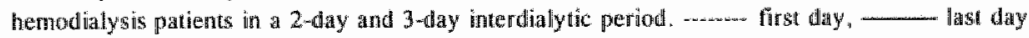

In the normotensive patients, the systolic day-time and night-time blood pressures were significantly higher on the last day as compared with the 1st day of the 2-day inter-dialytic period $(p=0.005$ and $p=0.005$; figure 3.1). Changes in diastolic daytime and night-time blood pressures were not statistically significant during the 2day inter-dialytic period. During the 3-day inter-dialytic period, the systolic as well as the diastolic day-time and night-time blood pressures were significantly higher on the last day as compared with the 1 st day $(p=0.012, p=0.028, p=0.009$, and $p=0.016$, respectively). 
In the hypertensive patients, no significant inter-dialytic systolic or diastolic blood pressure changes were found during the 2-day and 3-day inter-dialytic periods (figure 3.1). Only the night-time diastolic blood pressure on the last day of the 2day inter-dialytic period was significantly higher as compared with the 1 st day $(\mathrm{p}=0.012)$.

However, when comparing the normotensive and hypertensive patients, 2-day and 3-dlay inter-dialytic blood pressure changes in the hypertensive group were not significantly different from inter-dialytic blood pressure changes in the normotensive group.

In the normotensive patients, systolic and diastolic inter-dialytic blood pressure changes during the 3-day inter-dialytic period were not significantly different from blood pressure changes during the 2-day inter-dialytic period, although the interdialytic weight gain was significantly greater during the 3-day inter-dialytic period (figure $3.2,3.3$ ). Also in the hypertensive patients, no significant differences in inter-dialytic blood pressure changes were found between the 2-day and the 3-day inter-dialytic periods. No significant correlation could be found between interdialytic weight gain and inter-dialytic systolic or diastolic blood pressure changes.

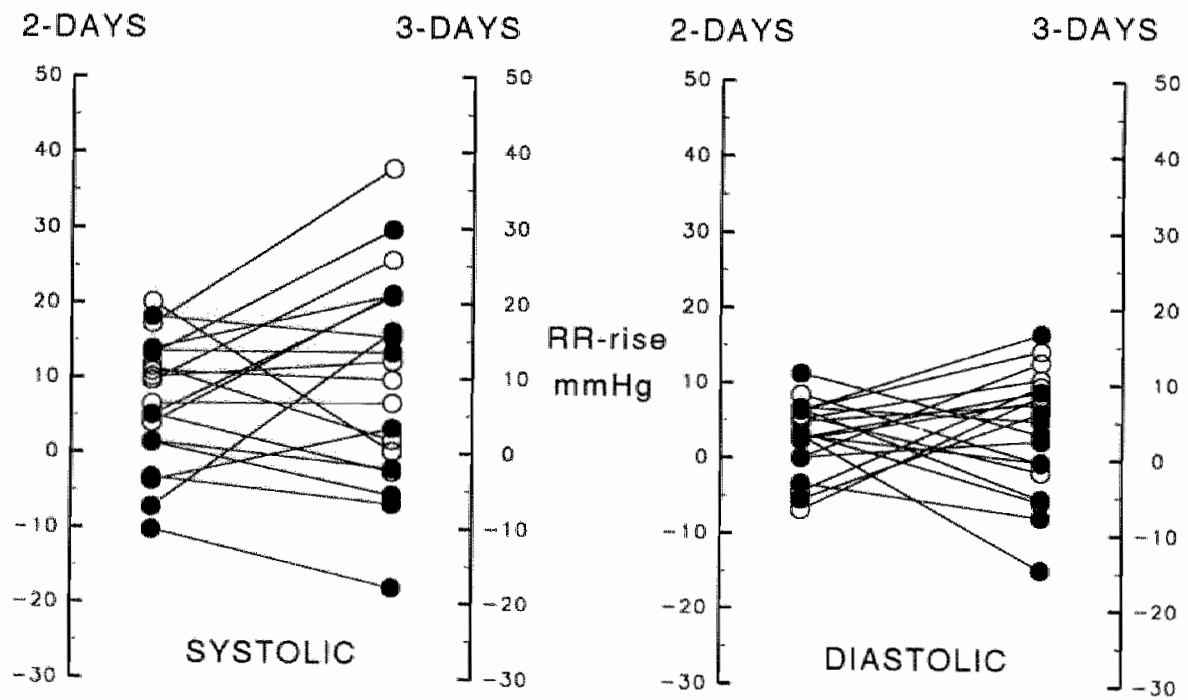

- hypertensive $\quad$ normotensensive

Figure 3.2 Day-lime blood pressure changes in the 2 -day and 3 -day interdiallytic period $(\mathrm{N}=200$ 


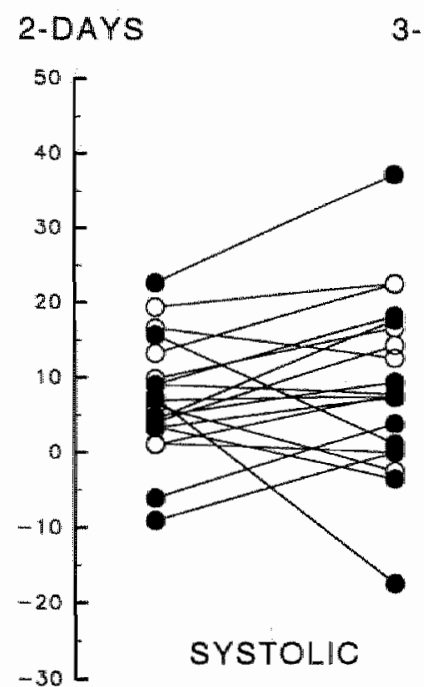

- hypertensive
3-DAYS

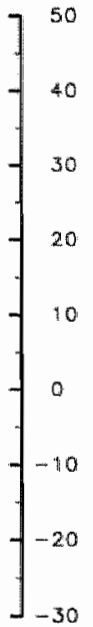

2-DAYS

3-DAYS

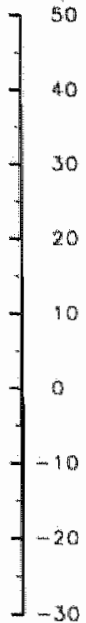

Figure 3.3 Night time blood pressure changes in the 2-day and 3-day interdialytic period $(\mathrm{N}=20)$

\section{Discussion}

In this study, we found no relationship between inter-dialytic weight gain and interdialytic blood pressure changes in normotensive and untreated hypertensive hemodialysis patients in whom dry weight was established on the basis of echography of the inferior caval vein. Also, the greater increase in weight gain during a 3-day inter-dialytic period as compared with a 2-day inter-dialytic period did not result in a different inter-dialytic blood pressure change. These results suggest that the inter-dialytic increase in fluid volume is not a major determinant of inter-dialytic blood pressure changes. The absence of a relationship between interdialytic weight gain and inter-dialytic blood pressure changes has also been found by others ${ }^{11,13}$.

Looking at the individual data in our study, most of the normotensive and hypertensive patients do not have a different inter-dialytic blood pressure change during the 3-day inter-dialytic period as compared with the 2-day inter-dialytic period. However, a few patients show a higher inter-dialytic blood pressure rise during the 3-day inter-dialytic period as compared with the 2-day inter-dialytic period (figure $3.2,3.3$ ). It is possible that these patients are more sensitive to fluid 
load. The threshold for a blood pressure rise due to fluid load may vary greatly between individuals and is perhaps related to differences in venous, arterial, or left ventricular compliance, which have been found to be reduced in some hemodialysis patients 6.7 .14 .

Fluid overload has always been considered the major cause of hypertension in dialysis patients. This was explained in terms of Guyton's concept of autoregulation of the systemic blood flow ${ }^{15}$. According to this theory, blood flow to peripheral tissues is carefully regulated by changes in local vascular resistance. Any increase in cardiac output, induced by expansion of extra-cellular volume and/or blood volume, augments peripheral blood flow which in turn elicits an increase in peripheral vascular resistance in order to restore blood flow towards baseline. However, in a study of 10 anephric dialysis patients who underwent salt and water loading ${ }^{16}$, only 1 of these patients followed the classic pattern of Guyton's autoregulation hypothesis.

The idea that hypervolemia would be a major cause of hypertension in hemodialysis patients was supported by the observation that most of the patients with end-stage renal failure have hypertension which improves after the start of renal replacement therapy ${ }^{17}$. Pre-dialysis patients with end-stage renal disease are usually severely overhydrated. The better blood pressure control after renal replacement therapy is started can then be explained by the better fluid control in these patients. An other explanation could be a better clearance of substances with direct or indirect influences on hemodynamics and blood pressure.

Some authors ${ }^{18}$ suggest that fluid removal in hemodialysis patients should be done softly and slowly over time. An optimal blood pressure control was found in a dialysis regimen of three times a week during $8 \mathrm{~h}$ with a slow ultra-filtration rate ${ }^{18}$. The explanation is that by preventing hemodynamic instability due to short highefficiency dialysis with high ultra-filtration rates, optimal dry weight is easier to achieve during long softly hemodialysis with slow ultra-filtration rates. However, the present dialysis techniques with the use of bicarbonate and more biocompatible membranes with a better intradialytic blood pressure stability and techniques to determine more accurately the dry weight based on both intravascular and interstitial volume measurements ${ }^{9}$ make it possible to ultra-filtrate patients to their idleal dry weight within a much shorter time. Therefore, it is doubtful that a more optimal fluid state in patients on a long softly dialysis regimen is the explanation for the better blood pressure control in these patients. Another explanation could be a better clearance of vasoactive substances in the middle molecule range by the longer dialysis time. One of these substances could be asymmetric dimethyl arginine which appears to be an endogenous inhibitor of nitric oxide synthesis and is found to be accumulating in hemodialysis patients ${ }^{19}$.

We conclude that in both normotensive and hypertensive dialysis patients, volume overload is not the only factor influencing inter-dialytic blood pressure increase. 
There seems to be an interindividual different susceptibility to volume overload in dialysis patients concerning the blood pressure rise. This could be related to factors such as arterial or venous compliance and sympathetic nervous system overactivity. 


\section{References}

1. Fassbinder $W$, Brumer $F P$, Brynger $H$, Ehrich $J H H$, Geerlings W, Raine AEG, Rizzoni G, Selwood NH, Tufveson G, Wing AJ. Combined report on regular dialysis and transplantation in Europe, XX, 1989. Nephrol Dial Transpl 1991;6 (supp 1).

2. Degoulet $P$, Legrain $M$, Reach I, Aime F, Devries C, Rojas $P$, Jacobs C. Mortality risk factors in patients treated by chronic haemodialysis. Nephron 1982;31:103-110.

3. Acosta JH. Hypertension in renal disease. Kidney Int 1982;22:702-712.

4. McGrath BP, Ledingham JGG, Benedict CR. Catecholamines in peripherall venous plasma in patients on chronic haemodialysis. Clin Sci Mol Med 1978;55:89-96.

5. Converse RL, Jacobsen TN, Toto RD, Jost CJ, Cosentino F, Fouad-Tarazi DOF, Victor RG. Sympathetic overactivity in patients with chronic remal failure. New Eng J Med 1992;327:1912-1918.

6. London GM, Marchais SJ, Guerin AP, Metivier F, Pannier B. Cardiac hypertrophy and arterial alteriations in end-stage renal disease: Hemodynamic factors. Kidney Int $1993 ; 43$ suppl.41:S42-S49.

7. JP Kooman, JAG Wijnen, P Draaijer, L van Bortel, U Gladziwa, HAJ Struyker Boudier, HG Peltenburg, JP van Hooff, KML Leunissen. Compliance and reactivity of the peripheral venous system in patients treated with chronic intermittent haemodialysis. Kidney Int 1992;41:1041-1048.

8. Maher JF. Replacement of renal function by dialysis. Boston. Kluwer Academic Publishers, 1989, p776.

9. Leunissen KML, Kouw P, Kooman JP, Cherieux EC, deVries PMJM, Donker ALM, van Hooff JP. New techniques to determine fluid status in hemodialyzed patients. Kidney Int 1993;suppl 41:S50-S56.

10. Leunissen KML, Cheriex EC, Janssen JHA, Mooy JMV, van Hooff JP. Echography of the interior caval vein is a simple and reliable tool for estimation of dry weight in haemodialysis partients. Nephrol Dial Transpl 1989;4:563-568.

11. Kooman JP, Gladziwa $U$, Bocker $G$, Wijnen JAG, van Bortel $L$, Luik AJ, de Leeuw PW, van Hooff JP, Leunissen KML. Representative blood pressure in haemodialysis patients by 48 -hour ambulatory blood pressure monitoring. Nephrol Dial Transpl 1992;7:917-923.

12. O'Brien E, Mee F, Atkins N, O'Malley K. Accuracy of the Spacelabs 90207 determined by the British Hypertension Society Protocol. J Hypert 1991;9:573-574.

13. Battistella $P$, De Cornelissen $F_{n}$ De Gaudemaris $R$, Contard $S$, Janin G. Profi tensionnel ambulatoire de 48 heures chez l'hemodialyse chronique. Arch Mal Coeur 1990;83:1223-1227.

14. Ritz E, Rambausek M, Mall G, Ruffman K, Mandelbaum A. Cardiac changes to uremia and their possible relation to cardiovascular instability on dialysis. Contrib Nephrol 1990;78:221-229.

15. Coleman TG, Bower JD, Langford HG, Guyton AC. Regulation of arterial pressure in the anephric state. Circulation 1970;42:509-514. 
16. Kim KE, Onesti G, Del Guerico ET, Fernandes $M_{*}$, Eidelson B, Swartz C. Sequential hemodynamic changes in end-stage renal disease and the anephric state during volume expansion. Hypertension 1980;2:102-110.

17. Vertes V, Cangiano JL, Berman LB. Hypertension in end stage renal disease. N. Engl J Med 1969;280:978-981.

18. Charra $B$, Calemard E, Ruffet $M$, Chazot $C$, Terrat IC, Vanel $T$, Laurent $G$. Survival as an index of adequacy of dialysis. Kidney Int 1992;41:1286-91.

19. Vallance $\mathrm{P}$, Leone A, Calver A, Collier, Moncada S. Accumulation of an endogenous inhibitor of nitric oxide synthesis in chronic renal failure. Lancet 1992;339:572-575. 


\title{
Chapter 4
}

\section{The effects of hypervolemia on inter-dialytic hemodynamics and blood pressure control in hemodialysis patients}

\author{
AJ Luik, WHM v Kuijk, J Spek, F de Heer, \\ LMAB v Bortel, PMH Schiffers, JP v Hooff, \\ KML Leunissen
}

Am J Kidney Dis 1997;30:466-474 


\section{Abstract}

The influence of hyperwolemia on hemodynamics and inter-dialytic blood pressure, as well as in relation to vascular compliance, was inwestigated in 10 hemodialysis patients who were not receiving vasoactive medication. All subjects were studied during a relative normovolemic inter-dialytic period (from $1 \mathrm{~kg}$ below dry weight post-dialytic until dry weight pre-dialytic) and a hypervolemic inter-dialytic period (from $1 \mathrm{~kg}$ above dry weight post-dialytic until $3 \mathrm{~kg}$ above dry weight pre-diallytic).

Inter-dialytic blood pressure was measured with an ambulatory blood pressure monitor. Cardiac output was echographically measured and systemic vascular resistance calculated post-dialytic, mid-inter-dialytic, and pre-dialytic. At the same time a blood sample was drawn for analyzing vasoactive hormones, sodium, and hematocrit. In all patients, ideal dry weight was estimated by echography of the caval vein. Arterial and venous compliance were measured with an ultrasound vessel wall movement detector system and a strain-gauge plethysmograph.

After fluid load, an increase in intravascular volume, an increase in caval vein diameter and cardiac output, and a decrease in peripheral resistance was observed. No significant influence of a $3 \mathrm{~L}$ fluid load was found on inter-dialytic blood pressure course $(153 \pm 24 \mathrm{mmHg} / 90 \pm 19 \mathrm{mmHg}$ in the hypervolemic period and $146 \pm 27 \mathrm{mmHg}$ / $89 \pm 22 \mathrm{mmHg}$ in the normovollemic period). Sodium and osmolality were similar in the hyperwolemic and the normovolemic inter-dialytic periods. After fluid load, a decrease in arginine vasopressine and angiotensin II was observed, which probably contributed to the decreased systemic vascular resistance. Catecholamines were not influenced by fluid load, but increased during the inter-dialytic period, suggesting accumulation after dialysis. Three of the 10 patients had higher systolic but not diastolic blood pressures after fluid load $(159 \pm 13 \mathrm{mmHg} / 81 \pm 22 \mathrm{mmHg}$ in the hypervolemic period and $135 \pm 16 \mathrm{mmHg} /$ $81 \pm 22 \mathrm{mmHg}$ in the normovolemic period). No correlation could be found between arterial or venous compliance and blood pressure changes.

We concluded that a $3 \mathrm{~L}$ inter-dialytic fluid load does not result in higher blood pressure in most hemodialysis patients. 


\section{Introduction}

Hypertension is a major risk factor for cardiovascular complications in dialysis patients ${ }^{1}$. The pathogenesis of hypertension is multifactorial and not completely understood $^{2}$. Hypervolemia has always been considered a major pathogenetic factor ${ }^{3}$. In addition a disturbed hormonal profile with an activated renin angiotensin system, increased catecholamine, vasopressin, endothelin and perhaps decreased nitrous oxide (NO) activity seem to play a role in the high incidence of hypertension in dialysis patients ${ }^{48}$. Sympathetic neural activity is found to be increased in dialysis patients 9 . The influence of autonomic dysfunction on blood pressure control in hemodialysis patients is not clear $^{10}$. The frequent use of erythropoietin during the last decade may have contributed to the increased incidence of hypertension in the dialysis population ${ }^{11}$.

Although hypertension in the dialysis patient is a multifactorial problem, the general opinion is that hypertension in most dialysis patients can be regulated by vigorous ultra-filtration ${ }^{12}$. Studies of the relationship between blood pressure and exchangeable sodium and extra-cellular volume in hemodialysis patients are conflicting ${ }^{13-17}$, and the abnormal relationship between exchangeable sodium and the renin-angiotensin system makes it even more complicated ${ }^{18}$. In addition, functional and structural vascular changes such as a reduced venous and arterial compliance can possibly affect the relationship between fluid status and blood pressure ${ }^{19,20}$. In previous studies, we found no relationship between inter-dialytic weight gain and inter-dialytic blood pressure changes, suggesting that there is no major influence of inter-dialytic fluid load on blood pressure control ${ }^{21,22}$. A higher inter-dialytic weight gain during a 3-day inter-dialytic period also did not result in a higher inter-dialytic blood pressure increase when compared with a lower inter-dialytic weight gain during a 2-day inter-dialytic period. The lack of a correlation between inter-dialytic weight gain and inter-dialytic blood pressure changes also has been confirmed by other investigators ${ }^{23}$.

In the present study, we prospectively studied whether short-term inter-dialytic fluid changes have a significant effect on blood pressure regulation. The effects of low and high inter-dialytic volume increases on hemodynamics and the interdialytic blood pressure course were studied in 10 hemodialysis patients who were not receiving vasoactive medication. These changes also were analyzed in relationship to hormonal changes and vascular compliance.

\section{Subjects and methods}

Ten stable hemodialysis patients (seven men and three women), dialyzed $4 \mathrm{~h}$ three times a week and a residual creatinine clearance of less then $5 \mathrm{ml} / \mathrm{min}$ were 
studied. Patients with diabetes mellitus, severe valvular disease, cardiac failure, or clinically evident autonomic neuropathy, defined as a decrease in orthostatic blood pressure of more than $20 \mathrm{mmHg}$ with no change in heart rate, were excluded. Four patients were initially using antihypertensive medication. Two patients were using angiotensin-converting enzyme inhibitors, one patient was using Labetolol, and one patient was using an calciurm-antagonist with a beta-blocker. All antihypertensive medication was discontinued 3 weeks before the start of the study.

Optimal dry weight in the hemodialysis patients was estimated by echographic measurement of the inferior caval vein diameter (Sonos 100 echo-doppler cardiograph with a $3.5 \mathrm{MHz}$ transducer [Hewlett-Packard, Andover, MA] ${ }^{24}$. Interobserver and intraobserver variability for caval vein diameter was less than $5 \%$ and $2.5 \%$, respectively. This method is a reliable tool for the assessment of overhydration and underhydration, and has been successfully validated against objective standards as right arterial pressure, total blood volume and change in hemodynamic parameters during dialysis ${ }^{25}$. The patients were dialyzed with an AK100 dialysis machine (Gambro, Lund, Sweden) with bicarbonate as dialysate buffer and biocompatible polysulfone or polyacrylonitrile membranes. Dialysate contained $141 \mathrm{mmol} / 1$ sodium, $2.0 \mathrm{mmol} / \mathrm{l}$ potassium, $34 \mathrm{mmol} / 1$ bicarbonate, $3 \mathrm{mmol} / 1$ acetate, $1.75 \mathrm{mmol} / \mathrm{l}$ calcium, $0.5 \mathrm{mmol} / 1 \mathrm{magnesium}$, and $108 \mathrm{mmol} / \mathrm{l}$ chloride.

The patients were randomly studied during a normal/slightly hypovolemic interdialytic period and a relatively hypervolemic inter-dialytic period. For the normovolemic study period patients were dialyzed in the morning and ultra-filltrated until $1 \mathrm{~kg}$ under their estimated dry weight. They were instructed to gain $1 \mathrm{~kg}$ weight during the following inter-dialytic period. After the 2-days inter-dialytic study period they were dialyzed in the afternoon. For the hypervolemic study period patients were dialyzed in the morning and ultra-filtrated until they were $1 \mathrm{~kg}$ above their estimated dry weight. They were then instructed to gain $2 \mathrm{~kg}$ weight during the 2-days inter-dialytic study period, after which they were dialyzed in the afternoon. With this protocol, patients were studied from $-1 \mathrm{~kg}$ until dry weight during the normovolemic study period and from $+1 \mathrm{~kg}$ until $+3 \mathrm{~kg}$ dry weight cluring the hypervolemic study period.

During the two inter-dialytic study periods blood pressure was measured using Spacelabs 90207 ambulatory blood pressure monitors (SpaceLabs, Redmond, WA ${ }^{26}$. Between 7:00 am and 23:00 pm (day-time), blood pressure was measured every 15 minutes; between 11:00 pm and 7:00 am (night-time), blood pressure was measured every 30 minutes. Average blood pressure was calculated for each hour. From these data, average day-time, night-time, and 24-hour blood pressure values were calculated.

In all patients venous compliance, arterial distensibility and arterial compliance 
were measured while the patients were normovolemic.

Venous compliance was measured by strain-gauge plethysmography (Periflow; Jansen Scientific Instruments, Beerse, Belgium) with direct intravenous pressure measurements by an intravenous catheter (internal diameter $\mathbb{1 m m}$ ) inserted into an antecubital vein ${ }^{27}$. The arm cuff was inflated for three minutes at a pressure of $25 \mathrm{mmHg}$. The changes in arm volume and intravenous pressure were measured following cuff deflation. After 2 minutes, the same procedure was followed at cuff pressures of $30,35,40,45$, and $50 \mathrm{mmHg}$. Venous compliance was obtained as the slope of the regression curve, constructed from the obtained volume/pressure ratios at the subsequent cuff pressures. This method for measuring venous compliance is a reproducible method with a coefficient of variation of $6.0 \%$ in hemodialysis patients and $11.0 \%$ in controls ${ }^{28}$.

Arterial distensibility measurements were performed on the carotid artery using a noninvasive ultrasound wall movement detector system ${ }^{29}$. Arterial diastolic diameter and arterial wall distension on the pressure wave were measured. Blood pressure was simultaneously measured every 2 minutes with an automated blood pressure device. The average pulse pressure was calculated. From the arterial diameter, the change in diameter during the heart cycle (distension) and the pulse pressure, arterial distensibility, and compliance were calculated. The intra-observer variability of the diameter measurement appeared to be less than $10 \%$ in the carotid artery $^{30}$.

Directly after dialysis, 24 hours after dialysis, and before the next dialysis, the patients were evaluated for weight and echographic measurement of the caval vein diameter. At the same time, stroke volume was obtained by measuring ascending aortic blood flow velocity using a continuous wave Doppler system with a $10 \mathrm{MHz}$ transducer positioned at the apex, and the aortic annular cross-sectional area was determined with bidimensional echocardiography with a $3.5 \mathrm{MHz}$ transducer positioned at the third or fourth intercostal space at the left sternal edge (HewlettPackard Sonos 100 echo-Doppler cardiograph ${ }^{31}$. This method correlates well with other invasive and noninvasive techniques and has an intraobserver variability of $9 \%{ }^{32.33}$. Cardiac index (CI) was calculated by multiplying stroke index with hear: rate. Systemic vascular resistance index (SVRI) was calculated from the $\mathrm{Cl}$ and mean arterial pressure (MAP) according to the following formula: SVRI $=\left\{\left(\mathrm{MAP}(\mathrm{mmHg}) / \mathrm{CI}\left(\mathrm{ml} / \mathrm{sec} / \mathrm{m}^{2}\right)\right\} \times 1,332\right.$.

All hemodynamic measurements were performed by the same investigator between approximately $12: 00 \mathrm{pm}$ and 3:00 pm after 15 minutes of rest in the supine position in a temperature-controlled room $\left(23^{\circ} \mathrm{C}\right)$.

Directly after dialysis, 24 hours after dialysis, and before the next dialysis, also a blood sample was drawn into ice-chilled tubes from an intravenous catheter (internal diameter $1 \mathrm{~mm}$;Venflon) inserted into an anticubital vein, with the patient still in supine position. Blood was analyzed for hematocrit, sodium ( $\mathrm{Na}$ ), colloid 
osmotic pressure(COP), osmolality atrial natriuretic peptide (ANP), epinephrine, norepinephrine, arginine vasopressin (AVP), renin, and angiotensin II. ANP, aldosterone, angiotensin II, and AVP were measured with a radioimmunoassay. Renin was measured with immunoradiometric assay. Epinephrine and norepinephrine were measured with fluorescence high-performance liquid chromatography.

Data are given as mean value \pm SD. Statistical analysis was performed using non parametric Wilcoxon matched-pairs signed-rank test for paired data and linear Pearson correlation for testing the relationship between inter-dialytic weight gain, hemodynamic measurements, hormonal changes, and blood pressure changes. $P<0.05$ was considered significant.

\section{Results}

The mean patients age was $53 \pm 15$ years. The origin of renal disease was polycystic disease in four patients, hemolytic uremic syndrome in one patient, acute tubular necrosis with cortical necrosis in one patient, chronic interstitial nephritis in one patient, and glomerulosclerosis in three patients.

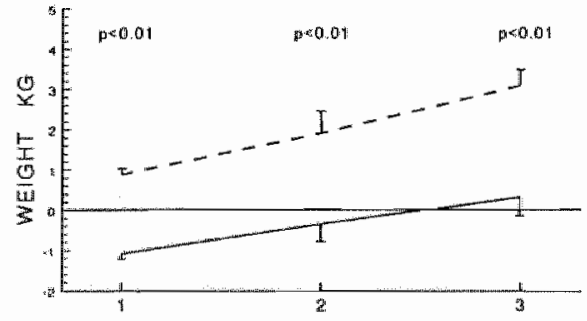

4. $1 \mathrm{~A}$

pos idilativitie

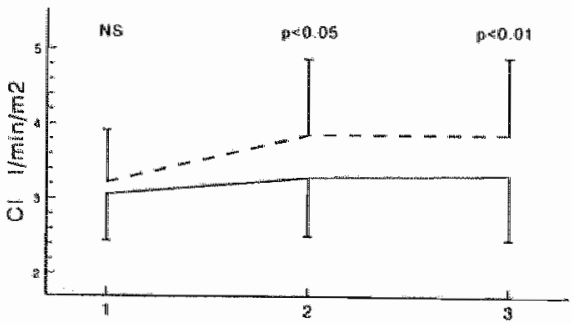

4. 10

$24 \mathrm{~h}$ atop aiantsis

predialytic
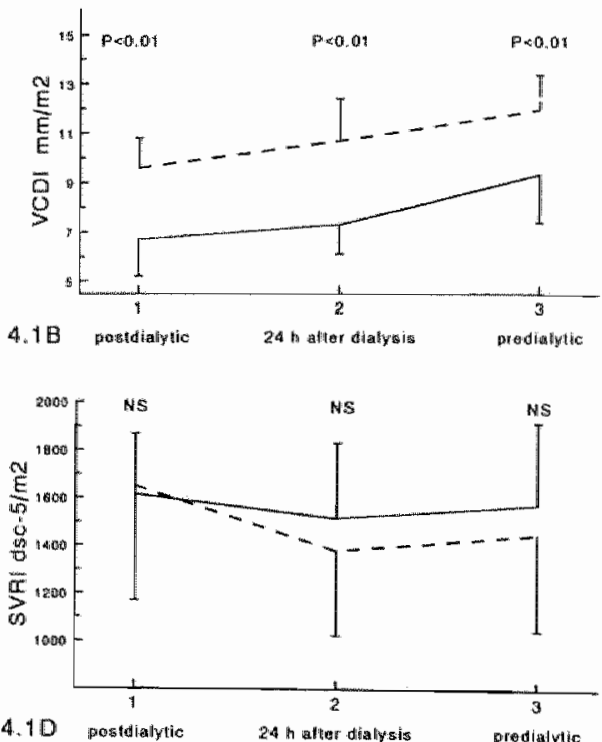

Figure 4.1 Memodynamic measurements during a normovolemic and hyperwolemic interdialytic period.

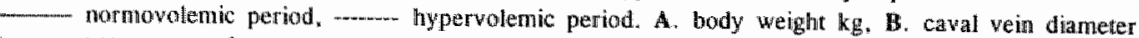

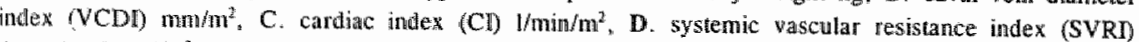
dyenes $/ \mathrm{sec} / \mathrm{cm}-5 / \mathrm{mm}^{2}$ 
Mean dry weight was $70 \pm 10 \mathrm{~kg}$ and mean body surface area was $1.8 \pm 0.2 \mathrm{~m}^{2}$. Residual urine volume was $480 \pm 430 \mathrm{ml} /$ day. Six patients had a residual urine volume greater than $100 \mathrm{ml} /$ day. Mean post-dialytic systolic and diastolic blood pressure were $143 \pm 27 \mathrm{mmHg}$ (range, 104 to $191 \mathrm{mmHg}$ ) and $91 \pm 24 \mathrm{mmHg}$ (range, 58 to $136 \mathrm{mmHg}$ ), respectively.

The patients adhered well to their fluid regime (figure 4.1a). Body weight was $0.3 \pm 0.5 \mathrm{~kg}$ above dry weight after the normovolemic period and $3.1 \pm 0.4 \mathrm{~kg}$ above dry weight after the hypervolemic period. Caval vein diameter index increased significantly after fluid loading (figure 4.1 b) and was $9.4 \pm 2.0 \mathrm{~mm} / \mathrm{m}^{2}$ after the normovolemic period and $12.0 \pm 1.4 \mathrm{~mm} / \mathrm{m}^{2}$ after the hypervolemic period $(p<0.01)$. Hematocrit and colloid osmotic pressure decreased significantly during hypervolemia (figure $4.2 \mathrm{a}, 4.2 \mathrm{~b}$ ), indicating an increase in plasma volume. Sodium concentration and osmolality were not different during the hypervolemic period compared with the normovolemic period (figure $4.2 \mathrm{c}, 4.2 \mathrm{~d}$ ). Changes in hematocrit and colloid osmotic pressure were not significantly correlated with changes in blood pressure. The same was true for changes in sodium concentration and osmolality.
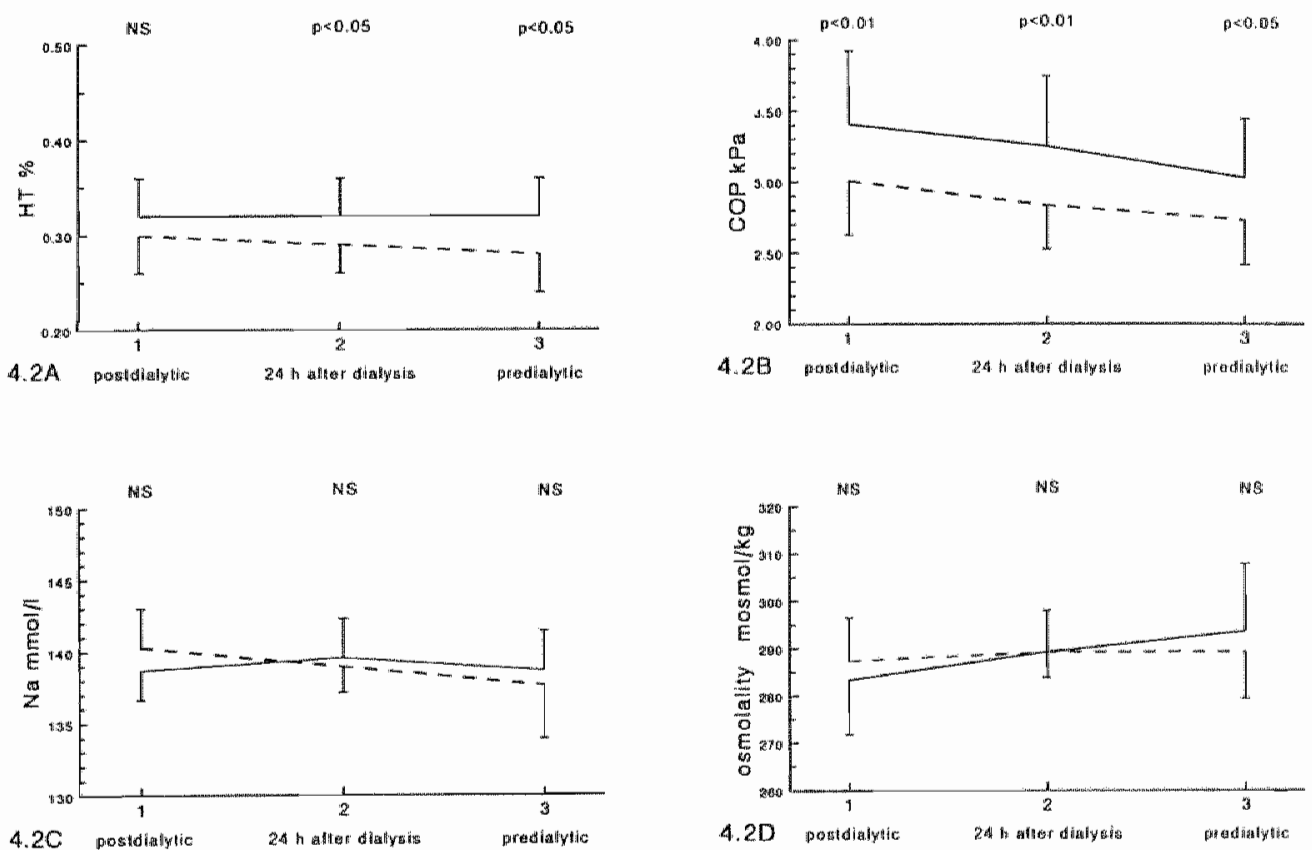

Figure 4.2 Chemical measurements during the nomovolemic and hypervolemic interdialytic period. normovolemic period, hypervolemic period. A: Hematoculit. (Ht) $\%$ B: colloid osmotic pressure (COP) $\mathrm{kPa}, \mathrm{C}$ : sodium concentration $(\mathrm{Na})$ mmol/1, D: osmolatiry mos mol/kg 
Blood pressure level during the hypervolemic inter-dialytic period was not significantly different compared with blood pressure level during the normovolemic period $(153 \pm 24 \mathrm{mmHg} / 90 \pm 19 \mathrm{mmHg}$ and $146 \pm 27 \mathrm{mmHg} / 89 \pm 22 \mathrm{mmHg}$; figure 4.3). However, systolic and diastolic blood pressure were slightly but significantly higher on the second inter-dialytic day compared with the first interdialytic day during the normovolemic period $(149 \pm 26 \mathrm{mmHg} / 91 \pm 22 \mathrm{mmHg}$ and $143 \pm 27 \mathrm{mmHg} / 88 \pm 22 \mathrm{mmHg} ; \mathrm{p}<0.01$ ) as well as during the hypervolemic period $(155 \pm 24 \mathrm{mmHg} / 91 \pm 19 \mathrm{mmHg}$ and $151 \pm 25 \mathrm{mmHg} / 89 \pm 20 \mathrm{mmHg}$; $\mathrm{p}<0.05)$.

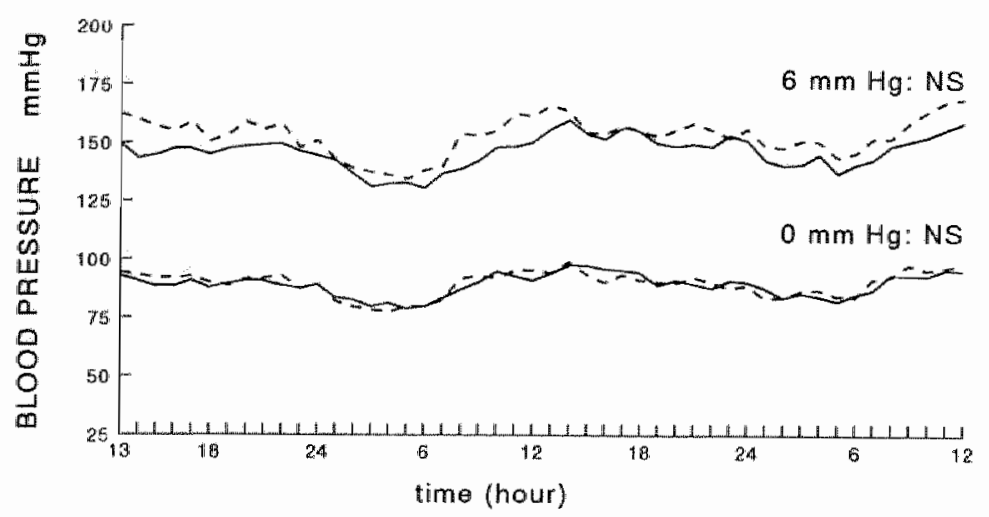

Figure 4.3 Interdiallytic blood pressure course during a normovolemic and a hypervolemic interdialytic period. - nomovolemic period, ........... hypervolemic period.

Table 4.1 Individual mean interdialytic systolic and diastolic blood pressure (nmmig) during the normovolemic inerdislytic period and during the hypervolemic interdialyzic period

\begin{tabular}{lcc}
\hline Phatient & $\begin{array}{c}\text { Interdialytic blood pressure (mmHg) } \\
\text { Normovolemic period }\end{array}$ & $\begin{array}{c}\text { Interdialytic blood pressure (inmig) } \\
\text { Hypervolenic period }\end{array}$ \\
\hline 1 & $142 / 84$ & $138 / 77$ \\
2 & $123 / 55$ & $150 / 63$ \\
3 & $135 / 80$ & $139 / 82$ \\
4 & $120 / 72$ & $130 / 76$ \\
5 & $119 / 72$ & $114 / 71$ \\
6 & $174 / 119$ & $177 / 117$ \\
7 & $130 / 90$ & $151 / 101$ \\
8 & $155 / 97$ & $174 / 102$ \\
9 & $167 / 98$ & $163 / 94$ \\
10 & $198 / 126$ & $194 / 116$ \\
\hline
\end{tabular}


When looking to the individual blood pressure levels (table 4.1 ), three of the 10 patients (one normotensive and two hypertensive patients) displayed a higher (systolic) blood pressure ( $>10 \mathrm{mmHg}$ ) during the hypervolemic period (volume responders) compared to the normovolemic period $(159 \pm 13 \mathrm{mmHg} / 81 \pm 22$ $\mathrm{mmHg}$ and $135 \pm 16 \mathrm{mmHg} / 81 \pm 22 \mathrm{mmHg}$ ).
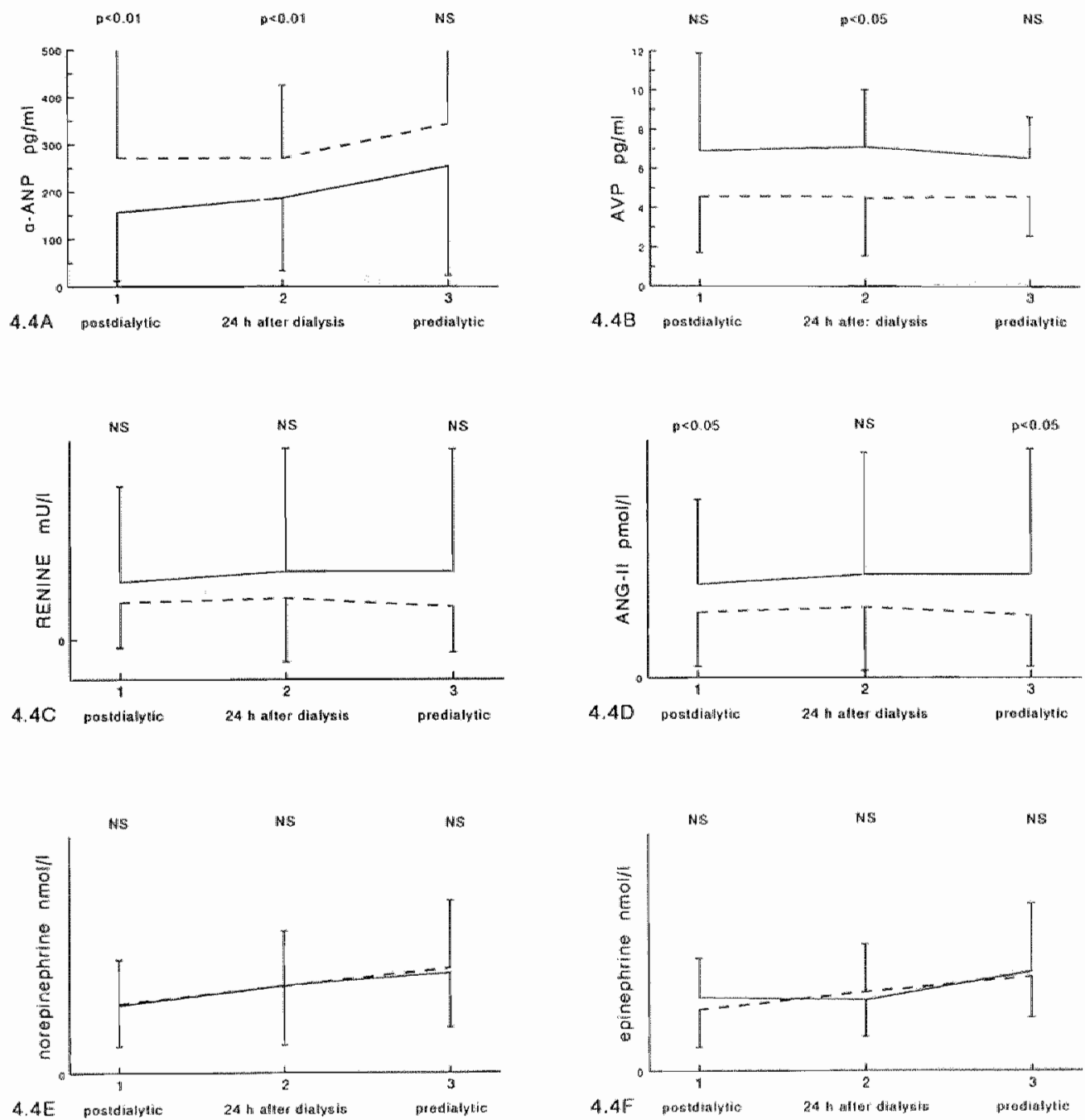

Figure 4.4 Hormonal measurements during a normowolemic and hypervolemic interdialytic period.

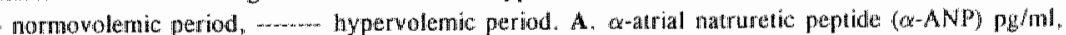
B. arginine wasopressin (AVP) pg/ml, C, renime mU/1, D) angiotensin II (ANG II) pmol/h, $\mathrm{E}$, norepinephrine nmol/l, F. epinephrine nmol/ll 
CI was significantly higher during the hypervolemic period compared with the normovolemic period (figure $4.1 \mathrm{c}$ ) and increased in the normovolemic period from $3.1 \pm 0.6 \mathrm{l} / \mathrm{min} / \mathrm{m}^{2}$ to $3.3 \pm 0.9 \mathrm{l} / \mathrm{min} / \mathrm{m}^{2}$, and in the hypervolemic period from $3.2 \pm 0.8 \mathrm{l} / \mathrm{min} / \mathrm{m}^{2}$ to $3.9 \pm 1.0 \mathrm{l} / \mathrm{min} / \mathrm{m}^{2}$. This was due to an increase in stroke index. Changes in $\mathrm{Cl}$ did not correlate with changes in blood pressure. Heart rate did not change during fluid loading. SVRI had a tendency to decrease during hypervolemia, but the differences did not reach a significant level (figure 4.1d).

Venous compliance could be measured in all 10 patients. The average venous compliance was $0.048 \pm 0.013 \mathrm{ml} / 100 \mathrm{ml} / \mathrm{mmHg}$. Venous compliance did not correlate with changes in blood pressure.

Arterial compliance and distensibility of the carotid artery could be measured in all 10 patients. The mean carotid arterial compliance was $0.61 \pm 0.25 \mathrm{~mm}^{2} / \mathrm{kPa}$ and carotid arterial distensibility coefficient was $11.4 \pm 5.410^{-3} / \mathrm{kPa}$. No significant correlation could be found between carotid arterial compliance or carotid distensibility and blood pressure changes.

The hormonal levels showed a high interindividual variability with a much lower intraindividual variability. $\alpha$-ANP was significantly higher during the hypervolemic period compared with the normovolemic period (figure 4.4a). $\alpha$-ANP increased during the inter-dialytic period, which only reached a significant level in the normovolemic period $(\mathrm{p}<0.01)$. AVP tended to be higher during the normovolemic period compared with the hypervolemic period, but only reached significance 24 hours after the dialysis (figure $4.4 \mathrm{~b}$ ). Renin was tending to be lower after fluid load, but these differences did not reach significance (figure 4.4c). However, angiotensin II concentrations were significantly lower pre-dialysis and post-dialysis during the hypervolemic period compared with the hypervolemic period (figure 4.4d). Norepinephrine and epinephrine concentrations were comparable in the hypervolemic and normovolemic periods (figure $4.4 \mathrm{e}$ and figure 4.4f). The catecholamines increased during the inter-dialytic period. Pre-dialytic norepinephrine was significantly higher compared with the post-dialytic values, in the normovolemic period $(\mathrm{p}<0.05)$ as well as in the hypervolemic period $(p<0.01)$. Pre-dialytic epinephrine was significantly higher than post-dialytic values in the hypervolemic period $(p<0.05)$. The changes in hormonal levels were not correlated with changes in blood pressure.

When comparing volume responders and non-volume responders, no clear different pattern in volume and sodium parameters could be seen. No differences in dry weight $(71 \pm 14 \mathrm{~kg}$ and $70 \pm 9 \mathrm{~kg})$ and rest diuresis $(390 \pm 340 \mathrm{ml}$ and $510 \pm 480 \mathrm{ml})$ was seen. Two of the three volume responders had a rest diuresis of more than 500 $\mathrm{ml}$. Four of the volume non-responders were using antihypertensive drugs up to 3 weeks before the study. In three of these four patients, the normovolemic study period preceded the hypervolemic study period, making a hangover effect of these 
drugs on the results unlikely. In addition, no clear difference could be detected in the hemodynamic response to fluid load or in the compliance measurements.

We only found a tendency to a smaller decrease of renin and angiotensin II after volume loading in the volume responders compared with the volume nonresponders. In volume responders, renin and angiotensin II, respectively, were $5 \pm 10 \mathrm{mU} / 1$ and $4 \pm 6 \mathrm{pmol} / 1$ lower in the hypervolemic period compared with the normovolemic period. In volume non-responders, renin and angiotensin II were, respectively, $17 \pm 38 \mathrm{mU} / 1$ and $8 \pm 15 \mathrm{pmol} / 1$ lower in the hypervolemic period compared with the normovolemic period.

\section{Discussion}

This study shows that in hemodialysis patients who are not receiving antihypertensive medication, an inter-dialytic weight gain of 2 to $3 \mathrm{~kg}$ had no significant effect on inter-dialytic blood pressure. In three of 10 patients, systolic blood pressure increased substantially after volume loading.

The fluid load in the hypervolemic period not only resulted in an increase of extravascular volume but also in an increase of intravascular volume, reflected by a decrease in hematocrit and colloid osmotic pressure and an increase in $\alpha$-ANP. Serum sodium concentration and osmolarity were not different in the hypervolemic period compared with the normovolemic period. Therefore, the increase in body weight in the hypervolemic period was due not only to an increase in body water but also to a proportional increase in exchangeable sodium. The increase in circulatory volume resulted in an increase in caval vein diameter and $\mathrm{CI}$. SVRI tended to decrease, resulting in an unchanged blood pressure.

Hemodynamic studies on the short-term effect of fluid load in hemodialysis patients are scarce. In several studies using ambulatory blood pressure monitors, interdialytic blood pressure changes were not correlated to inter-dialytic weight changes $^{21-23}$. In another study, pre-dialysis blood pressure and inter-dialytic weight gain were measured in 19 hemodialysis patients during 17 to 25 treatments. A significant MAP/excess weight slope could be found in five of the 19 patients, averaging $5.35 \mathrm{mmHg} / \mathrm{kg}^{34}$. However, 10 patients were using antihypertensive drugs, and dry weight was determined on clinical grounds. Another prospective study, analyzing the effects of inter-dialytic saline infusion in seven hemodialysis patients, showed a significant increase in blood pressure after saline infusion; however, this was not different from the usual inter-dialytic blood pressure increase $^{35}$. Furthermore, the pre-dialysis blood pressure was comparable to the predialysis blood pressure in the previous inter-dialytic period, suggesting no major influence of the extra saline infusion on the inter-dialytic blood pressure course.

In three of the 10 patients, we saw an increase in systolic pressure. This was not 
found to be an effect of less rest diuresis. In addition, inter-dialytic weight gain in these patients followed the desired pattern. Dry weight was not lower in the volume responders, so $3 \mathrm{~kg}$ inter-dialytic weight gain had comparable increase in body fluid state.

Pulse pressure increased in the volume responders after fluid load. Although a decreased arterial compliance in these patients could be one explanation ${ }^{19}$, this could not be found in our study. Whether the carotid artery compliance is the correct representative for changes in muscular artery compliance, such as the femoral artery, is unknown. Further studies are necessary to analyze the relationship between volume-induced blood pressure changes and arterial compliance in hemodialysis patients.

Furthermore, venous compliance is found to be decreased in hemodialysis patients ${ }^{28}$ and could have some influence on blood pressure control by changes in venous return. In our study, a relationship between venous compliance with blood pressure changes after inter-dialytic fluid load was not apparent. Venous compliance seems to be more important for the hemodynamic response after acute changes in fluid state as during a dialysis treatment ${ }^{20}$.

In hemodialysis patients, the reciprocal relationship between volume and exchangeable sodium is disturbed ${ }^{18}$. Circulating levels of renin and angiotensin are inappropriately increased in relationship to sodium and volume state ${ }^{4}$. However, the response to saline infusion seems to be normal in lowering plasma renin activity ${ }^{35}$, whereas volume depletion during dialysis increases plasma renin activity ${ }^{36}$. In addition, in the present study, we found a decrease in renin and angiotensin II after fluid load. This inhibition of the renin angiotensin system after fluid load can be a factor in decreasing systemic vascular resistance through a direct vascular effect or through an indirect effect by decreasing sympathetic (neural) activity ${ }^{37}$. It is interesting that we found a tendency to a smaller decrease in renin and angiotensin 11 after fluid loading in the three volume responders; there probably is a parallel with the phenomenon of salt-sensitive hypertension in nonuremic patients ${ }^{38}$. It is hypothesized that in salt-sensitive subjects, the apparently compensatory decrease in systemic vascular resistance after a salt load is prevented by an inability to adequately inhibit angiotensin II and sympathetic activity ${ }^{37}$. A similar inadequate inhibition of the renin-angiotensin system could contribute to the blood pressure increase in the volume-responding hemodialysis patients.

Plasma catecholamines were not influenced by fluid load. The inter-dialytic course of norepinephrine and epinephrine in the hypervolemic period was equal to that in the hypovolemic period. Nevertheless, we found a significant increase in plasma catecholamines during the inter-dialytic period, suggesting an accumulation during the inter-dialytic period and a decrease during dialysis. Indeed Hegbrant et al ${ }^{39}$ found a decrease in norepinephrine during isovolemic hemodialysis, while 
norepinephrine increased during isolated ultra-filtration. The effect of catecholamines on blood pressure control in hemodialysis patients is not clear. Plasma norepinephrine varies markedly, and is not correlated with the increased neural sympathetic activity ${ }^{40}$. The blood pressure response to norepinephrine is decreased in hemodialysis patients ${ }^{44}$.

In our study, we found a decrease in AVP after fluid load. The decrease in AVP must be a direct effect of volume changes because osmolarity and sodium concentration were not lower in the hypervolemic period compared with the normovolemic period ${ }^{42}$. The inhibition of AVP in the hypervolemic period also can contribute to the decreased systemic vascular resistance.

$\alpha$-ANP was found to increase after fluid load. The increase in $\alpha$-ANP after fluid load must merely be seen as an index of fluid state ${ }^{33}$. In a recent study, $\alpha$-ANP had no influence on hemodynamics in hemodialysis patients ${ }^{43}$.

From this study we conclude that a $3 \mathrm{~kg}$ inter-dialytic weight gain does not result in a higher blood pressure in most dialysis patients. The inter-dialytic fluid load causes an increase in cardiac output with a proportional decrease in systemic vascular resistance. This decrease in systemic vascular resistance is probably due to an inhibition of the renin-angiotensin system and AVP levels. Some patients, however react with a systolic blood pressure increase after fluid load. Which factors are responsible for this different reaction on short-term inter-dialytic fluid load, must be subjected to further research. In addition the hemodynamic effects of more long-term fluid changes need to be elucidated. 


\section{References}

1. Degoulet P, Legrain M, Reach I, Aime F, Devries C, Rojas P, Jacobs C. Mortality risk factors in patients treated by chronic haemodialysis. Nephron 1982;31:103-110.

2. de Leeuw PW. Pathophysiology of hypertension in patients on renal replacement therapy. Blood Purif 1994;12:245m251.

3. Vertes $\mathrm{V}$, Cangiano $\mathrm{JL}$, Berman LB: Hypertension in end stage renal disease. $\mathrm{N}$ Engl J Med 1969;280:978-981.

4. Weidman P, Baretta-Piccoli C, Steffen F, Blumberg A, Reubi FC. Hypertension in terminal renal failure. Kidney Int 1976;9:294-301.

5. Schohn D, Weidmann P, Jahn H, Baretta-Piccoli C. Norepinephrine-related mechanism in hypertension accompanying renal failure. Kidney Int $1985 ; 28: 814-822$.

6. Argent NB, Burrell LM, Goodship THJ, Wilkinson R, Baylis PH. Osmoregulation of thirst and vasopressin release in severe chronic renal failure. Kidney Int $1991 ; 39: 295-300$.

7. Brunet P, Lorec AM, Leonetti F, Roubicek C, Jaber K, Roux F, Berland. Plasma endothelin in haemodialysis patients treated with recombinant human erythropoitin. Nephrol Dial Transpl 1994;9:650-654.

8. Vallance P, Leone A, Calver A, Collier J, Moncada S. Accumulation of an endogenous inhibitor of nitric oxide synthesis in chronic renal failure. Lancet $1992 ; 339 \div 572-575$.

9. Converse RL, Jacobsen TN, Toto RD, Jost CMT, Cosentino F, Fouad-Tarazi F, Victor RG. Sympathetic overactivity in patients with chronic renal failure. $N$ Engl $J$ Med 1992;327:1912-1918.

10. Agarawal A, Anand IS, Sakhuja V, Chugh KS. Effect of dialysis and renal transplantation on autonomic dysfunction in chronic renal failure. Kidney Int $1991 ; 40: 489-495$.

11. Esbach JW, Egrie JC, Downing MR, Browne JK, Adamson JW. Correction of anemia of end-stage renal disease with recombinant human erythropoietin. $\mathrm{N}$ Eng $\mathrm{J}$ Med $1987 ; 316: 73-78$.

12. Scribner BH. Editorial: Adequate control of blood pressure in patients on chronic hemodialysis. Kidney Int 1992;41:1286.

13. Wilkinson $R_{*}$ Scott DF, Uldall PR, Kerr DNS, Swinney J. Plasma renin and. exchangeable sodium in the hypertension of chronic renal failure, $Q J$ Med 1969;39:377-394.

14. Planque BA de, Mulder $E_{,}$Dorhout Mees EJ. The behaviour of blood and extracellular volume in hypertensive patients with renal insufficiency. Acta Med Scand 1969;186:75-81.

15. Dathan IRE, Johnson DB, Goodwin FJ. The relation between body fluid compartment volumes, renin activity and blood pressure in chronic renal failure. Clin Science Mol Med 1973;45:77-88.

16. Schultze G, Piefke $S$, Molzahn $M$. Blood pressure in terminal renall failure. Nephron 1980;25:15-24. 
17. Boer P, Koomans HA, Dorhout Mees EJ. Renin and blood volume in chronic renal failure: a comparison with essential hypertension. Nepron 1987;45:7-15.

18. Schalekamp MA, Beevers DG, Briggs JD, Brown JJ, Davies DL, Fraser R, Lebel M, Lever AF, Medina A, Morton JJ, Robertson JLS, Tree M. Hypertension in chronic renal failure: An abnormal relation between sodium and the renin-angiotensin system. Am J Med 1973;55:379-390.

19. London G, Guerin A, Pannier B, Marchais S, Benetos A, Safar M. Increased systolic pressure in chronic uremia: Role of arterial wave reflections. Hypertension 1992;20:10-19.

20. Kooman JP, Van Hooff JP, Leunissen KML. Role of the venous system in hemodynamics during hemodialysis. Blood Purif 1993;11:32-33.

21. Kooman JP, Gladziwa U, Bocker G, Wijnen JAG, van Bortel L, Luik AJ, de Leeuw PW, van Hooff JP, Leunissen KML. Blood pressure during the inter-dialytic period in haemodialysis patients: Estimation of representative blood pressure values. Nephrol Dial Transpl 1992;7:917-923.

22. Luik AJ, Gladziwa U, Kooman JP, van Hooff JP, de Leeuw PW, van Bortel LMAB, Leunissen KML. Influence of inter-dialytic weight gain on blood pressure in hemodialysis patients. Blood Purif 1994;12:259-266.

23. Chazot C, Charra B, Laurent G, Didier C, Vo Van C, Terrat JC, Calemard E, Vanel $T$, Ruffet $M$. Interdialysis blood pressure control by long haemodialysis sesions. Nephrol Dial Transpl 1995;10:831-837.

24. Cheriex EC, Leunissen KML, Janssen JHA, Mooy JMV, van Hooff JP. Echography of the vena cava inferior is a simple and reliable tool for estimation of dry weight in hemo-dialysis patients. Nephrol Dial Transpl 1989;4:563-568.

25. Leunissen KML, Kouw P, Kooman JP, Cheriex EC, de Vries PMJM, Donker AJM, van Hooff JP. New techniques to determine fluid status in hemodialyzed patients. Kidney Int 1993;43 suppl 41:S50-S56.

26. O'Brien E, Mee F, Atkins N, O'Malley K. Accuracy of the Spacelabs 90207 determined by the British Hypertension Society Protocol. J Hypert 1991;9:573-574.

27. Jageneau AFM. Noninvasive diagnosis in the management of cardiovascular diseases. Amsterdam, New York, London. North Holland Biomedical Press 1981.

28. Kooman JP, Wijnen JAG, Draaijer P, Van Bortel LMAB, Gladziwa U, Peltenburg HG, Struyker Boudier HAJ, Van Hooff JP, Leunissen KML. Compliance and reactivity of the peripheral venous system in chronic intermittent hemodialysis. Kidney Int 1992;41:1041-1048.

29. Hoek APG, Brand PJ, Smeets GAM, Reneman R. Assessment of the distensibility of superficial srteries. Ultrasound Med Biol 1980;16:121-128.

30. Kool MJF, van Merode T, Reneman RS, Hoeks APG, Struijker Boudier HAJ, van Bortel LMAB. Evaluation of reproducibility of a vessel wall movement detector system for assesment of large artery properties. Cardiovasc Research 1994;28:610-614. 
31. Bouchard A, Blumleir S, Schiller NB, Schlitt S, Byrd BF III, Ports T, Chatterjee K. Measurements of left ventricular stroke volume using continuous wave Doppler echocardiografie of the ascending aorta and $M$-mode echocardiografie of the aortic valve. J Am Coll Cardiol 1987;9:75-83.

32. Schuster AH, Nanda NC. Doppler echocardiogargraphic measurement of cardiac output: Comparison with a non-golden standard. Am J Cardiol 1984;53:257-259.

33. Leunissen KML, Menheere PPCA, Cheriex EC, van den Berg BW, Noordzij TC, van Hooff JP. Plasma alpha-human atrial natriuretic peptide and dry weight in chronic hemodialysis. Nephrol Dial Transpl 1989;4:382-386.

34. Sherman RA, Daniel A, Cody RP. The effect of inter-dialytic weight gain on predialysis blood pressure. Artif Organs 1993;17:770-774.

35. Leenen FHH, Galla SI, Geyskes GG, Murdaugh HV, Shapiro AP. Effects of hemodialysis and saline loading on body fluid compartments, plasma renin activity, and blood pressure in patients on chronic hemodialysis. Nephron 1977;18:93-100.

36. Brown JJ, Curtis JR, Lever AF, Robertson JIS, de Wardener HE, Wing AJ. Plasma renin concentration and the control of blood pressure in patients on maintenance haemodialysis. Nephron 1969;6:329-349.

37. Brooks VL, Osborn JW. Hormonal-sympathetic interactions in long-term regulation of arterial hypertension: an hypothesis. Am J Physiol 1995;268:R1343-R1358.

38. Dimsdale JE, Ziegler M, Mills P, Berry C. Prediction of salt sensitivity. Am J Hypert 1990;3:429-435.

39. Hegbrant J, Thysell H, Mårtensson L, Ekman R, Boberg U. Changes in plasma levels of vasoactive peptides during sequential bicarbonate hemodialysis. Nephron 1993;63:309-313.

40. Converse RL, Jacobsen TN, Toto RD, Jost CJ, Cosentino F, Fouad-Tarazi DOF, Victor RG. Sympathetic overactivity in patients with chronic renal failure. New Eng J Med 1992;327:1912-1918.

41. Schohn $D_{\text {" Weidmann }} \boldsymbol{P}$, Jahn $\mathbf{H}$, Baretta-Piccoll $C$. Norepinephrine-retated mechanism in hypertension accompanying renal failure. Kidney Int 1985;28:814-822.

42. Schrier RW, Berl T, Anderson RJ. Osmotic and nonosmotic control af vasopressin release. Am J Physiol 1979;236:F321-F332.

43. Mallamaci $F$, Postorino $M$, Zoccali $C$. Influence of ANP on the cardiovascular reponse to volume expansion in haemodialysis patients. Nephrol Dial Transpl 1994;9:1279-1282. 


\section{Chapter 5}

\section{Blood pressure control and hemodynamic changes in patients on long-treatment- time dialysis}

AJ Luik, B Charra, K Katzarski, J Habets,

EC Cheriex, PCA Menheere, G Laurent, J Bergström, KML Leunissen

Blood Purif (in press) 


\section{Abstract}

In dialysis patients blood pressure can be well controlled with long-treatment-time dialysis ( 3 times a week 8 hours) this in contrast to a more common short-treatment-time dialysis regime ( 3 times a week 4 hours). We studied if the good blood pressure control in patients on long-treatment-time dialysis as compared to patients on short-treatment-time dialysis, was associated with a decrease of extra-cellular fluid volume. 2-Day interdialytic ambulatory blood pressure monitoring was performed in 26 non-diabetic patients on long-treatment-time dialysis, in 22 patients on short-treatment-time dialysis matched for the years they had been on dialysis treatment, and during 24 hours in 19 healthy volunteers. After full equilibration, 24 hours after dialysis, echography of the inferior cavall vein was performed to determine fluid state. Cardiac dimensions and stroke index were measured by echocardiography. A blood sample was drawn for the determination of electrolytes and vasoactive hormones. $73 \%$ of the patients on short dialysis were using antihypertensive medication in contrast to none of the patients on long dialysis. However, blood pressure was significantly lower in patients on long dialysis (115 $\pm 21 / 67 \pm 11$ $\mathrm{mmHg})$ as compared to patients on short-treatment-time dialysis $(143 \pm 26 / 81 \pm 16$ $\mathrm{mmHg}$ ). Cavall vein diameter index, left ventricular diameter index, and ANP were not significantly different in patients on long dialysis as compared to patients on short dialysis. Also cardiac index was comparable in patients on long and short dialysis. However, systemic vascular resistance index was significantly lower in patients on long dialysis as compared to patients on short dialysis and normal controls. Left ventricular mass index was increased in both patients on long and short dialysis as compared to controls.

We conclude that patients on long-treatment-time dialysis have an adequate blood pressure control which seems mainly to be caused by a low systemic vascular resistance. This data suggests that also other factors than a lower fluid state contributes to the good blood pressure control in patients on long-treatment-time dialysis. 


\section{Introduction}

In Western Europe, the percentage of hemodialysis patients with primary or secondary vascular disease has risen profoundly $y^{1,2}$. Today cardiovascular complications are the main cause of mortality and morbidity in dialysis patients. Cardiac symptoms in hemodialysis patients usually are the result of systolic dysfunction, left ventricular hypertrophy ( $\mathrm{LVH}$ ) with diastolic dysfunction, or ischemic heart disease ${ }^{3}$. Although disturbance of calcium, glucose and lipid metabolism, anemia, and uremic toxins all contribute to the cardiovascular complications, hypertension is the most important risk factor ${ }^{4,5}$.

The pathophysiology of hypertension is complex and not fully understood ${ }^{6}$. An activated renin-angiotensin system and an elevated hormonal and neural sympathetic activity have an important effect on blood pressure control ${ }^{7-9}$. Also autonomic dysfunction and the frequent use of erythropoietin can play a role ${ }^{10-11}$. However, fluid overload has always been considered the most important pathogenetic factor in hypertension in hemodialysis patients ${ }^{12}$. This is illustrated by the determination of dry weight in most dialysis units according to the definition as can be found in textbooks: that weight below which a normo-albuminemic patient on dialysis will become hypotensive with fiuid removal, and above which the patient will either be hypertensive or show subtle signs of fluid expansion ${ }^{13}$. However, a low blood pressure at the end of dialysis can also be a sign of transient intra-vascular hypovolemia due to too rapid ultra-filtration in relationship to the circulatory refilling capacity or can be related to an inhibition of counter regulatory vasoconstricting mechanisms ${ }^{14}$. More accurate tools for determination of ideal dry weight are being developed ${ }^{15}$. Especially ultrasonography of the vena cava inferior has proven to be a reliable and clinically useful method for accurate determination of dry weight in hemodialysis patients ${ }^{16}$. But also this method faces the problem of uncompleted refilling when the echographic measurement is performed too quick after dialysis when the fluid compartments are not fully equilibrated.

Although in most dialysis centers the occurrence of hypertension is high, Charra et al. reports a good blood pressure control with less than $5 \%$ of their patients having hypertension $^{17}$. They treat their patients with a long dialysis treatment 3 times a week 8 hours, mostly with cuprophane membranes and acetate as a buffer. Dry weight is determined by lowering body weight until a normotensive level is reached. The long dialysis makes it possible to ultra-filtrate fluid excess more gradual with a better plasma volume preservation which reduces the chance of intradialytic hypotension. During the long dialysis sessions, patients are also more efficiently dialyzed in terms of removing small and middle molecular toxins.

The present study was performed in order to investigate if the good bllood pressure control in patients on long-treatment-time dialysis was associated with a decreased 
fluid state as compared to patients on a more usual short-treatment-time dialysis regime, matched for dialysis history. Also the hemodynamic profile of these patients was studied, in order to get insight in the possible pathophysiological mechanisms responsible for the good blood pressure control. Furthermore we analyzed if the good blood pressure control in patients on long-treatment-time dialysis results in a better cardiac situation in respect to systolic function, LVH and diastolic function.

\section{Methods}

We studied 26 patients on long-treatment-time dialysis 3 times a week 8 hours, and 22 patients on short-treatment-time dialysis 3 times a week $3-4$ hours. The long dialysis patients were studied at the Centre de Rein Artificiel at Tassin, France. The short dialysis patients were studied at the university hospital Maastricht, the Netherlands. The patients were matched for the years they had been treated with dialysis and for origin of renal disease, in order to get comparable groups in respect to exposure to uremia. As a control 19 healthy Dutch volunteers were studied in a comparable age group without a history of hypertension or cardiovascular disease.

The dialysate in Tassin contained sodium $138 \mathrm{mmol} / 1$, potassium $1.5 \mathrm{mmol} / \mathrm{l}$, calcium $1.75 \mathrm{mmol} / \mathrm{l}$, magnesium $0.75 \mathrm{mmol} / \mathrm{l}$, glucose $0 \mathrm{gr} / 1$. The dialysate in Maastricht contained sodium $140 \mathrm{mmol} / \mathrm{l}$, potassium $2.0 \mathrm{mmol} / \mathrm{l}$, calcüum 1.7 $\mathrm{mmol} / \mathrm{l}$, magnesium $0.5 \mathrm{mmol} / \mathrm{l}$, glucose $2 \mathrm{gr} / 1$. Blood flow was $250 \mathrm{ml} / \mathrm{min}$ in Tassin and $300 \mathrm{ml} / \mathrm{min}$ in Mastricht. Dialysate flow was $500 \mathrm{ml} / \mathrm{min}$ in Tassin as well as in Mastricht. Ideal dry weight in Tassin was determined on clinical criteria; no edema or pulmonary congestion and especially a normotensive pre- and post-dialytic blood pressure without antihypertensive medication. Ideal dry weight in Maastricht was assessed by echographic measurement of the inferior caval veint ${ }^{66}$.

Blood pressures were measured during a 2 -day inter-dialytic period in the dialysis patients and during 24 hours in the controls, using Spacelabs 90207 ambulatory blood pressure monitors ${ }^{18}$. Blood pressure was measured every 15 minutes during the day (from 07.00 to $23.00 \mathrm{~h}$ ) and every 30 minutes during the night (from 23.00 to $7.00 \mathrm{~h}$ ). Day-night blood pressure difference was determined by calculating the difference between day-time and night-time blood pressure. The day after the dialysis, so after full equilibration of the fluid compartments, the inferior caval vein diameter was standardized ultrasonographically measured (Hewlett Packard sonos 100 echo-doppler cardiograph, 3.5 megahertz transducer). Echocardiography was 
performed with the same device for measuring left atrial diameter (LAD), left ventricular enddiastolic diameter (LVEDD), left ventricular endsystolic diameter (LVESD), interventricular septum enddiastolic wall thickness (IVSEDWT), posterior wall enddiastolic wall thickness (PWEDWT), and aortic valve diameter ${ }^{19}$. Transmural peakflow velocity in early diastole ( $E$ wave) and late diastole (A wave) was measured with pulse wave Doppler. Ascending aortic blood flow velocity was measured with continuous wave doppler with a 10 megahertz transducer. The cardiac dimensions were standardized by dividing the indices by body surface area (LADI, LVEDDI, IVSEDWTI, PWEDWTI). Indexed Left Ventricular Mass Index (LVMI) was calculated with the formula of Devereux and Reichek ${ }^{20}$. Left Ventricular Ejection Fraction (LFEF), E/A ratio, stroke index (SI), and cardiac index $(\mathrm{CI})$ were calculated with standard formulas ${ }^{21}$. Systemic vascular resistance index (SVRI) was calculated from the $\mathrm{CI}$ and mean arterial pressure (MAP) according to the formula: SVRI $=\left\{\left(\mathrm{MAP}(\mathrm{mmHg}) / \mathrm{Cl}\left(\mathrm{ml} / \mathrm{sec} / \mathrm{m}^{2}\right)\right\} \times 1,332\right.$. The same measurements were also executed in the healthy controls.

A blood sample was drawn from an intravenous catheter (internal diameter 1 mm;Venflon) inserted into an antecubital vein, into ice-clilled tubes, with the patient still in supine position. Blood was analyzed for hematocrit, sodium ( $\mathrm{Na}$ ), albumin, creatinine, BUN, colloid osmotic pressure (COP), osmolality, ANP, epinephrine, norepineprine, arginine vasopressin (AVP), renin, and angiotensin II. ANP, aldosterone, angiotensin II, AVP and PTH were measured with a radioimmunoassay. Renin was measured with an immunoradiometric assay. Epinephrine and norepineprine were measured with a fluorescence HPLC. All samples were analyzed in the same laboratory of the University Hospital of Maastricht.

Significance of differences between the groups was calculated by the KruskalWallis 1-way ANOVA and Mann Whitney $U$ test. Pearsons two-tails linear correlation was used for calculating correlation coefficients. Differences were considered significant when $\mathrm{p}$ values were $<0.05$.

\section{Results}

Patients characteristics are shown in table 5.1. Patients on long dialysis were significantly older as compared to patients on short dialysis $(p<0.01)$ and to controls $(\mathrm{p}<0.01)$. Sex distribution, dry weight and BSA were not different. Interdialytic weight gain tended to be lower in patients on long dialysis but did not reach a significant level. On long dialysis none of the patients were using antihypertensive medication. However in patients on short clialysis a majority of them were using one or more antihypertensive, vasodilating agents; mostly calcium 
antagonists and ACE inhibitors. Four of the patients on short dialysis were using 1 antihypertensive drug, 5 patients were using 2 drugs, and 7 patients were using 3 or more drugs to control their blood pressure. Dialysis dose, reflected by the $\mathrm{Kt} / \mathrm{V}$ was significantly higher in patients on long dialysis $(p<0.001)$. All patients on short dialysis were dialyzed with bicarbonate as a buffer in contrast to patients on short dialysis who for $88 \%$ were dialyzed with acetate.

Table 5.1

Patients chanacteristics (mean \pm SD) for sex (male, female), age (years), dry weight, body surface area, years on dialysis, interdialytic weight gain, number of pacients using anthypertemsive medication, number of patients using erythropoietin "dialysate buffer (acetate, byctarbonate)

\begin{tabular}{|c|c|c|c|}
\hline & $\begin{array}{c}\text { Long dialysis } \\
\mathrm{n}=\mathbf{2 6}\end{array}$ & $\begin{array}{c}\text { Short dialysis } \\
\mathrm{n}=22\end{array}$ & $\begin{array}{c}\text { Control } \\
\mathrm{n}=19\end{array}$ \\
\hline Sex: male & $20(77 \%)$ & $6(730)$ & $12(63 \%)$ \\
\hline fentle & $6(23 \%)$ & $6(27 \%)$ & $7(37 \%)$ \\
\hline Age lyears & $67 \pm 9^{* *}$ & $69 \pm 14$ & $59 \pm 10$ \\
\hline Dry weight (kis) & $71 \pm 15$ & $69 \pm 14$ & $72 \pm 10$ \\
\hline $\operatorname{BSA}\left(\mathrm{m}^{2}\right)$ & $1.8 \pm 0.2$ & $1.8 \pm 0.2$ & $1.8 \pm 0.1$ \\
\hline Years on dialysis & $4.2 \pm 4.6$ & $4.3 \pm 4.4$ & \\
\hline Weight gain $(\mathrm{kg})$ & $1.1 \pm 1.0^{\circ}$ & $1.7 \pm 0.9$ & \\
\hline Antihypertensive medicanion & $0(0 \%)^{*}$ & $16(73 \%)$ & \\
\hline EPO & $4(15 \%)^{\circ}$ & $20(91 \%)$ & \\
\hline $\mathrm{kH} / \mathrm{N}$ & $1.8 \pm 0.4^{*}$ & $1.1 \pm 0.2$ & \\
\hline Buffer: Acetate & $23(88 \%)^{*}$ & $0 \%$ & \\
\hline Bicarbonates & $3(12 \%)^{\circ}$ & $22(100 \%)$ & \\
\hline
\end{tabular}

"sugntricant as compared to conurot." significant as compared to short dialysis

Blood pressure was well controlled in patients on long dialysis and significantly lower $(115 \pm 21 / 67 \pm 11 \mathrm{mmHg})$ as compared to patients on short dialysis $(143 \pm 26 / 81 \pm 16 \mathrm{mmHg} ; \mathrm{p}<0.001)$, but also as compared to healthy controls $(126 \pm 10 / 79 \pm 6 \mathrm{mmHg} ; \mathrm{p}<0.05$, figure 5.1$)$. Systolic blood pressure in patients on short dialysis was significantly higher compared to controls $(p<0.05)$.

Systolic and diastolic day-might blood pressure rythm was blunted in patients on long dialysis $(6 \pm 9 / 6 \pm 5 \mathrm{mmHg})$ and short dialysis $(6 \pm 8 / 7 \pm 6 \mathrm{mmHg})$ as compared to normal controls $(17 \pm 7 / 14 \pm 5 \mathrm{mmHg} ; \mathrm{p}<0.001)$. However, no differences were found in day-night blood pressure rhythm comparing patients on long dialysis to patients on short dialysis. $15(58 \%)$ Of the patients on long dialysis had a day-night blood pressure difference of more than $5 \mathrm{mmHg}$, compared to 12 
(55\%) of the patients on short dialysis.

Pulse pressure was significant higher in the patients on short dialysis $(62 \pm 17$ $\mathrm{mmHg}$ ) as compared to patients on long dialysis $(49 \pm 13 \mathrm{mmHg} ; \mathrm{p}<0.01)$ and healthy controls $(47 \pm 7 \mathrm{mmHg}$; $\mathrm{p}<0.001$ ).

Patients on long dialysis and the patients on short dialysis had a tendency to a higher heart rate $(78 \pm 10$ beats $/ \mathrm{min}$ and $76 \pm 11$ beats/min) as compared to controls $(73 \pm 10$ beats/min). However, these differences were not significant.

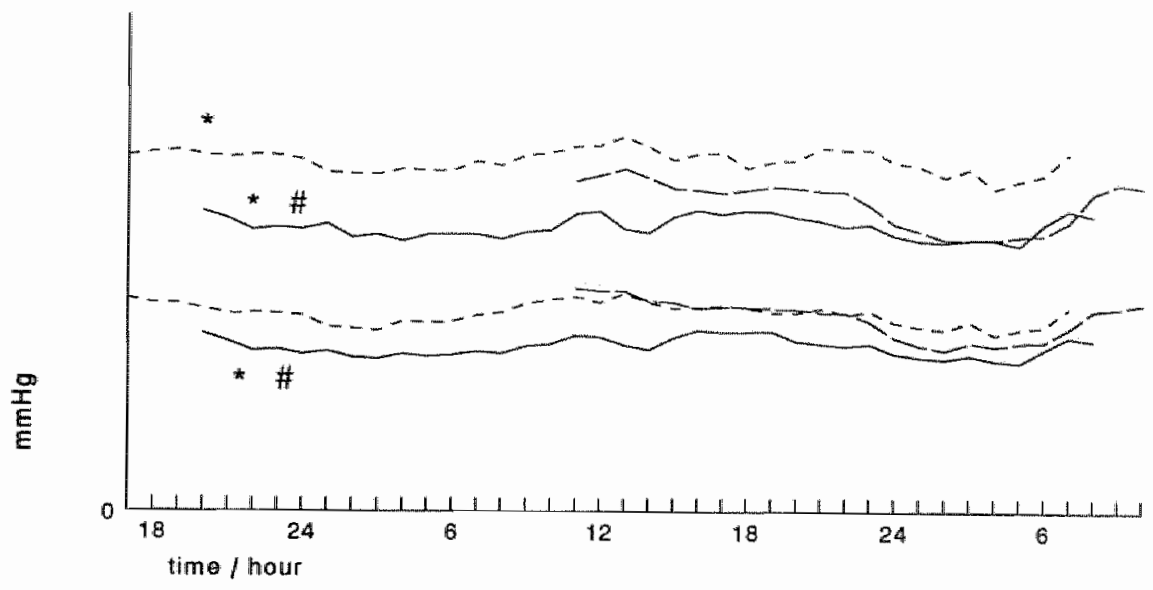

Figure 5.1 Interdialytic blood pressure. __ long-treatment-time hemodialysis patients, short-treatmentwime hemodialysis patients, - - healthy controls. "Significantly different as compared to short-treatmenttime hemodialysis, significantly different as compared to healthy controls

The caval vein diameter index (VCI) 24 hours after dialysis was not significantly different in the patients on long dialysis as compared to the patients on short dialysis (figure 5.2a). VCI in patients on long dialysis tended to be lower, but the differences were small and the overlap large. No significant correlation could be found between VCI and systolic or diastolic blood pressure in long dialysis patients $(r=0.15$ and $r=0.22)$, or in the whole dialysis group $(r=0.23$ and $r=0.24)$.

It was technically possible to measure cardiac output in 25 patients on long dialysis, in 19 patients on short dialysis, and in all healthy controls. There were no significant differences in SI comparing patients on long dialysis $\left(48 \pm 14 \mathrm{ml} / \mathrm{m}^{2}\right)$, short dialysis $\left(50 \pm 12 \mathrm{ml} / \mathrm{m}^{2}\right)$, and controls $\left(41 \pm 7 \mathrm{ml} / \mathrm{m}^{2}\right)$. Also no significant differences in $\mathrm{CI}$ could be found between patients and controls (figure 5.2b). However, there was a tendency for a lower SI and CI in dialysis patients compared to controls. SVRI was significantly lower in patients on long dialysis (figure $5.2 \mathrm{c}$ ) as compared to short dialysis patients $(p<0.05)$ as well as to controls $(p<0.01)$. 


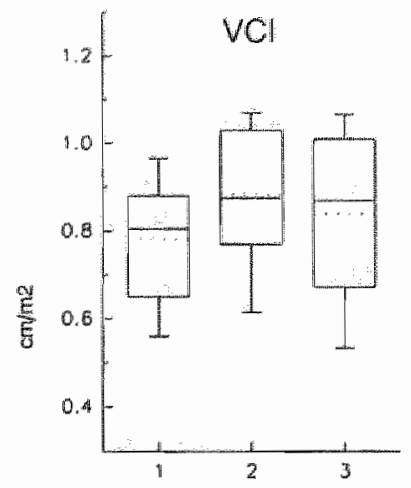

$5.2 \mathrm{~A}$

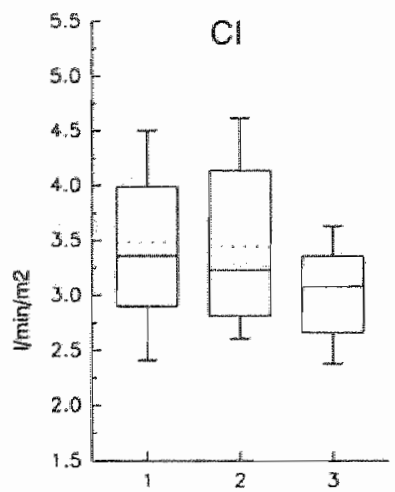

$5.2 \mathrm{~B}$

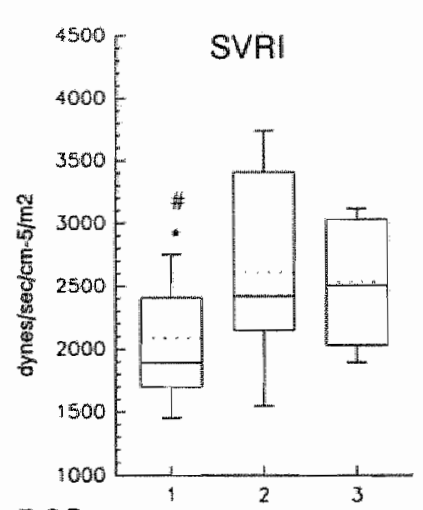

$5.2 \mathrm{C}$

Figure 5.2 Hemodynamic parameters, Box undicate the 25 th 75 th percenthe range, Capped bar indicate the 10th-90th percentile range, _- Median, ........ Mean. 1 long treatment-time hemodialysis patients. 2 short. treatment-time hemodialysis patients. 3 heallthy controls. A. Caval vein diameter index $\left(\mathrm{WCl} \mathrm{cm} / \mathrm{m}^{2}\right)$,

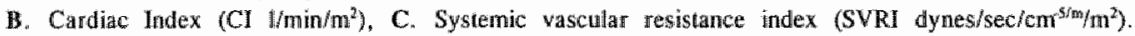
"significantly different as conpared to short-treatment-time hemodialysis, "significantly different as compared to healthy controls

Cardiac dimensions could be measured in all but one patient on long dialysis. LVMI was significantly higher in patients on long dialysis and short dialysis as compared to the healthy controls $(p<0.001$ and $p<0.001$; figure 5.3a). Comparing the patients on long and short dialysis, no significant differences were found in patients on long and short dialysis. The increase of the IVSEDWT was comparable to the increase of the PWEDWT indicating a symmetric LVH (table 5.2). In patients on long dialysis LVMI was significantly and inversely correlated with hemoglobin concentration $(r=-0.44 ; p<0.05)$ but there was no correlation with blood pressure $(r=0.13)$ or day-night blood pressure difference $(r=0.06)$.

LADI was significantly larger in the patients on long dialysis and short dialysis as compared to controls ( $\mathrm{p}<0.001, \mathrm{p}<0.001$; table 5.2 ). In the hemodialysis patients LADI was significantly correlated with VCI $(r=0.43 ; \mathrm{p}<0.01)$ and LVMI $(r=0.054 ; p<0.001)$. E/A ratio tended to be lower in dialysis patients as compared to controls, but these differences did not reach a significant level (figure 5.3b). $\mathrm{E} / \mathrm{A}$ ratio in patients on long dialysis and short dialysis did not differ. LVEF was significantly lower in patients on short dialysis as compared to controls $(p<0.05$; figure 5.3c). Also in patients on long dialysis LVEF tended to be lower as compared to controls, but these differences were not significant. LVEF was comparable in patients on long and short dialysis. 
Table 5.2 Cardiac parameters measured 24 hours after dialysis. LWEDDI= left ventriatar anddastho dianatior index, IVSEDWTI = interwentricular septal endotistolic wall thickness index, PWEDWTI $=$ posterior wall enddastolic wall thicknes undex, $\mathrm{LADI}=$ left athal diandmet index

\begin{tabular}{lccc}
\hline & $\begin{array}{c}\text { Long dialysis } \\
\mathrm{n}=25\end{array}$ & $\begin{array}{c}\text { Short dialysis } \\
\mathrm{n}=22\end{array}$ & $\begin{array}{c}\text { Control } \\
\mathbf{n}=19\end{array}$ \\
\hline LVEDDI $\left(\mathrm{mm} / \mathrm{m}^{2}\right)$ & $29 \pm 4^{*}$ & $30 \pm 5^{*}$ & $26 \pm 2$ \\
IVSEDWTI $\left(\mathrm{mm} / \mathrm{m}^{2}\right)$ & $6.2 \pm 1.3^{8}$ & $6.1 \pm 1.1^{*}$ & 4.92410 .7 \\
PWEDWTI $\left(\mathrm{mm} / \mathrm{m}^{2}\right)$ & $6.0 \pm 1.1^{*}$ & $6.1 \pm 1.1^{*}$ & $5.1 \pm 0.7$ \\
LADI $\left(\mathrm{mm} / \mathrm{m}^{2}\right)$ & $26 \pm 4^{*}$ & $27 \pm 5^{*}$ & $21 \pm 2$ \\
\hline
\end{tabular}

" significant as compared to control; " significant as companed to short dialysis

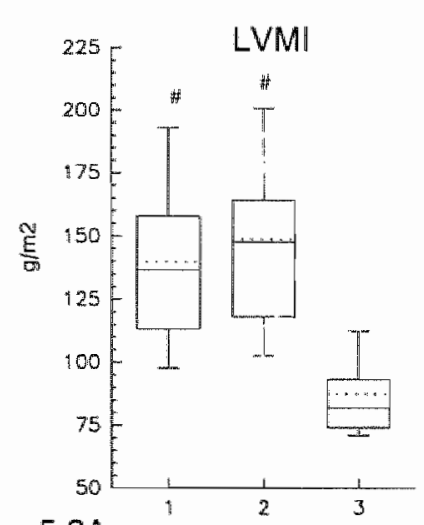

$5.3 \mathrm{~A}$

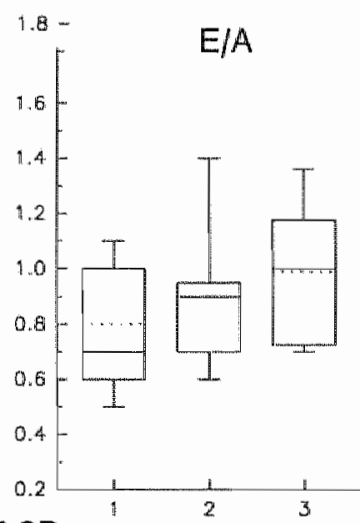

$5.3 \mathrm{~B}$

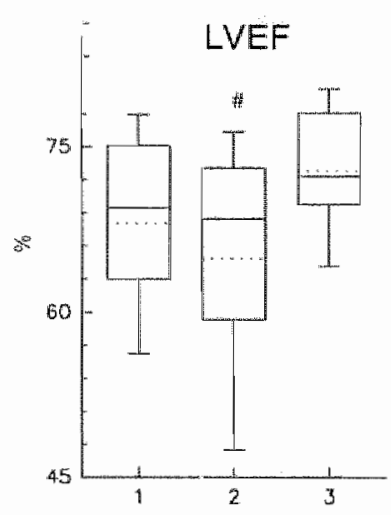

$5.3 \mathrm{C}$

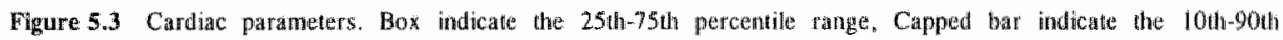
percentile range. — Median, ........ Mean. I long-treatuentime hemodialysis patients. 2 short treatment-time hemodialysis patients, 3 heathy comtrols. A. Lefi Ventriculat Mass Index (LVMI g/min).

1. E/A ratio (E/A), C. Left Ventricular Ejection Fraction (LVEF \%). "siguficantly different as comparted to short-treatnent-time hemod halysiss, significantly different as compared to bealthy gontrols

Hemoglobin levels and biochemical data are given in table 5.3. Hb and Ht were significantly lower both in patients on long $(\mathrm{p}<0.001)$ and short dialysis $(p<0.001)$ as compared to normal controls. Patients on short dialysis had a significant higher $\mathrm{Hb}$ than the patients on long dialysis $(\mathrm{p}<0.05)$.

Sodium $(\mathrm{Na})$ was significantly lower in patients on long dialysis as compared to patients on short dialysis $(p<0.001)$ and normal controls $(p<0.001)$. Sodium was comparable in patients on short dialysis and healthy controls. Potassium (K) was significantly higher in patients on short compared to patients on long dialysis $(p<0.05)$ and healthy controls $(p<0.001)$ 
Osmolarity was comparable in patients on long dialysis and controls. Osmolarity was significantly higher in the patients on short dialysis compared to controls $(p<0.05)$. Osmolarity was also higher in patients on short compared to long dialysis, but these differences did not reach a significant level. When correcting osmolarity to a BUN of 0 , the corrected osmolarity was comparable in patients on long and short dialysis $(271 \pm 9 \mathrm{mosmol} / \mathrm{kg}$ and $271 \pm 8 \mathrm{mosmol} / \mathrm{kg})$. COP was comparable in patients on long and short dialysis, but significantly higher compared to controls $(p<0.01$ and $p<0.05)$. Also albumin was comparable in both dialysis groups but significantly lower as compared to controls $(p<0.001$ and $p<0.001$ ). BUN and creatinine were significantly lower in patients on long compared to short dialysis $(\mathrm{p}<0.001$ and $\mathrm{p}<0.001)$.

Table 5.3 Hemoglobin and biochemical date measured 24 hours after dialysis in patients on long- and shorttreatmentime dialysis as compared to healthy comtrols

\begin{tabular}{|c|c|c|c|}
\hline & $\begin{array}{c}\text { Long dialysis } \\
n=26\end{array}$ & $\begin{array}{c}\text { Short dialysis } \\
\quad \mathbf{n}=22\end{array}$ & $\begin{array}{c}\text { Contrall } \\
n=19\end{array}$ \\
\hline Hb (monol/l) & $6.0 \pm 1.0^{\circ}$ & $6.8 \pm 1.1^{*}$ & $8.2 \pm 0.7$ \\
\hline Hit $(\%)$ & $30 \pm 5^{\prime}$ & $34 \pm 6^{\prime \prime}$ & $40 \pm 3$ \\
\hline Na $(\mathrm{mmol} / \mathrm{l})$ & $1.35 \pm 3^{* *}$ & $138 \pm 3$ & $139 \pm 2$ \\
\hline $\mathrm{K}(\mathrm{mm} \mathrm{mol} / \mathrm{l})$ & $4.7 \pm 0.9^{*}$ & $5.4 \pm 1.0^{4}$ & $4.5 \pm 0.4$ \\
\hline Osmolality (mosm $/ \mathrm{kg}$ ) & $284 \pm 9$ & $290 \pm 10^{\prime \prime}$ & $282 \pm 8$ \\
\hline $\mathrm{COP}(\mathrm{KPA})$ & $3.6 \pm 0.4^{\prime \prime}$ & $3.6 \pm 0.4^{x}$ & $3.4 \pm 0.2$ \\
\hline Creatinine (Unnd/ll) & $556 \pm 132^{\prime *}$ & $886 \pm 228^{7}$ & $74 \pm 16$ \\
\hline BUN (mmull) & $12.8 \pm 4.1^{3 *}$ & $19.5 \pm 3.7^{*}$ & $5.7 \pm 1.4$ \\
\hline Aburnin (g/t) & $38 \pm 4^{\circ}$ & $37 \pm 5^{\prime}$ & $42 \pm 2$ \\
\hline
\end{tabular}

'significhnt as compared to control; 'significant as compared to short dialysis.

Hormonal parameters are depicted in table 5.4. Norepinephrine but not epinephrine was significantly elevated in patients on long and short dialysis as compared to controls $(p<0.001$ and $p<0.001)$. Catecholamines were however not different in patients on long dialysis as compared to patients on short dialysis. Renin was significantly higher in patients on long dialysis compared to controls $(p<0.01)$. Renin was comparable in patients on short dialysis as compared to long dialysis but the difference with controls did not reach a significant level. Angiotensin II was significantly elevated in patients on long dialysis as well as in patients on short dialysis as compared to controls $(p<0.001$ resp. $p<0.01)$. Differences in angiotensin II between patients on long dialysis and short dialysis did not reach significancy. ANP was higher in patients on long dialysis and short dialysis as compared to controls $(p<0.001$ and $p<0.001)$. No differences in ANP was found 
between patients on long and short dialysis. AVP was significantly elevated in patients on long dialysis and short dialysis compared to controls $(p<0.05$ and $p<0.001)$. However, AVP in patients on short dialysis was twice as high as in patients on long dialysis $(\mathrm{p}<0.001)$.

PTH was not significantly different in patients on long-treatment-time dialysis as compared to patients on short dialysis. As well in patients on long dialysis as in patients on short dialysis, LVMI was not significantly correlated with PTH ( $\mathrm{r}=$ $0.375, \mathrm{r}=0.286$ ).

Table 5.4 Hormonal parameters measured 24 thours after dialysis in patients on long- and short-treatiment-time: dialysis as compared to healthy controls

\begin{tabular}{lccc}
\hline & $\begin{array}{c}\text { Long dialysis } \\
\mathbf{m}=\mathbf{2 6}\end{array}$ & $\begin{array}{c}\text { Short dialysis } \\
\mathbf{n}=\mathbf{2 2}\end{array}$ & $\begin{array}{c}\text { Conitrol } \\
\mathbf{n}=19\end{array}$ \\
\hline Norepinephrine (nmol//) & $2.3 \pm 1.1^{*}$ & $2.4 \pm 1.0^{*}$ & $1.3 \pm 1.2$ \\
Epinephrine (nmol/l) & $0.10 \pm 0.08$ & $0.14 \pm 0.12$ & $0.14 \pm 0.11$ \\
Renine (mU/l) & $128 \pm 240^{*}$ & $128 \pm 324^{*}$ & $15 \pm 8$ \\
Angiotensin II (pmol/) & $47 \pm 80^{*}$ & $21 \pm 24^{*}$ & $5 \pm 3$ \\
ANP (pg/ml) & $260 \pm 258^{*}$ & $359 \pm 342^{*}$ & $74 \pm 62$ \\
AVP (pg/ml) & $3.5 \pm 1.2^{* *}$ & $6.2 \pm 4.1^{*}$ & $2.9 \pm 0.6$ \\
PTH (pmol/1) & $7.3 \pm 12.4$ & $10.9 \pm 14.2$ & $3.4 \pm 1.7$ \\
\hline
\end{tabular}

"significant as compared to control; "significant as compared to short dialysis

\section{Discussion}

We studied fluid state and hemodynamic profile of patients on long-treatment-time dialysis in order to get more insight in possible mechanisms responsible for the well controlled blood pressure in these patients. We compared this data with data obtained in patients on short dialysis matched for dialysis years and primary renal disease and with data from healthy controls. Because we could not find enough healthy normotensive volunteers above the age of 70 years, the controls are 8 years younger as compared to patients on long dialysis. Although patients on long dialysis were French and patients on short dialysis and healthy controls were Dutch, they were comparable in respect to weight and BSA.

We found an adequate controlled blood pressure, without antihypertensive medication, in patients on long-treatment-time dialysis. Although $73 \%$ of the patients on short-treatment-time dialysis were using antihypertensive medication, blood pressure was significantly higher as compared to patients on long dialysis. 
Blood pressure in patients on long dialysis was even significantly lower as compared to healthy controls. The differences in age between patients on long dialysis and short dialysis can not explain the difference in blood pressure, for blood pressure is increasing with age $\mathrm{e}^{22}$. Diurnal blood pressure rhythm was equally blunted in patients on long dialysis and short dialysis. A blunted diurnal blood pressure rhythm in dialysis patients has been found in other studies ${ }^{23,24}$ and has been associated with an increased incidence of $\mathbb{L V H}{ }^{25}$.

Pulse pressure was elevated in patients on short dialysis and not in patients on long dialysis as compared to controls. A higher pulse pressure can be the result of from a higher stroke volume and of a stiffened arterial $s s^{2}{ }^{26}$. Arterial compliance is found to be reduced in hemodialysis patients ${ }^{27.28}$. SI was comparable in patients on long dialysis and short dialysis. Therefore, the difference in pulse pressure could be related to a better arterial compliance in patients on long dialysis as compared to patients on short dialysis.

Fluid state in patients on long dialysis, reflected by VCI and ANP, was tended to be lower as compared to patients on short dialysis. However, the differences were small and not statistically significant. Furthermore $\mathrm{Cl}$ was not decreased in patients on long dialysis. On the other hand SVRI was low in patients on long dialysis, although no antihypertensive vasodilating agents were used in these patients, in contrast to patients on short dialysis. Therefore it is likely that a lower fluid state is not the sole explanation of the good blood pressure control in patients on long dialysis. Studies on the relationship between volume status and blood pressure are not conclusive. De Planque found a good correlation between blood pressure and extra-cellular volume in hypertensive patients with advanced renal failure who were not yet treated with dialysis ${ }^{29}$. Dathan failed to find a correlation between extracellular water and blood pressure in patients with chronic renal failure not yet on dialysis $^{30}$. However, they could find a relationship between blood pressure and exchangeable sodium and blood volume. Wilkinson could not find a relationship between blood pressure and exchangeable sodium in hemodialysis patients ${ }^{31}$. Only after nephrectomy in 14 patients, he was able to find a correlation between diastolic blood pressure and exchangeable sodium. Schultze studied normotensive and hypertensive hemodialysis patients ${ }^{32}$. In spite of efforts to reduce dry weight, hypertensive patients were found not to be volume expanded as compared to normotensive patients.

Although no significant differences in fluid state could be found, sodium levels were significantly lower in patients on long-treatment-time dialysis. This difference in sodium level is mainly explained by a lower sodium concentration and the longer dialysis treatment-time in patients on long dialysis. Also a difference in dietary sodium intake cannot be ruled out. Although the differences in sodium level were 
small, we can not exclude this as a factor in better blood pressure control in patients on long dialysis. A direct relationship between an increase in intra-cellular sodium concentration and an increase in arterial tone by an increase in free cytosolic calcium is suggested ${ }^{33}$. However, Henrich increased exchangeable sodium in hemodialysis patients by elevating dialysate sodium concentration over a 6 weeks period $^{34}$. Although inter-dialytic weight gain increased, there was no effect on blood pressure control.

The less frequent use of EPO in patients on long dialysis can contribute to better blood pressure control in these patients. EPO use can increase systemic vascular resistance by an increase in blood viscosity and less peripheral arterial anoxic vasodilatation $^{35,36}$. The differences in hemoglobin concentration and hematocrit between long dialysis and short dialysis patients were however relatively small. This could be explained by a more restricted strategy in routinely taken blood samples, and a better hematopoiesis in the patients on long dialysis.

Another factor involved in a better blood pressure control in patients on longtreatment-time dialysis, could be a better clearance of some vasoactive substance with direct or indirect effect on SVRI, as recently suggested ${ }^{37}$. Longer dialysis treatment-time in the French dialysis patients results in an higher small molecular clearance reflected by the higher $\mathrm{Kt} / \mathrm{V}$. However, another benefit of a longer dialysis treatment-time could be a better clearance of middle molecules.

Which vasoactive substances could be responsible for the better blood pressure control, remains unclear. Norepinephrine, renin, angiotenin II, and AVP are all found to be increased in patients with end stage renal failure ${ }^{38-40}$. Although we found norepinephrine and renin/angiotensin to be elevated in the dialysis patients, no differences could be found when comparing patients on long dialysis and patients on short dialysis. The results have to be considered with some reserve, for the patients on short dialysis were using various antihypertensive medication including ACE-inhibitors. Remarkable were the differences in AVP levels. Vasopressin release is mainly regulated by serum osmolarity, although also hypovolemia can increase vasopressin release ${ }^{41}$. The differences in AVP between short dialysis and long dialysis can not be explained by a lower fluid state in patients on short dialysis, for the parameters of fluid state did not point to a lower fluid state in patients on short diallysis compared to patients on long dialysis as discussed above. The differences in osmolarity between patients on long dialysis and patients on short dialysis, is mainly caused by a difference in BUN. Urea is an ineffective osmol without an effect on AVP secretion. Osmolarity corrected for BUN were not different compared to patients on long dialysis and short dialysis. However sodium concentration was lower in patients on long dialysis and could contribute to a lower AVP concentration in these patients. Another explanation 
could be a higher clearance of AVP in patients on long-treatment-time dialysis. ANP was both elevated in patients on long dialysis and short dialysis, although there was a slight tendency for higher levels in patients on short dialysis. A recent study did not show any effect of ANP on hemodynamics in hemodialysis patients ${ }^{42}$. ANP in dialysis patients is correlated with left and right atrial wall stress and must be seen as an index of fluid state ${ }^{43,44}$. Also in the present study ANP was significantly correlated with LADI.

A longer dialysis treatment could also provide a better clearance of other known or unknown substances with direct or indirect vasoactive properties. A better clearance of asymmetric dimethylarginine (ADMA), an endogenous inhibitor of $\mathrm{NO}^{45}$, by long dialysis compared to short dialysis has recently been suggested ${ }^{37}$. Whether ADMA levels in dialysis patients are high enough to cause blood pressure elevation is however controversial ${ }^{46}$.

Although patients on long dialysis had a good blood pressure control, concentric LVH was still present in most patients, and LVMI was comparable to LVMI in patients on short dialysis. In patients on long dialysis LVMI was not correlated with blood pressure or day-night blood pressure difference. However, a significant correlation was found with hemoglobin concentration, suggesting anemia to be an important factor in LVH. LVH is found to improve after starting EPO therapy ${ }^{47-49}$. An important factor in the high incidence of LVH in patients on long dialysis could be the history of hypertension before dialysis treatment was started. We did not found a relationship of $\mathrm{LVH}$ with PTH levels. Other factors contributing to LVH are age, hypervolemia, dialysis fistulae, and perhaps uremic toxins ${ }^{50}$.

Also systolic and diastolic cardiac function measured by LVEF and E/A ration, were comparable in patients on long dialysis and short dialysis. Diastolic dysfunction in hemodialysis patients is often seen in combination with $\mathrm{LVH}^{51,52}$. The reduced ventricullar compliance results in an impaired capacity of the ventricle to accept blood without a disproportionate increase in ventricular pressure. A problem in using E/A ratio in dialysis patients as a marker for diastolic function, is the influence of volume status on left ventricular filling pattern and E/A ratio ${ }^{53}$. The increased LADI, as we found in both dialysis groups, is most likely due to an increased atrial contribution to left ventricular filling caused by the noncompliant hypertrophied ventricular wall ${ }^{\text {s4 }}$.

In this study we tried to get some insight in the pathophysiological mechanisms leading to an improved control of blood pressure in patients on long-treatment-time dialysis. We realise that studying patients in Tassin and Maastricht is rather difficult, for patients are not completely comparable. However this is the only way to get enough data which can be used as a basis for more controlled prospective studies. From this study we can conclude that patients on long-treatment-time 
dialysis have a good inter-dialytic blood pressure control which seems mainly caused by a low SVRI. Although fluid state was not significantly different in patients on long dialysis compared to short dialysis, there was a tendency for somewhat lower fluid state in patients on long dialysis. Also sodium concentration was lower in patients on long dialysis as compared to short dialysis. This data suggest that other factors than a lower fluid state also contribute to the good blood pressure control in patients on long-treatment-time dialysis. Although a good blood pressure control is achieved with long-treatment-time dialysis, LVH is still present. The degree of anemia seems to be an important factor in causing LVH in the patients of Tassin. A prospective study, analyzing the effect of reducing dry weight and extending dialysis-treatment-time on blood pressure and LVMI is currently being performed. 


\section{References}

1. Degoulet P, Legrain M, Reach I, Aime F, Devries C, Rojas P, Jacobs C. Mortality risk factors in patients treated by chronic haemodialysis. Nephron 1982;31:103-110.

2. Mailloux LU, Bellucci AG, Mossey RT, Napolitano B, Moore $T$, Wilkes BM. Bluestone PA. Predictors of survival in patients undergoing dialysis. Am J Med $1988 ; 84: 855-862$.

3. Kooman JP, Leunissen KML. Cardiovascular aspects in renal disease. Curr Opinion Nephr Hypert 1993:2:791-797

4. Fernandez JM, Carbonell $M E_{*}$ Mazzuchi $N$, Petruccelli. Simultanous analysis of morbidity and mortality factors in chronic hemodialysis patients. Kidney Int $1992: 41: 1029-1034$

5. Foley RN, Parfrey PS. Risk factors for cardiac morbidity and mortality in dialysis patients. Curr Opinion Nephr Hypert 1994;3:608-614.

6. de Leeuw PW. Pathophysiology of hypertension in patients on renal replacement therapy, Blood Purif 1994; 12:245-251.

7. Weidman P, Baretta-Piccoli C, Steffen F, Blumberg A, Reubi FC. Hypertension in terminal renal failure. Kidney Int 1976;9:294-301.

8. Schohn D, Weidmann P, Jahn H, Baretta-Piccoli C. Norepinephrine-related mechanism in hypertension accompanying renal failure. Kidney Int $1985 ; 28: 814-822$

9. Converse RL, Jacobsen TN, Toto RD, Jost CMT, Cosentino F, Fouad-Tarazi F, Victor RG. Sympathetic overactivity in patients with chronic renal failure. N Engl J Med 1992;327:1912-1918.

10. Agarawal A, Anand IS, Sakhuja V, Chugh KS. Effect of dialysis and renal transplantation on autonomic dysfunction in chronic renal failure. Kidney Int 1991;40:489-495.

11. Esbach JW, Egrie JC, Downing MR, Browne JK, Adamson JW. Correction of anemia of end-stage renal disease with recombinant human erythropoietin. $\mathrm{N}$ Eng $\mathrm{J}$ Med $1987 ; 316: 73-78$.

12. Vertes V, Cangiano JL, Berman LB. Hypertension in end stage renal disease. $\mathrm{N}$ Engl Med 1969;280:978-981.

13. Maher JF, Replacement of renal function by dialysis. Boston. Kluwer Academic Publishers $1989,776-777$.

14. Daugirdas JT. Dialysis hypotension: A hemodynamic analysis. Kidney Int $1991 ; 39: 233-246$

15. Leunissen KML, Kouw P, Kooman JP, Cheriex EC, deVries PMJM, Donker ALM, van Hooff JP. New techniques to determine fluid status in hemodialyzed patients. Kidney Int 1993; suppl 41:S50-S56.

16. Cheriex EC, Leunissen KML, Janssen JHA, Mooy JMV, van Hooff JP. Echography of the inferior caval vein is a simple and reliable tool for estimation of dry weight in haemodialysis partients. Nephrol Dial Transpl 1989;4:563-568.

17. Charra $B$, Calemard $E$, Ruffet $M$, Chazot $C$, Terrat JC, Vanel $T$, Laurent $G$. Survival as an index of adequacy of dialysis. Kidney Int 1992;41:1286-1291. 
18. O'Brien $E$, Mee $F$, Atkins $N$, O'Malley $K$. Accuracy of the Spacelabs 90207 determined by the British Hypertension Society Protocol. I Hypert 1991;9:573-574.

19. Bouchard A, Blumlein S, Schiller NB, Schlitt S, Byrd BF III, Ports T, Chatterjee $\mathrm{K}$. Measurements of left ventricular stroke wolume using continuous wave Doppler echocardiografie of the ascending aorta and $M$-mode echocardiografie of the aortic value. I Am Coll Cardiol 1987;9:75-83.

20. Devereux RB, Reichek N. Echographic determination of left ventricular mass in mann: anatomic validation of the method. Circulation 1971;55:613-620.

21. Alpert MA, Wizeman V, Hüting J, Massey CV. Noninvasive assessment of left ventricular structure and function in patients with end-stage renal clisease. Contrib Nephrol 1994;106:13-25.

22. Vokonas PS, Kannel WB, Cupples LA. Epidemiology and risk of hypertension in the elderly: the Framingham study. J Hypert 1988;6(suppl 1):S3-S9.

23. Kooman $J_{P}$, Gladziwa $U$, Backer $G_{*}$ Wijnen JAG, van Bortel $L$, Luik AJ, de Leeuw PW, van Hooff JP, Leunissen KML. Representative blood pressure in haemodialysis patients by 48-hour ambulatory blood pressure monitoring. Nephrol Dial Transpl 1992;7:917-923.

24. Luik AJ, Struijk DG, van Olden RW, van Hooff JP, de Leeuw PW, Leunissen KML. Diurnal blood-pressure variations in haemodialysis and CAPD patients. Nephrol Dial Transpl 1994;9:1616-1621.

25. Verdecchia P, Schillaci G, Guerrieri M, Gatteschi C, Benemio G, Boldrini F, Porcellati $\mathrm{C}$. Circadian blood pressure changes and left ventricular hypertrophy in essentiall hypertension. Circullation 1990;81:528-536.

26. London GM, Guerin A, Pannier B, Marchais S, Benetos A, Safar M. Increased systolic pressure in chronic uremia: Role of arterial wave reflections. Hypertension 1992;20:10-19.

27. London GM, Marchais SJ, Safar ME, Genest AF, Guerin AP, Metivier F, Chedid $K$, London AM. Aortic and large artery compliance in end-stage renal failure. Kidney Int 1990;37:137-142.

28. Barenbrock M, Spieker C, Laske V, Heidenreich S, Hohage H, Bachmann J, Hoeks APG, Rahn KH. Studies of the vessel wall properties in hemodialysis patients. Kidney Int 1994;45:1397-1400.

29. Planque BA de, Mulder E, Dorhout Mees ET. The behaviour of blood and extracellular volume in hypertensiwe patients with renal insufficiency. Acta Med Scand $1969 ; 186: 75-81$.

30. Dathan JRE, Jolunson DB, Goodwin F. The relation between body fluid compartment volumes, renin activily and blood pressure in chronic renal failure. Clin Science Mol Med 1973;45:77-88.

31. Wilkinson $R$, Scott DF, Uldall PR, Kerr DNS, Swinney J. Plasma renin and exchangeable sodium in the hypertension of chronic remal failure. Q J Med $1969 ; 39: 377-394$.

32. Schultze G. Piefke S, Molzahn M. Blood pressure in terminal renal failure. Nephron 1980;25:15-24. 
33. Blaustein MP, Hamlyn M. Sodium transport inhibition, cell calcium and hypertension: the natriuretic hormone $\mathrm{Na}-\mathrm{Ca}$ exchange/hypertension hypothesis. Am J Med 1988:77:45-59.

34. Henrich WL, Woodard TD, McPhaul JJ. The chronic efficacy and safety of high sodium dialysate: Double-blind, crossover study. Am J Kidney Dis 1982;2:349-353.

35. Wirtz JJM, Leunissen KML, van Esser IWJ, Cheriex EC, Slaaf DW, Reneman

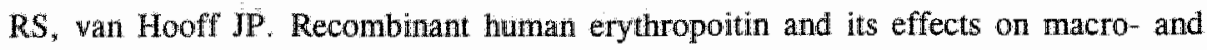
micro-circulation during normovolemia. Blood Purif 1990;8:285-294.

36. London GM, Zins B, Pannier B, Naret C, Bertelot JM, Jacquot C, Safar M, Drueke $T B$. Vascular changes in hemodialysis patients in response to recombinant human erythropoitin. Kidney Int 1989;36:878-882.

37. Ritz $\mathrm{E}$, Vallance $\mathrm{P}$, Nowicki $\mathrm{M}$. The effect of malnutrition on cardiovascular mortality in dialysis patients: is L-arginine the answer. Nephr Dial Transpl 1994:9:129-130.

38. Cuche JL, Prinseau J, Selz F, Ruget G, Baglin A. Plasma free, sulfo- and glucuroconjugated catecholamines in uremic patients. Kidney Int 1986;30:566-572.

39. Weidman P, Baretta-Piccoli C, Steffen F, Blumberg A, Reubi FC. Hypertension in terminal renal failure. Kidney Int 1976;9:294-301.

40. Jespersen B, Pedersen EB, Christensen NJ, Danielsen H, Sorensen SS. Reduced angiotensin II induced wascular reactivity in chronic renal failure. Scand J Clin Lab Invest 1988;49:705-713.

41. Rose BD. Clinical physiology of acid-base and electrolyte disorders, 4th edition. McGraw-Hill, Inc 1994, pp 155-164.

42. Mallamaci F, Postorino M, Zoccali C. Influence of ANP on the cardiovascular reponse to volume expansion in haemodialysis patients. Nephrol Dial Transpl $1994 ; 9: 1279-1282$.

43. Corboy JC, Walker RJ, Simmonds MB, Wilkins GT, Richards AM, Espiner EA. Plasma natriuretic peptides and cardiac volume during acute changes in intravascular volume in haemodialysis patients. Clin Science 1994;87:679-684.

44. Leunissen KML, Menheere PPCA, Cheriex EC, van den Berg BW, Noordzij TC, van Hooff JP. Plasma alpha-human atrial natriuretic peptide and dry weight in chronic hemodialysis. Nephrol Dial Transpl 1989;4:382-386.

45. Vallance P, Leone A, Calver A, Collier J, Moncada S. Accumulation of an endogenous inhibitor of nitric oxide synthesis in chronic renal failure. Lancet 1992;339:572-575.

46. Anderstam B, Katzarski $K$, Bergström $J$. Methylarginines in uremia. JASN 1994;5:572.

47. Cannella G, La Canna G, Sandrini M, Gaggiotti M, Nordio G, Movilli E, M ombelloni $S$, Visioli $O$, Maiorca $R$. Reversal of left ventricular hypertrophy following recombinant human erythropoitin treatment of anemia dialysed uraemic patients. Nephrol Dial Transpl 1991;6:31-37.

48. Goldberg N, Lundin AP, Delano B, Friedman EA, Stein RA. Changes in left ventricualr size, wall thickness, and function in anemic patients treated with recombinant human erythropoietin. Am Heart J 1992;124:424-427. 
49. Wirtz JJJM, Leunissen KML, van Kuijk W, Cheriex EC, Slatef DW, Reneman RS, van Hooff JP. Long-term effects of recombinant human erythropoitin on macro- and microcirculation in chronic hemodialysis patients. Blood Purif 1993;11:237-247.

50. London GM, Guerin AP, Marchais SJ. Pathophysiology of left ventricular hypertrophy in dialysis patients. Blood Purif 1994;12:277-283.

51. Fujimoto $S$, Koghoshima $T$, Hashimoto $T$, Nakajima $T$, Dohi $K$. Left ventricular diastolic function in patients on maintenance hemodialysis: comparison with hypertensive heart disease and hypertrophic cardiomyopathy. Clin Nephrol 1994;42:109-116.

52. London GM, Marchais SJ, Guerin AP, Metivier F, Pannier B. Cardiac hypertroplay and arterial alterations in end-stage renal disease: Hemodynamic factors. Kidney Int $1993 ; 43$ suppl $41:$ S42-S49.

53. Sztajzel J, Ruedin P, Monin C, Stoermann C, Leski M, Rutsihauser W, Lerch R. Effect of altered loading conditions during haemodialysis on left ventricular filling. pattern. Eur Heart J 1993;14:655-661.

54. Miyaguchi K, Iwase M, Yokota M, Hayashi $H$, Tsuzuki J, Katoh M. Influence of left ventricular preload reduction by hemodialysis on the doppler-derived left ventricular filling profille. Am J Noninvas Cardiol 1990;4:345-351. 


\section{Chapter 6}

The influence of increasing dialysis treatment-time and reducing dry weight on blood pressure control in hemodialysis patients; a prospective study

AJ Luik, FM vd Sande, P Weideman, EC Cheriex, KML Leunissen

Submitted for publication 


\section{Abstract}

A good blood pressure control can be achieved with long hemodialysis sessions, 3 times at week eight hours (Charra, Tassin). If a higher dialysis dose or a lower dry weight is responsible for the good blood pressure control is still a matter of debate. We tested the hypothesis that by increasing dialysis-treatment-time blood pressure can be better controlled with less antihypertensive drugs. The effect of lowering dry weight and increasing dialysis time on 48 hours inter-dialytic blood pressure was prospectively studied. 21 Hypertensive patients, dialyzed 3 times a week 3-5 hours, and treated with antihypertensive medication, were studied during 3 months. Prior to the study, echocardiography was performed at the mid-dialytic day, to determine cardiac index and left ventricular mass index. Forearm vascular resistance was measured at the non-fistula arm using strain gauge plethysmography. A blood sample was drawn for hemoglobin, sodium, potassium, BUN, creatinine, arginine vasopressin, and atrial natriuretic peptide. In 6 patients dialysis treatment-time was increased with 2 hours and dry weight was gradually decreased (group 1). In 7 patients dialysis treatment-time was increased 2 hours without a change in dry weight (group 2). In 8 patients dry weight was gradually lowered without changing the dialysis treatment-time (group 3). Antihypertensive medication was reduced when post-dialytic blood pressure became $<130 / 80 \mathrm{mmHg}$. After three months, all hemodynamic measurements were repeated.

Dry weight was reduced $2.6 \pm 1.4 \mathrm{~kg}$ in group 1 and $2.3 \pm 0.8 \mathrm{~kg}$ in group 3 . Antihypertensive medication could be reduced in all patients groups by 30 to $60 \%$. Interdialytic systolic blood pressure decreased significantly after increasing dialysis time without changing dry weight (group 2: $7 \pm 5 \mathrm{mmHg}, \mathrm{p}<0.05$ ). Systolic blood pressure was also lower in the other patients groups; group 1: $13 \pm 26 \mathrm{mmHg}$, group 3: $7 \pm 16$ $\mathrm{mmHg}$, but these differences were not significant. No change in diastolic blood pressure was found. Cardiac Index and Left Ventricular Mass did not change significantly. Forearm vascular resistance tended to decrease in the patients on long dialysis (group 1 : $4420 \pm 1590$ to $3420 \pm 1740 \mathrm{mmHg} / \mathrm{ml} / 100 \mathrm{ml} / \mathrm{sec}$, ns; group 2: $3930 \pm 1850$ to $3050 \pm 1020$, ns) in contrast to the patients on short dialysis (group 3: $2850 \pm 1350$ to $3070 \pm 2377 \mathrm{mmHg} / \mathrm{ml} / 100 \mathrm{ml} / \mathrm{sec}$, ns). No change in serum sodium and potassium was found. Also hemoglobin levels did not change significantly. Arginine vasopressin levels decreased after lowering dry weight (group 1 and group 3). Although $\mathrm{Kt} / \mathrm{V}$ increased after increasing dialysis treatment-time, mid-dialytic BUN did not change.

From this study we conclude that dialysis treatment-time influences blood pressure control and blood pressure is better controlled when patients are longer dialyzed. 


\section{Introduction}

Cardiovascular morbidity and mortality are a major concern in hemodialysis patients ${ }^{1}$. Hypertension is found to be an important risk factor for cardiovascular disease in dialysis patients, besides disturbance of calcium, glucose and lipid metabolism, anemia, hypervolemia, and accumulation of uremic toxins ${ }^{2}$. The incidence of hypertension is very high ${ }^{3}$. Hypervolemia has always been considered the most important determinant of inadequate blood pressure control in hemodialysis patients ${ }^{4}$. Although most nephrologists try to control blood pressure by lowering dry weight, $80 \%$ of the patients in Europe are reported to have hypertension and need treatment with antihypertensive drugs ${ }^{3}$. In the USA the incidence of hypertension is even higher. This parallels the higher cardiovascular mortality in the USA compared to Europe ${ }^{5}$. If an elevated blood pressure is mainly a matter of hypervolemia, it should be controlled by decreasing dry weight. The ability to ultra-filtrate during the dialysis session, preventing hypotension, depends on plasma volume preservation and on the adequacy of cardiovascular regulatory mechanisms, like the increase of venous tone and peripheral vascular resistance ${ }^{6}$. A shorter dialysis treatment-time and an higher inter-dialytic weight gain, limits the ability to reach a certain dry weight goal. Dialysis treatment-time is shorter in the USA compared to Europe, and it is speculated that this is the most important factor for the higher incidence of hypertension in the USA. However, modern dialysis techniques with biocompatible membranes and bicarbonate as a buffer make it possible to ultra-filtrate in most patients a certain amount of fluid in a much shorter time without inducing intra-dialytic hypotension. Are there other factors in patients on a short dialysis treatment-time that frustrate the efforts to control blood pressure by reducing dry weight? A better blood pressure control with less cardiovascular morbidity and mortality can be achieved by long-treatment-time dialysis 3 times a week 8 hours as is performed by Dr Charra at the Tassin dialysis center in France $^{7}$. $95 \%$ Of his patients are reported to have an adequate blood pressure control without antihypertensive medication. The longer dialysis session makes it possible to ultra-filtrate more fluid during a dialysis session while preventing hypotension despite the use of cuprophane membranes, and acetate as a buffer. However, with the longer dialysis treatment-time, dialysis dose is also increased which theoretically could have an effect on blood pressure control. In a previous study, inter-dialytic blood pressure and fluid state was evaluated in the Tassin dialysis patients on long-treatment-time dialysis by echography of the inferior caval vein, and compared to hemodialysis patients in Maastricht, the Netherlands with a more usual short dialysis treatment-time and a much higher incidence of hypertension ${ }^{8}$. Inter-dialytic blood pressure was found to be significantly lower in the Tassin patients compared to the Maastricht patients based on a significantly lower systemic vascular resistance, although the latter used many antihypertensive 
drugs. Dialysate sodium concentration was $138 \mathrm{mmol} / \mathrm{l}$ in Tassin, which was 2 mmol lower compared to dialysate sodium concentration in Maastricht. This resulted in 3 mmol lower serum sodium concentration in the Tassin patients as compared to the Maastricht patients. However, there was no significant difference in volume status between the Tassin patients and the Maastricht patients, suggesting other factors to be responsible for the better blood pressure control. Dialysis dose was higher in the Tassin patients which was also reflected by a higher $\mathrm{Kt} / \mathrm{V}$ of 1.7 compared to a $\mathrm{Kt} / \mathrm{V}$ of 1.1 in the Maastricht patients. It has been hypothesized that accumulation of uremic toxins influences blood pressure control in dialysis patients 9 . Accumulation of asymmetric dimethyl arginine (ADMA), an endogenous inhibitor of nitric oxide (NO), may lead to increased vascular resistance ${ }^{10}$. Inhibition of NO may also affect blood pressure control by increasing sympathetic nervous activity, as has been suggested from animal studies ${ }^{11}$.

In the present study we prospectively evaluated the effect of increasing dialysis time and decreasing dry weight on inter-dialytic blood pressure control. We tested the hypothesis that by increasing dialysis dose by increasing dialysis treatmenttime, blood pressure can be better controlled with less antihypertensive drugs, independent of salt and water loading.

\section{Subjects and methods}

29 Hypertensive hemodialysis patients, using one or more antihypertensive drugs, dialyzed 3 times a week 3-5 hours, were included in the study. All patients were studied during the period of 3 months. A study period of three months was chosen because most of the effects of long-treatment-time dialysis on blood pressure control are seen during the first three months after initiating long-treatment-time dialysis ${ }^{12}$. The patients were randomly placed on one of the three following dialysis regime's in order to control their blood pressure. In group 1 (long and dry; 10 patients) dialysis treatment-time was increased by 2 hours and dry weight was gradually decreased during the study period. In group 2 (long; 10 patients) dialysis treatment-time was increased by 2 hours without any change in dry weight. In group 3 (dry; 9 patients) dry weight was decreased without changing dialysis treatment-time. During the study period, antihypertensive medication was reduced when post-dialytic blood pressure became $<130 / 80 \mathrm{mmHg}$. Antihypertensive drugs were stopped when post-dialytic Blood pressure remained $<130 / 80 \mathrm{mmHg}$ even after dose reduction.

The dialysate contained sodium $140 \mathrm{mmol} / 1$, potassium $2.0 \mathrm{mmol} / 1$, calcium 1.7 $\mathrm{mmol} / \mathrm{l}$, magnesium $0.5 \mathrm{mmol} / \mathrm{l}$, glucose $2 \mathrm{gr} / \mathrm{l}$. Blood flow was $300 \mathrm{ml} / \mathrm{min}$ and dialysate flow was $500 \mathrm{ml} / \mathrm{min}$. Kt/V was calculated with a Urea Kinetic Calculator 
using single pool modeling.

All patients were analyzed just before the three months study period, and at the end of the three months study period. At these time points, inter-dialytic blood pressures were measured, a blood sample was taken, and hemodynamic measurements were performed.

Blood pressure was measured during a 2-day inter-dialytic period using Spacelabs 90207 ambulatory blood pressure monitors, measuring every 15 minutes during the day (from 07.00 to $23.00 \mathrm{~h}$ ) and every 30 minutes during the night (from 23.00 to $7.00 \mathrm{~h})$.

In the same period, one day after dialysis, so after full equilibration of the fluid compartments, hemodynamic measurements were performed in a temperature controlled room with a room temperature of $23^{\circ} \mathrm{C}$. The measurements were performed after 20 minutes of rest in supine position. Blood pressure and heart rate were measured. The mean of 3 recordings was calculated. Echocardiography was performed for measuring cardiac dimensions, wall thickness, and aortic valve diameter (Hewlett Packard sonos 100 echo-doppler cardiograph, 3.5 megahertz transducer). Ascending aortic blood flow velocity was measured with continuous wave doppler with a 10 megahertz transducer. Left Ventricular Mass Index (LVMI) was calculated with the formula of Devereux and Reichek ${ }^{13}$. Cardiac index (CI) was calculated with standard formulas. The results of this method correlates well with other, invasive and non-invasive techniques ${ }^{14}$. In our clinic, the intra- and interobserver variability of this method to assess stroke volume has been established to be $9 \%$ and $11 \%$, respectively ${ }^{15}$.

Forearm blood flow was measured at the non-fistula arm using strain-gauge plethysmograph (Periflow, Jansen Scientific Instruments, Beerse, Belgium) with an inflatable cuff applied to the upper arm while the mercury-filled strain gauge was positioned at the thickest part of the forearm. The measurement of forearm blood flow is based on the measurement of initial volume change during three heart beats after initial occlusion. To measure forearm blood flow, the upper arm cuff was rapidly inflated, $5 \mathrm{msec}$ after the R-top of the electrocardiogram, to a cuff pressure of $50 \mathrm{mmHg}$. The inflation/deflation ratio was $3: 2$ heart beats. Forearm blood flow was measured during four minutes and estimated with a computerized integrator. The mean value of the last 2 minutes was calculated. Forearm vascular resistance was calculated by dividing mean arterial pressure by forearm blood flow $(\mathrm{mmHg} / \mathrm{ml} / 100 \mathrm{ml} / \mathrm{sec})$. Measurement of forearm blood flow by venous occlusion plethysmography has been sluown to correlate well with electromagnetic flow measurements ${ }^{16}$. The coefficient of variation of consecutive flow measurements is $14 \%{ }^{17}$.

At the same day a blood sample was drawn from an intravenous catheter (internal diameter $1 \mathrm{~mm}$;Venflon) inserted into an antecubital vein, into ice-chilled tubes, with the patient still in supine position. Blood was analyzed for hemoglobin ( $\mathrm{Hb}$ ), 
hematocrit ( $\mathrm{Ht})$, sodium $(\mathrm{Na})$, potassium $(\mathrm{K})$, creatinine, BUN, ANP, and arginine vasopressin (AVP). ANP and AVP were measured with a radio immunoassay. The intra- and inter assay variation for ANP and AVP were below $10 \%$.

Significance of differences was calculated by a Wilcoxon test for paired data. Differences were considered significant when $p$ values were $<0.05$.

\section{Results}

21 Patients completed the study. In group 1 (long and dry), 3 patients refused to complete the three months on long dialysis, and 1 patient stopped because of peripheral vascular disease for which surgical intervention was needed. In group 2 (long normovolemic), 2 patients did not want to complete the study, and one patient stopped because of three vessel disease with unstable angina for which he underwent cardiac surgery. In group 3 (short and dry), 1 patient did not complete the study because of cardiac death. So the study was completed with 6 patients in group 1 (long and dry), 7 patients in group 2 (long normovolemic), and 8 patients in group 3 (short and dry). In the remaining patients there was no intercurrent illness in the three months follow up period. Patients characteristics are shown in table 6.1 .

The origin of renal disease was: glomerulonephritis 3, Ig-A Nephropathy 3, glomerulosclerosis with generalized vascular disease 6, interstitial nephritis 2, polycystic disease 1, diabetes mellitus 1 , Alport 1, unknown 4 . These were equally distributed over the three patients groups.

\begin{tabular}{lccc}
\hline & $\begin{array}{c}\text { Group 1 } \\
\mathbf{n}=6\end{array}$ & $\begin{array}{c}\text { Group 2 } \\
\mathbf{n}=7\end{array}$ & $\begin{array}{c}\text { Group 3 } \\
\mathbf{n}=8\end{array}$ \\
\hline Male / Fenale & $5 / 1$ & $5 / 2$ & $7 / 1$ \\
Age (years) & $52 \pm 18$ & $51 \pm 10$ & $60 \pm 13$ \\
Weight (kg) & $65 \pm 10$ & $67 \pm 12$ & $72 \pm 13$ \\
Lenght (m) & $1.68 \pm 0.07$ & $1.72 \pm 0.05$ & $1.74 \pm 0.07$ \\
Dialysis treatment-tine (hi) & $3.8 \pm 0.4$ & $3.7 \pm 1.3$ & $3.8 \pm 0.8$ \\
\hline
\end{tabular}

All patients were using one ore more antihypertensive drugs consisting of; $\mathrm{Ca}$ channel blockers (18 patients), ACE-inhibitors (15 patients), $\beta$-blockers (12 patients), $\alpha$-blockers ( 8 patients), direct acting vasodilators (4 patients), central 
acting agents ( 2 patients). During the study period, antihypertensive medication could be reduced in all patient groups: the number of classes of antihypertensive drugs as well as the dose of the remaining antihypertensive medication (figure 6.1).

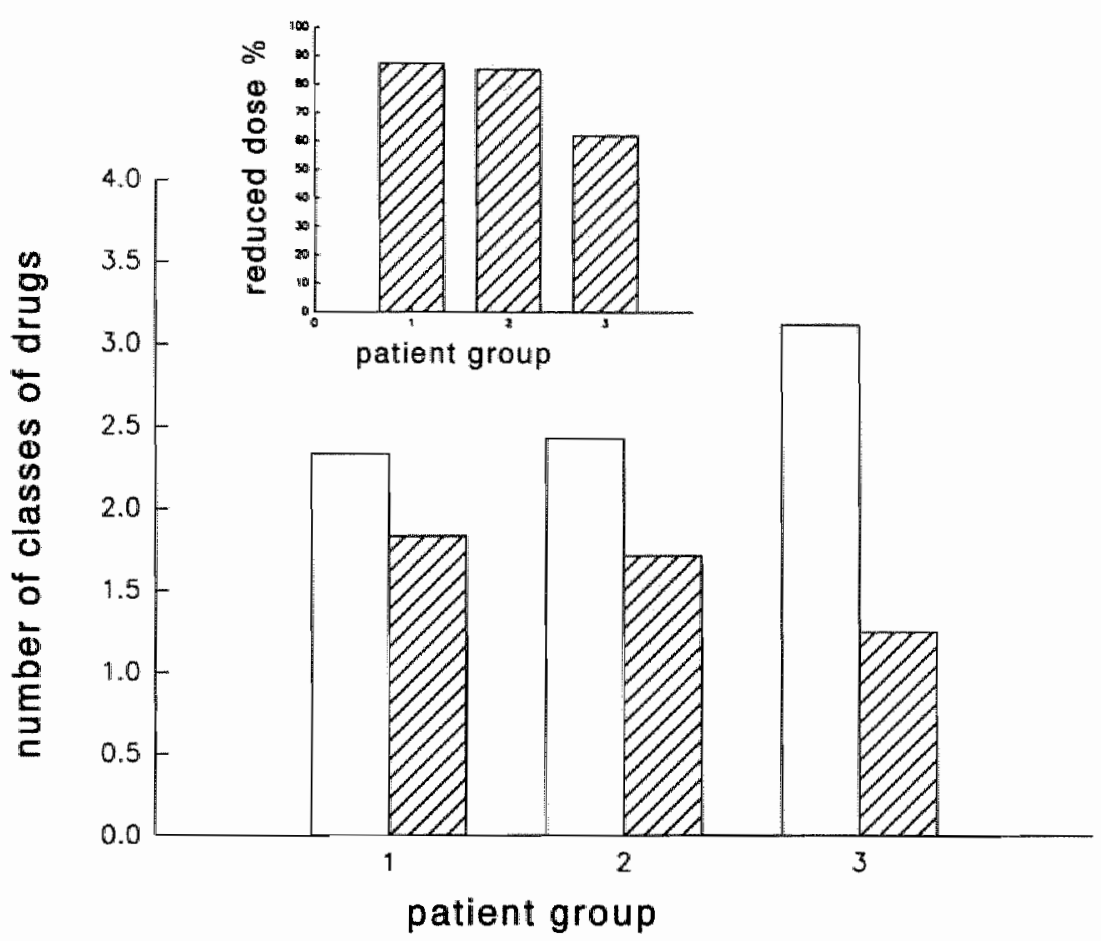

Figure 6.1 Reduction of classes of antihypertensive drugs in patients group I (long dialysis and dry weight reduetion), group 2 (long dialysis without change in dry weight), group 3 (short dialysis and dry weight reduction). Open bar is basic condition, accented bar is situation after 3 months. INSTET: reduced dose of the remaining antihypertensive drugs after 3 months (\%)

After 3 months, inter-dialytic systolic blood pressure tended to be lower in all patient groups and reached a significant level in group 2 (figure 6.2). Diastolic blood pressure did not change after three months. Day-night blood pressure difference decreased, although not significantly after increasing dialysis treatmenttime. In patients of group 1 (long and dy) dry weight was $2.6 \pm 1.4 \mathrm{~kg}$ lower after 3 months. Inter-dialytic blood pressure before changing dialysis regime was $160 \pm 35 / 87 \pm 17 \mathrm{mmHg}$ and $147 \pm 26$ (ns) $/ 85 \pm 12$ (ns) $\mathrm{mmHg}$ at the end of the study. Day-night systolic/diastolic blood pressure difference decreased from $15 \pm 12$ $/ 11 \pm 7 \mathrm{mmHg}$ to $4 \pm 8 / 4 \pm 7 \mathrm{mmHg}$ (ns). No change in mean inter-dialytic heart rate was seen $71 \pm 7$ bpm to $72 \pm 8$ bpm after 3 months. Patients in group 2 (long) had no change in dry weight, and with increasing dialysis treatment-time inter- 
dialytic blood pressure significantly decreased from $150 \pm 19 / 88 \pm 8 \mathrm{mmHg}$ to $144 \pm 16(\mathrm{p}<0.05) / 89 \pm 8(\mathrm{~ns}) \mathrm{mmHg}$. Day-night systolic/diastolic blood pressure difference changed from $7 \pm 7 / 7 \pm 3 \mathrm{mmHg}$ to $2 \pm 9 / 6 \pm 6 \mathrm{mmHg}$ (ns). Mean inter-dialytic heart rate increased significantly: $73 \pm 14 \mathrm{bpm}$ at the start of the study, $80 \pm 12 \mathrm{bpm}$ after 3 months $(\mathrm{p}<0.05$ ). In group 3 (short and dry) dry weight could be lowered with $2.3 \pm 0.8 \mathrm{~kg}$. Inter-dialytic blood pressure changed from $152 \pm 9 / 86 \pm 15 \mathrm{mmHg}$ to $145 \pm 11$ (ns) / $85 \pm 9$ (ns) $\mathrm{mmHg}$ after 3 months. Daynight systolic/diastolic blood pressure difference was $7 \pm 11 / 6 \pm 6 \mathrm{mmHg}$ at the start of the study and $9 \pm 12 / 8 \pm 6 \mathrm{mmHg}$ (ns) after 3 months. Mean inter-dialytic heart rate increased after lowering dry weight: $72 \pm 13 \mathrm{bpm}$ at the start of the study, $83 \pm 11$ bpm after 3 months $(\mathrm{p}<0.05)$. CI did not change throughout the study (table 6.2). Also LVMI did not change. Forearm vascular resistance tended to decrease in group $1(23 \% ; \mathrm{p}=0.07)$ and in group $2(22 \% ; \mathrm{p}=0.50)$ although not significantly, and increased in group $3(8 \% ; \mathrm{p}=0.78)$.

Table 6.2 Henodynamic measurements, at the start of the study before changing dialysis regime and after 3 months at the end of the study. Group $1: 2 \mathrm{~h}$ increase diallysis treatment-time and decreasing ory weight; Group 2 : 2 th ifterease dfallysis treatment-time with any change in dry weight: Group 3: decreasing dry weigh without change in diallysis treatment-time. VCDI: Caval Vein Diameter Index, CI: Cardic Index, LVMI: Left Ventricular Mfass Index, FVR: Forearm Vascular Resistance

\begin{tabular}{llccc}
\hline & & Group 1 & Group 2 & Group 3 \\
\hline H.R (beats/min) & basic & $71 \pm 7$ & $73 \pm 14$ & $72 \pm 13$ \\
& 3 months & $72 \pm 8$ & $80 \pm 12^{*}$ & $83 \pm 11^{\circ}$ \\
Cl (l/min/ $\left./ \mathrm{m}^{2}\right)$ & basic & $3.4 \pm 0.8$ & $3.1 \pm 0.5$ & $3.9 \pm 1.2$ \\
& 3 months & $3.6 \pm 1.1$ & $3.1 \pm 0.7$ & $3.7 \pm 1.2$ \\
L.VMI $\left(\mathrm{g} / \mathrm{rm}^{2}\right)$ & basic & $154 \pm 24$ & $138 \pm 23$ & $134 \pm 15$ \\
& 3 months & $134 \pm 14$ & $128 \pm 30$ & $132 \pm 25$ \\
FVR $(\mathrm{mmHg} / \mathrm{ml} / 100 \mathrm{ml} / \mathrm{sec})$ & basic & $4418 \pm 11587$ & $3927 \pm 1847$ & $2849 \pm 1353$ \\
& 3 morths & $3425 \pm 1741$ & $3055 \pm 1024$ & $3072 \pm 2377$ \\
\hline
\end{tabular}

$* 00.05$

No changes in $\mathrm{Hb}$ and $\mathrm{Ht}$ were seen during the study (table 6.3). No significant changes in epo dosage was seen in either of the patients group although the patients on long-treatment-time dialysis had a lower epo dosage after 3 months; group 1: $6000 \pm 4400 \mathrm{U} /$ week to $4300 \pm 1500 \mathrm{U} /$ week after 3 months; group 2: $5900 \pm 5000$ $\mathrm{U} /$ week to $5300 \pm 5000 \mathrm{U} /$ week after 3 months; group 3: $6300 \pm 2900 \mathrm{U} /$ week to $6300 \pm 2900 \mathrm{U} /$ week after 3 months. No changes in $\mathrm{Na}$ and $\mathrm{K}$ were seen $. \mathrm{Kt} / \mathrm{V}$ increased in group 1 from $1.16 \pm 0.22$ to $1.57 \pm 0.41$ ( $p<0.05$ ) after 3 months. In group $2 \mathrm{Kt} / \mathrm{V}$ increased from $1.11 \pm 0.24$ to $1.53 \pm 0.36(p<0.05)$ after 3 months. 


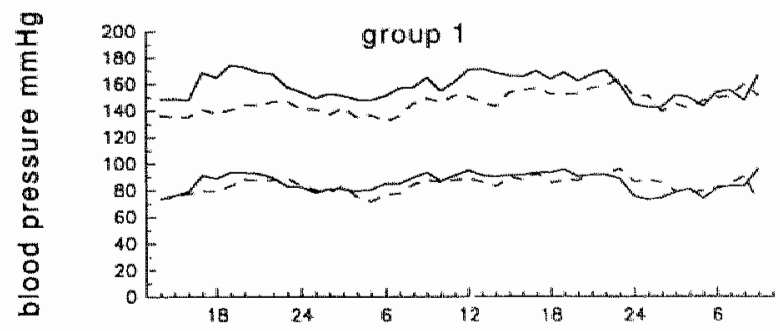

time h

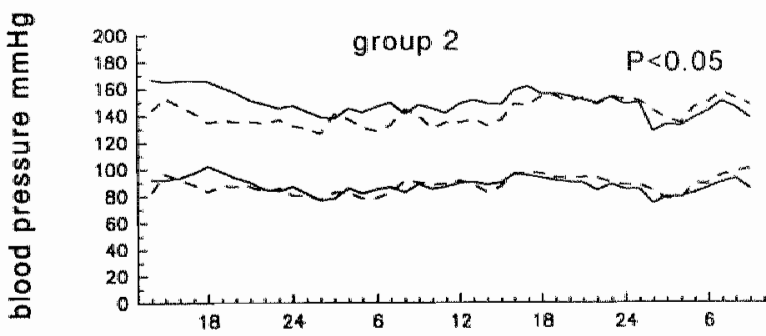

time h

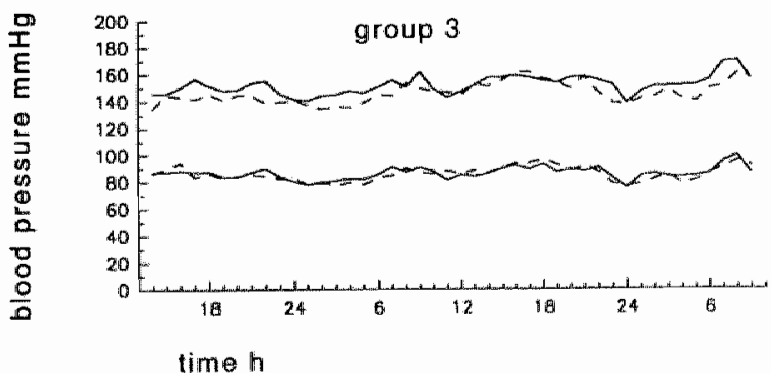

Figure 6.2 Interdialytic blood pressure. Solid line: basic sinution, striped line: after 3 months. Group 1. Iong dialysis and dry weight reduction, group 2: Iong dialysis without change in dry weight group 3: short dialygs and dry weight reduction

$\mathrm{Kt} / \mathrm{V}$ increased also slightly in group $31.04 \pm 0.14$ to $1.13 \pm 0.14(\mathrm{p}<0.05)$. BUN and creatinine did not change significantly (table 6.3). AVP did not change in group 1 and tended to increase in group 2 and group 3. ANP decreased significantly in group 1 and group 3 . 


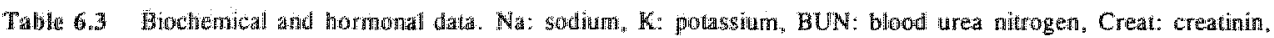
AVP: arginine vasopiessin, ANP: atrial atatruretic peptide

\begin{tabular}{|c|c|c|c|c|}
\hline & & Group 1 & Group 2 & Group 3 \\
\hline \multirow[t]{2}{*}{$\mathrm{Hb}$ (munol/l) } & basic & $6.7 \pm 1.4$ & $6.0 \pm 0.5$ & $6.6 \pm 1.2$ \\
\hline & 3 monthes & $6.3 \pm 0.7$ & $6.6 \pm 1.0$ & $6.6 \pm 0.8$ \\
\hline \multirow[t]{2}{*}{ Hil } & basite & $0.33 \pm 0.07$ & $0.29 \pm 0.03$ & $0.32 \pm 0.06$ \\
\hline & 3 months & $0.30 \pm 0.03$ & $0.32 \pm 0.06$ & $0.32 \pm 0.04$ \\
\hline \multirow[t]{2}{*}{ Na (mnol/l) } & basic & $142 \pm 3$ & $140 \pm 2$ & $142 \pm 4$ \\
\hline & 3 months & $141 \pm 2$ & $139 \pm 2$ & $140 \pm 3$ \\
\hline \multirow[t]{2}{*}{ K (nimmol/l) } & basic & $5.1 \pm 1.2$ & $6.0 \pm 0.6$ & $58 \pm 1.1$ \\
\hline & 3 months & $4.7 \pm 0.9$ & $6.2 \pm 0.7$ & $5.4 \pm 1.2$ \\
\hline \multirow[t]{2}{*}{ BUN (mmol/I) } & basic & $14.4 \pm 3.4$ & $18.9 \pm 3.1$ & $17.5 \pm 5.5$ \\
\hline & 3 months & $12.0 \pm 3.6$ & $19.5 \pm 8.0$ & $19.4 \pm 6.0$ \\
\hline \multirow[t]{2}{*}{ Creat (Umol/l) } & basic & $796 \pm 226$ & $818 \pm 171$ & $807 \pm 297$ \\
\hline & 3 months & $626 \pm 40$ & $780 \pm 180$ & $812 \pm 302$ \\
\hline \multirow[t]{2}{*}{$A V P(p g / m l)$} & basic & $3.2 \pm 2.5$ & $2.0 \pm 2.4$ & $2.0 \pm 1.5$ \\
\hline & 3 months & $3.2 \pm 4.1$ & $4.1 \pm 2.4$ & $3.4 \pm 1.7$ \\
\hline \multirow[t]{2}{*}{$\mathrm{ANP}(\mathrm{pg} / \mathrm{ml})$} & basic & $760 \pm 520$ & $634 \pm 672$ & $466 \pm 479$ \\
\hline & 3 months & $412 \pm 248^{\circ}$ & $416 \pm 528$ & $356 \pm 474^{\circ}$ \\
\hline
\end{tabular}

$* 00.05$

\section{Discussion}

In the present study the influence of increasing dialysis treatment-time and decreasing dry weight on blood pressure control was prospectively evaluated. During a three month study period dry weight was gradually decreased in group 1 and $3(2.6 \mathrm{~kg}, 2.3 \mathrm{~kg}$ respectively). Dialysis treatment-time was prolonged by two hours in group $\mathbb{1}$ and group 2 . We were able to reduce blood pressure and antihypertensive medication by decreasing dry weight as well as by increasing dialysis treatment-time. Dry weight reduction only, resulted in a lower blood pressure with less antihypertensive therapy, although these differences were not significant. Increasing dialysis treatment-time by two hours without changing dry weight resulted in a significantly lower inter-dialytic blood pressure with less antilitypertensive medication.

In our study, increasing dialysis treatment-time decreases blood pressure with no change in Cardiac Index, suggesting a decrease in peripheral vascular resistance. 
Forearm vascular resistance directly measured in the mid-dialytic period indeed tended to decrease after prolonging dialysis treatment-time, while patients were using less antihypertensive vasodilating drugs in the follow up period. In contrast, decreasing dry weight without changing dialysis treatment-time resulted in a higher vascular resistance. In the present study we were not able to find a positive effect of increasing dialysis treatment-time on LVH in the three month study period.

The longer dialysis treatment-time resulted in a markedly increased $\mathrm{Kt} / \mathrm{V}$. Although dialysis treatment-time did not change in group $3, \mathrm{Kt} / \mathrm{V}$ increased slightly but significantly. This is mainly the result of a lower weight (and a lower " $V$ ") after three months. Prolonging dialysis treatment-time has a positive effect on erythropoietin response, as has recently been found ${ }^{18}$. In the present study EPO dosage tended to reduce after prolonging dialysis treatment-time which could contribute to better blood pressure control. However, hemoglobin levels were stable in these patient groups, while the decrease in EPO dosage in group 2. showing a significant blood pressure decrease, was limited.

So from this study it can be concluded that not only fluid state but also dialysis dose influences blood pressure control. Our study groups are small due to the relative large number of drop outs and difficulties to recruit patients due to limited social acceptance of longer dialysis treatment-time. The fact that dialysis dose influences blood pressure control confirms our observations in a previous retrospective study concerning the perfect blood pressure control in the Tassin dialysis population on long-treatment-time dialysis".

An effect of hydration state on blood pressure has been established. Volume overload can play an important role in the hypertension of dialysis patients. A recent study showed high ANP levels $(>800 \mathrm{pg} / \mathrm{ml})$ as an indicator of fluid overload in dialysis patients with an uncontrolled blood pressure ${ }^{19}$. In our study, inter-dialytic ANP levels were lower than $800 \mathrm{pg} / \mathrm{ml}$, nevertheless, a gradual, relative small decrease of dry weight of about $2.3 \mathrm{~kg}$ made it possible to reduce antihypertensive medication without increasing inter-dlialytic blood pressure, and without influencing $\mathrm{CO}$.

In our previous retrospective study concerning the Tassin patients on longtreatment-time dialysis, these patients had a lower serum sodium, induced by a lower dialysate sodium concentration as compared to our Maastricht patients on short dialysis ${ }^{8}$. In the present study, dialysate sodium was constant $140 \mathrm{mmol} / \mathrm{l}$ throughout the study. Also no change in serum sodium was found after increasing dialysis treatment-time without changing dry weight in group 2. A change in exchangeable sodium does not seem to be the explanation for the better blood pressure control after increasing dialysis treatment-time. Furthermore in our previous study, the Tassin patients on long-treatment-time dialysis had lower AVP levels compared to the Maastricht patients ${ }^{8}$. In the present study no influence of 
dialysis treatment-time on AVP levels could be found, so the lower AVP levels in the Tassin patients seems to be mainly related to the lower serum sodium concentration.

In previous studies no short-term relationships between inter-dialytic weight gain and inter-dialytic blood pressure changes could be found ${ }^{20,21}$. Short-term interdialytic fluid load of $3 \mathrm{~L}$ did not result in an increase in blood pressure in most patients ${ }^{22}$. After fluid load cardiac index increased, renin and angiotensin levels decreased as well as systemic vascular resistance, resulting in no change in blood pressure. The effects of reducing dry weight on blood pressure are perceptible only after several weeks. The long-term effects of fluid overload seem to be different from short-term inter-dialytic fluid overloading. So an accurate estimation of ideal dry weight is essential for a good blood pressure control.

Our study also shows a possitive effect of increasing dialysis dose by increasing dialysis treatment-time on blood pressure control. The pathogenetic mechanisms of this phenonemon is not clear. In our study vascular resistance tended to decrease after increasing dialysis treatment-time although vasodilating antihypertensive medication could be reduced. This confirms our observations in the Tassin dialysis population on long-treatment-time dialysis. We found a low peripheral vascular resistance in the Tassin patients compared to short-treatment-time dialysis of the Maastricht group ${ }^{8}$. However, the Tassin patient group was using less EPO, had a lower hemoglobin level, and was dialyzed with a lower dialysate sodium concentration, acetate as a buffer, and cuprophane membranes. In our present study we also saw a positive effect of increasing dialysis treatment-time on blood pressure control without a change in hemoglobin or serum sodium level. The patients were dialyzed with biocompatible membranes and bicarbonate as a buffer. This suggests that due to the long dialysis treatment-time, some accumulated vasoactive substance $(s)$ are better cleared compared to shorter dialysis treatmenttime, resulting in a lower vascular peripheral resistance and a better blood pressure control. The blood pressure lowering effect of prolonging dialysis treatment-time are perceptible after several weeks.

It is tempting to speculate on the effect of higher dialysis efficiency on blood pressure control. Increasing dialysis treatment-time both has an important effect on small and middle molecular clearance. So, increasing accumulated vasoactive substances could be reduced by increasing dialysis treatment-time. For this concept there is some support from animal experimental studies.

$\mathrm{NO}$ is a potent endothelial vasodilating substance. Accumulation of ADMA, an endogenous inhibitor of NO has been suggested to play a role in the pathogenesis of hypertension in dialysis patients ${ }^{10}$. However, others failed to find accumulation of ADMA in dialysis patients ${ }^{23}$. Sympathetic nervous activity is increased in end 
stage renal failure, which appears to be generated by an afferent signal arising in the failing kidney ${ }^{24}$. Apart from endothelial $N O$, neuronal NO probably also plays a role in blood pressure control in hemodialysis patients. Victor found a sympathetic mediated increase in blood pressure after chronic inhibition of neuronal NO in rats $^{11}$. He hypothized that neuronal NO could be an inhibitory neuromodulator involved in the tonic restraint of central sympathetic outflow. In chronic renal failure accumulation of endogenous NO inhibitors could lead to sympathetic overactivity. Another factor could be the increased Na-K-ATPase inhibitor activity found in hemodialysis patient $\mathrm{s}^{25}$. Intra-cellular sodium is found to be correlated with Na-K ATPase inhibitor activity and systolic blood pressure. Na-K ATPase inhibitor activity is probably better cleared during longer dialysis ${ }^{26}$.

Further studies are necessary to elucidate the role of renal replacement therapy on hypertension in dialysis patients, in order to get a better blood pressure control in these patients, and finally decreasing cardiovascular morbidity and mortality.

From this study we conclude that dialysis dose influences blood pressure control, and blood pressure is better controlled when patients are longer dialyzed. Short dialysis treatment-time with low $\mathrm{Kt} / \mathrm{V}$ can have negative effects on patients blood pressure and eventually worsen prognosis. 


\section{References}

1. Valderrabano $F$, Berthoux $\mathbb{F C}$, Jones EHP, Mehls $O$. Report on management of renal failure in europe, XXV, 1994. Nephrol Dial Transpl 1996;11 (supp 1).

2. Fernandez $\mathbb{N}$, Carbonell ME, Mazzuchi $N$, Petruccelli. Simultanous analysis of morbidity and mortality factors in chronic hemodialysis patients. Kidney Int 1992:41:1029-1034.

3. Raine AEG, Margreiter R, Brunner FP, Ehrich JHH, Geerlings W, Landais P, Loirat C, Mallick NP, Selwood NH, Tufveson G, Valderrabano F. Report on the management of renal failure in europe, XXII, 1991. Nephrol Dial Transpl 1992;7 (supp 2).

4. Dorhout Mees EJ. Volaemia and blood pressure in renal failure: Have old truths been forgotten? Nephrol Dial Transpl 1995;10:1297-1298.

5. Held PJ, Blagg CR, Liska DW, Port FK, Hakim R, Levin N. The dose of hemodialysis according to dialysis prescription in Europe and the United states. Kidney Int Supp! 1992;-138:S16-S21.

6. Leunissen KML, Kooman JP, van Kuijk W, van der Sande F, Luik AJ, van Hooff JP. Preventing haemodynamic instability in patients at risk for intra-dialytic hypotension. Nephrol Dial Transpl 1996;11(suppl 2):11-15.

7. Charra B, Calemard E, Ruffet M, Chazot C, Terrat JC, Vanel T, Laurent G. Survival as an index of adequacy of dialysis. Kidney Int 1992;41:1286-1291.

8. Luik AJ, Charra B, Katzarski K, Habets J, Cheriex M, Laurent G, Bergström J, Leunissen KML. Blood pressure control and fluid state in patients on longtreatment-time dialysis. JASN 1994;5:521.

9. Ritz E, Vallance $P$, Nowicki $M$. The effect of malnutrition on cardiovascular mortality in dialysis patients: is L-arginine the answer. Nephr Dial Transpl 1994;9:129-130.

10. Vallance $\mathrm{P}$, Leone A, Calver A, Collier J, Moncada S. Accumulation of an endogenous inhibitor of nitric oxide synthesis in chronic renal failure. Lancet 1992;339:572-575.

11. Victor RG. Reflex control of sympathetic nerve discharge in uremia. Blood purification 1997;15 suppl 1:43-45.

12. Charra B. Control of blood pressure in long slow hemodialysis. Blood Purif $1994 ; 12: 252-258$.

13. Devereux RB, Reichek N. Echographic determination of left ventricular mass in mann: anatomic validation of the method. Circulation 1971;55:613-620.

14. Scuster AH, Nanda NC. Doppler echocardiogrphic measurements of cardiac output: Comparison with a non-goldenstandard. Am J Cardiol 1984;53:257-259.

15. Leunissen KML, Menheere PPCA, Cheriex EC, van den Berg BW, Noordzij TC, van Hooff JP: Plasma alpha-human atrial natriuretic peptide and dry weight in chronic hemodialysis. Nephrol Dial Transpl 1989;4:382-386.

16. Jageneau AH. Noninvasive diagnosis in the management of cardiovascular diseases. Amstrerdam, New York, London, North Holland Biomedical Press 1981;169-229. 
17. Houben AJHM. Early (micro)circulatory hemodynamic changes in type I diabetes mellitus. Thesis, University of Limburg, Maastricht, The Nertherlands. 1993;p144.

18. Ifudu $\mathrm{O}$, Feldman $J$, Friedman EA. The intensity of hemodialysis and the response to erythropoietin in patients wh end-stage renall disease. $N$ Engl I Med $1996 ; 334: 420-425$.

19. Fishbane $S$, Natke E, Maesaka JK. Role of volume overload in dialysis-refractory hypertension. Am J Kidney Dis 1996;28:257-261.

20. Kooman JP, Gladziwa U, Bocker G, Wijnen JAG, van Bortel L, Luik A.J, de Leeuw PW, van Hooff JP, Leunissen KML. Blood pressure during the inter-dialytic period in haemodialysis patients: estimation of representative blood pressure values. Nephrol Dial Transpl 1992;7:917-923.

21. Luik AJ, Gladziwa U, Kooman JP, van Hooff JP, de Leeuw PW, wan Bortel LMAB, Leunissen KML. The influence of inter-dialytic weight gain on blood pressure in hemodialysis patients. Blood Purif $1994 ; 12 ; 259-266$.

22. Luik AJ, van Kuijk WHM, Spek J, de Heer F, van Bortel LMAB, Schiffers P, van Hooff IP, Leunissen KML. The effects of hypervolemia on inter-dialytic hemodynamics and blood pressure control in hemodialysis patients. Am J Kidney Dis (in press).

23. Anderstam B, Katzarski $\mathrm{K}$, Bergström J. Methylarginines in uremia. JASN $1994 ; 5: 572$.

24. Converse RL, Jacobsen TN, Toto RD, Jost CMT, Cosentino F, Fouad-Tarazi $F^{*}$, Victor RG. Sympathetic overactivity in patients with chronic renal failure. $\mathrm{N}$ Engl J Med 1992;327:1912-1918.

25. Krzesinski JM* Du F, Pequeux ML, Rorive GL. Plasma Na-K ATPase inhibitor activity and intracellular ions during hemodialysis. Int $\mathbb{J}$ Artif Organs $1993 ; 16: 23-30$.

26. Weiler EW, Saldanha LF, Khalil-Manesh F, Prins BA, Purdy RE, Gonick HC. Relationship of $\mathrm{Na-K}$-ATPase inhibitors to blood pressure regulation in continuous ambulatory peritoneal dialysis and hemodialysis. JASN 1996;7:454-463. 


\section{Chapter 7}

\section{Arterial compliance in patients on long-treatment-time dialysis}

AJ Luik, JJ Spek, B Charra, LMAB v Bortel, G Laurent, KML Leunissen

Nephr Dial Transpl (in press) 


\section{Abstract}

Arterial compliance is found to be reduced in hemodialysis patients. It is not clear whether the decreased arterial compliance in uremic patients is a consequence of longstanding increased mean arterial blood pressure or a consequence of the uremic state. An adequate blood pressure can be achieved by long-treatment-time dialysis of $8 \mathrm{~h}$ three times a week. We studied femoral and carotid artery wall properties in 24 normotensive patients on long-treatment-time dialysis and in 24 normal controls matched for mean arterial pressure, age, sex, and body mass index. Arterial distensibility coefficient and compliance coefficient were determined with a vessel wall movement detector system, 24 hours after dialysis in supine the position.

The patients were $5.9 \pm 6.6$ years on long-treatment-time dialysis at a $\mathrm{Kt} / \mathrm{V}$ of $1.8 \pm 0.4$. We found no significant differences in mean arterial pressure or pulse pressure between patients $(85 \pm 13,55 \pm 17 \mathrm{mmHg})$ and controls $(84 \pm 6,50 \pm 13 \mathrm{mmHg})$. Femoral distensibility coefficient and compliance coefficient were lower in patients $\left(6.0 \pm 2.410^{-3} / \mathrm{kPa} ; \mathrm{p}<0.05,0.52 \pm 0.28 \mathrm{~mm}^{2} / \mathrm{kPa} ; \mathrm{ns}\right)$ as compared to the controls $\left(8.8 \pm 4.010^{-3} / \mathrm{kPa}, \quad 0.67 \pm 0.38 \mathrm{~mm}^{2} / \mathrm{kPa}\right)$. No differences in carotid distensibility coefficient and compliance coefficient were found between patients $\left(12.8 \pm 4.610^{-3} / \mathrm{kPa}\right.$, $\left.0.72 \pm 0.30 \mathrm{~mm}^{2} / \mathrm{kPa}\right)$ and controls $\left(14.1 \pm 4.410^{-3} / \mathrm{kPa}, 0.70 \pm 0.23 \mathrm{~mm}^{2} / \mathrm{kPa}\right)$

We conclude that patients on long-treatment-time dialysis have an increased stiffening of the muscular femoral artery but not of the more elastic carotid artery. These results suggest that the uremic state itself has a deleterious effect on the elastic properties of the muscular femoral artery. 


\section{Introduction}

In hemodialysis patients, cardiovascular complications are the main cause of morbidity and mortality ${ }^{1}$. Hypertension is a major risk factor for cardiovascular disease ${ }^{2}$. Cardiac disease usually results from ischemic heart disease, systolic failure and left ventricular hypertrophy (LVH) with diastolic dysfunction?. Left ventricular hypertrophy is an independent risk factor in dialysis patients ${ }^{4}$. Furthermore in hemodialysis patients peripheral vascular changes have also been found i.e. a reduced venous and arterial compliance ${ }^{5,6}$. The consequence of a decreased arterial compliance i.e. a decreased cushioning function, is an increase in arterial pulse pressure resulting in a decrease of diastolic pressure and an increased systolic pressure ${ }^{7}$. Furthermore arteriall compliance affects pulse pressure amplitude also by an increased velocity of the-pressure wave through the stiffened arterial system, resulting in a change of the timing and incidence of reflected waves. By these effects a decreased arterial compliance contributes to the development of $\mathrm{LVH}^{8}$. It is not clear whether the decreased arterial compliance in uremic patients is a passive consequence of an increased mean blood pressure or the consequence of altered arterial composition, i.e. smooth muscle hypertrophy and increased or changed collagen content of the media".

In most dialysis centers the incidence of bypertension is high. An adequate blood pressure control with less than $5 \%$ of the patients having hypertension is achieved with long-treatment-time dialysis of $8 \mathrm{~h}$ three times weekly ${ }^{10}$. In the present study we investigated whether uremic patients on long-treatment-time dialysis with an adequate blood pressure control had different arterial wall properties, as compared to normal controls matched for age, sex, body mass index (BMI), and mean arterial pressure (MAP).

\section{Subjects and methods}

Vessel wall properties of the elastic common carotid artery and the common femoral artery were studied in 24 normotensive patients on long-treatment-time dialysis ( $9 \mathrm{~h}$, three times a week) and 24 normal controls matched for age, sex, BMI, and MAP. None of the dialysis patients were using antihypertensive drugs. Diabetic patients were excluded from the study. Dialysis patients were measured on the day after dialysis, after full equilibration of the intra- and extra-cellular fluid compartments. All subjects were evaluated in supine position after 15 min of rest. Blood pressure and heart rate were measured every $3 \mathrm{~min}$ with a semi-automated device (Dinamap). The average of at least 10 recordings was calculated. Pulse pressure $(\Delta \mathrm{P})$ was calculated as the difference between the systolic and diastolic blood pressure. 
The vessel wall properties of the carotid and femoral arteries were assessed with a vessel wall movement detector system, consisting of an echo-imaging system and a data acquisition system, connected to a personal computer ${ }^{11,12}$. Arterial diastolic diameter $(D)$ and change in diameter during the heart cycle $(\Delta D)$, were recorded over $5.6 \mathrm{~s}$. The means of three consecutive measurements were taken as the patient's reading. Vessel wall properties were calculated using the following equations:

Distensibility coefficient: $\mathrm{DC}=(2 \Delta \mathrm{D} / \mathrm{D}) / \Delta \mathrm{P}$

Compliance coefficient: $\mathrm{CC}=(\pi \mathrm{Dx} \Delta \mathrm{D}) / 2 \Delta \mathrm{P}$

Data were analyzed, using a non-parametric Mann-Whitney $U$ test. A p value $<0.05$ was considered statistically significant. Data are presented as mean $\pm \mathrm{SD}$.

\section{Results}

Dialysis patients had been $5.9 \pm 6.6$ years on long-treatment-time dialysis. Mean $\mathrm{Kt} / \mathrm{V}$ was 1.8 \pm 0.4 . 23 Patients were anuric, and one patient had a diuresis of 250 $\mathrm{ml} / \mathrm{day}$. Patients and controls characteristics are shown in table 7.1. No differences were apparent between patients and controls in respect to sex distribution, age, length, weight. BMI, MAP, and $\triangle \mathrm{P}$. Systolic / diastolic blood pressure in dialysis patients was $124 \pm 24 \mathrm{mmHg} / 70 \pm 10 \mathrm{mmHg}$ compared to $118 \pm 24 \mathrm{mmHg} / 69 \pm 6$ $\mathrm{mmHg}$ in controls. Heart rate was significantly higher in dialysis patients compared to healthy controls.

In all dialysis patients and healthy controls it was possible to measure carotid vessel wall dimensions. Femoral artery properties could be measured in 19 of 24 dialysis patients and in all healthy controls. Five patients had severe atheromatous changes, making it technically impossible to measure a reliable femoral diameter and distensibility.

Vessel wall properties are shown in table 7.2. Carotid artery diameter was significantly greater in dialysis patients compared to controls. No differences were found between dialysis patients and controls in respect to carotid distension, DC, and $\mathrm{CC}$. No significant differences were found in femoral artery diameter and distension between dialysis patients and controls. Femoral DC was significantly lower in dialysis patients compared to controls. Also femoral $\mathrm{CC}$ tended to be lower in dialysis patients, but these differences did not reach the level of significance. 


\begin{tabular}{lcc}
\hline & $\begin{array}{c}\text { Patients } \\
\mathbf{n}=\mathbf{2 4}\end{array}$ & $\begin{array}{c}\text { Controls } \\
\mathbf{n}=24\end{array}$ \\
\hline Male / female & $18 / 6$ & $18 / 6$ \\
Age (years) & $66.0 \pm 9.2$ & $65.8 \pm 7.4$ \\
Lenght (m) & $1.65 \pm 0.11$ & $1.67 \pm 0.06$ \\
Weight (kg) & $68.8 \pm 16.11$ & $73.1 \pm 9.5$ \\
BMI (kg/m $)$ & $25.0 \pm 4.0$ & $26.1 \pm 2.6$ \\
MAP (mmHg) & $85 \pm 13$ & $84 \pm 6$ \\
$\Delta P(m) H g)$ & $55 \pm 17$ & $50 \pm 13$ \\
Heart rate (beats/min) & $76 \pm 10^{\circ}$ & $59 \pm 6$ \\
\hline
\end{tabular}

" $p<0.001$

Table 7.2

Fiemoral and carotid arterial properties of long-treatment-time dialysis patients and healthy controls. DC: distensibility cosfffacient, $\mathrm{CC}$ : compliance coefficient

\begin{tabular}{lcccc}
\hline & \multicolumn{2}{c}{ Femoral artery } & \multicolumn{2}{c}{ Carotid artery } \\
& $\begin{array}{c}\text { Patients } \\
\mathrm{n}=\mathbf{1 9}\end{array}$ & $\begin{array}{c}\text { Controls } \\
\mathrm{n}=\mathbf{2 4}\end{array}$ & $\begin{array}{c}\text { Patients } \\
\mathbf{n}=\mathbf{2 4}\end{array}$ & $\begin{array}{c}\text { Controls } \\
\mathbf{n}=\mathbf{2 4}\end{array}$ \\
\hline Diameter $(\mathrm{mm})$ & $10.3 \pm 2.2$ & $9.8 \pm 1.2$ & $8.5 \pm 1.2^{*}$ & $8.0 \pm 0.9$ \\
Distension $(\mu \mathrm{m})$ & $217 \pm 124$ & $265 \pm 112$ & $376 \pm 141$ & $353 \pm 108$ \\
DC $\left(10^{-3 / \mathrm{kPA})}\right.$ & $6.0 \pm 2.4^{*}$ & $8.8 \pm 4.0$ & $12.8 \pm 4.6$ & $14.1 \pm 4.4$ \\
$\mathrm{CC}\left(\mathrm{mm}^{2} / \mathrm{kPA}\right)$ & $0.52 \pm 0.28$ & $0.67 \pm 0.38$ & $0.72 \pm 0.30$ & $0.70 \pm 0.23$ \\
\hline
\end{tabular}

\section{Discussion}

In the present study we investigated elastic properties of two different arteries using a vessel wall movement detector system ${ }^{11}$ in normotensive uremic patients on longtreatment-time dialysis matched for blood pressure, age, BMI, and sex. Femoral artery distensibility was decreased as compared to healthy controls. Also femoral artery compliance tended to be lower in dialysis patients as compared to controls, although these differences were not significant. No differences in carotid artery distensibility or compliance were found. Brachial $\Delta \mathrm{P}$ was used for calculating femoral and carotid $D C$ and $C C$. Although there are no significant differences between mean and diastolic pressure at the carotid, femoral and brachial artery, $\Delta \mathrm{P}$ is significantly amplified between central and peripheral arteries. This amplification depends on propagative properties of the arterial tree which are influenced by body 
length ${ }^{7,13}$. In normal controls the central $\Delta \mathrm{P}$ is lower than the peripheral $\Delta \mathrm{P}$. Femoral $\Delta \mathrm{P}$ is very closelly to brachial $\Delta \mathrm{P}$. However, for the carotid compliance one should keep some reserve because of the differences between brachial and central (carotid) $\Delta P$.

Using the same vessel wall movement detector system Barenbrock reported a decreased carotid artery distensibility in young dialysis patients as compared to agematched controls ${ }^{14}$. In older hemodialysis patients no difference could be found. Although the older patients group in the Barenbrock study were 6 years younger and their MAP was $6 \mathrm{mmHg}$ lower when compared to our long-treatment-time dialysis patients, DC of the carotid artery was similar to DC in long dialysis patients measured in our study $\left(11.7 \pm 1.1 \quad 10^{-3} / \mathrm{kPa}\right.$ and $\left.12.8 \pm 4.6 \quad 10^{-3} / \mathrm{kPa}\right)$. Barenbrock did not report how many years the patients had been on dialysis, and no data were given concerning the muscular femoral artery.

London also found a decreased large artery compliance in hemodialysis patients compared to controls matched for age and MAP, by measuring pulse wave velocity in the aorta, leg and $\operatorname{arm}^{6}$. He found pulse wave velocity to be more increased, so elastic properties more decreased, in the aorta as compared to the smaller femoral and brachial arteries. In our study we found muscular femoral artery elastic properties to be more affected in uremic patients than carotid artery elastic properties. While in all 24 dialysis patients elastic properties of the carotid artery could be measured, it was not possible to measure femoral artery properties in five of the 24 patients because of atheromatous plaques. This is compatible with the clinical observation that complications due to vascular disease of muscular arteries e.g. coronary and iliac arteries, are more common than complications due to vascular disease of elastic arteries e.g. carotid artery ${ }^{1}$.

In non-uremic subjects, alterations of arterial elastic properties are especially found to be influenced by blood pressure control and ageing ${ }^{15,16}$. Stiffening of the arterial vessels is most probably caused by structural changes of the vascular wall as atherosclerosis, medial and intimal thickening, accumulation of collagen fibers, deposition of calcium, and degeneration of elastic laminae ${ }^{17}$. Whether the uremic state itself has a deleterious effect on arterial elastic properties is still a subject of study. Arterial compliance is found to be decreased in hemodialysis patients ${ }^{6}$. Many hemodialysis patients are hypertensive, which will have a negative influence on the arterial compliance. On the other hand, factors other than an elevated blood pressure such as hypervolemia, anemia, lipid disorders, hyperparathyroidism, and perhaps uremic toxins cause (cardio)vascular changes in hemodialysis patients ${ }^{18,19}$. Intimal thickening and medial calcification are frequently seen in dialysis patients. There is however no strong correlation between pulse wave velocity and arterial calcification ${ }^{6}$.

In the present study we have investigated patients who had been more than 5 years 
on long-treatment-time dialysis. Blood pressure control was adequate for many years. Patients on long-treatment-time dialysis have a better survival and less cardiovascular complications as compared to patients on a more usual shorttreatment-time dialysis regime ${ }^{10}$. Nevertheless femoral artery distensibility was decreased in patients on long-treatment-time dialysis as compared to age and blood pressure matched controls. This suggests deleterious effects of other factors than blood pressure on arterial elastic properties. Another explanation for the decreased arterial elasticity could be the fact that irreversible vascular changes were already present before the patients were treated with renal replacement therapy.

Why the muscular femoral artery in dialysis patients is more affected than the elastic carotid artery is not clear. In several pathophysiological conditions such as hypercholesterolemia ${ }^{20}$ and in uncomplicated insulin dependent diabetes mellitus ${ }^{21}$, the femoral artery was more than carotid arteries suspectable for wall stiffening. In the present study heart rate was higher in patients on hemodialysis than in controls. Could this higher heart rate account for the lower distensibility in these uremic patients? Recently it has been shown in rats that increases in heart rate are accompanied with a decrease in arterial distensibility and compliance ${ }^{22}$. This decrease in arterial distensibility and compliance was more pronounced in elastic than in muscular arteries. Heart rates are about five times higher in rats than in men. It is not clear whether these findings with high heart rates in rats also apply to the much lower heart rates in humans. In addition, in the present study, a clear difference was seen at the muscular femoral artery and only a trend at the more elastic common carotid artery, which is the opposite of the results obtained in rats. It therefore is very unlikely that the smaller distensibility and compliance in these patients on hemodialysis would only be due to their increase in heart rate.

From these data we conclude that hemodialysis patients on long-treatment-time dialysis notwithstanding a good blood pressure control for many years and a decreased cardiovascular morbidity, have an increased stiffening of the femoral arteries but not of the carotid arteries as compared to controls. Whether the uremic state itself can have a deleterious effect on the elastic properties of the muscular femoral artery, or whether the decreased distensibility is related to pre-existent irreversible vascular changes, requires further study. 


\section{References}

1. Valderrábano $F$, Jones EHP, Mallick NP. Report on the management of renal failure in europe, XXIV, 1993. Nephrol Dial Transpl 1995;10 (supp 5).

2. Fernandez $\mathrm{JM}$, Carbonell ME, Mazzuchi N, Petruccelli. Simultanous analysis of morbidity and mortality factors in chronic hemodialysis patients. Kidney Int $1992 ; 41: 1029-1034$.

3. Kooman JP, Leunissen KML. Cardiovascular aspects in renal disease. Curr Opinion Nephr Hypert 1993;2:791-797.

4. Parfrey PS, Griffiths SM, Harnett IP, Taylor R, King A, Hand I, Barre PE. Outcome of congestive heart failure, dilated cardiomyopathy, hyperthrophic hyperkinetic disease and ischemic heart disease in dialysis patients. Am J Nephrol $1990 ; 10: 213-221$.

5. Kooman JP, Wijnen JAG, Draijer P, wan Bortel LMAB, Gladziwa U, Peltenburg $\mathrm{HG}$, Struyker Boudier HAJ, van Hooff $J \mathrm{P}$, Leunissen-KML. Compliance and reactivity of the peripheral venous system in chronic intermittent hemodialysis. Kidney Int 1.992;41:1041-1048.

6. London GM, Marchais SJ, Safar ME, Genest AF, Guerin AP, Metivier F, Chedid $\mathrm{K}$, London AM, Aortic and large artery compliance in end-stage renal failure. Kidney Int 1990;37:137-142.

7. London GM, Guerin A, Pannier B, Marchais S, Benetos A, Safar M. Increased systolic pressure in chronic uremia: Role of arterial wave reflections. Hypertension $1992 ; 20: 10-19$.

8. London GM, Marchais SJ, Guerin AP, Metivier F, Pannier B. Cardiac hypertrophy and arterial alterations in end-stage renal disease: Hemodynamic factors. Kidney Int $1993 ; 43$ suppl $41: S 42-S 49$.

9. London GM. Increased arterial stiffness in end stage renal failure: why is it of interest to the clinical nephrologist? Nephrol Dial Transpl 1994;9:1790-1712.

10. Charra B, Calenard E, Ruffet M, Chazot C, Terrat JC, Vanel T, Laurent G. Survival as an index of adequacy of dialysis. Kidney Int 1992;41:1286-1291.

11. Hoeks APG, Brands PJ, Smeets FAM, Reneman RS. Assessment of the distensibility of superficial arteries. Ultrasound Med Biol 1990;16:121-128.

12. Kool MJF, van Merode T, Reneman RS, Hoeks APG, Struyker Boudier HAJ, van Bortel LMAB. Evaluation of reproducibility of a vessel wall movement detector system for assesment of large artery properties. Cardiowasc Res 1994;28:610-614.

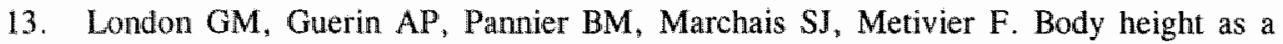
determinant of carotid pulse contour in humans. $J$ Hypertens $1992 ; 10$ Suppl 6:S93-\$95.

14. Barenbrock M, Spieker C. Laske V, Heidenreich S, Hohage H, Bachmann J, Hoeks $A P G$, Rahn KH. Studies of the vessel wall properties in hemodialysis patients. Kidney Int 1994;45:1397-1400.

15. Safar ME, London GM. Arterial and venous compliance in sustained essential hypertension. Hypertension $1987 ; 10: 133-139$. 
16. Reneman RS, wan Merode $T$, Hick $P$, Hoeks APG. Flow velocity patterns and distensibility of the carotid bulb in volunteers of varying age. Circulation 1985;71:500-509.

17. Petrovitch H, Vogt TM, Berge KG. Isolated systolic hypertension: lowering the risk of stroke in older patients. Geriatrics 1992;47:30-38.

18. London GM, Guerin AP, Marchais SJ. Pathophysiology of left ventricular hypertrophy in dialysis patients. Blood Purif 1994:12:277-283.

19. Linder A, Charra B, Sherrard DJ, Scribner BH. Accelerated atherosclerosis in prolonged maintenance hemodialysis. N Eng J Med 1972;290:697-701.

20. Kool M, Lustermans F, Kragten H, Struijker Boudier H, Hoeks A, Reneman R, Rila H, Hoogendam 1, van Bortel L. Does lowering of cholesterol levels influence functional properties of large arteries?. Eur J Clin Pharmacol 1995;48:217-223.

21. Kool MJ, Lambert J, Stehouwer CD, Hoeks AP, Struijker Boudier HA, van Bortel $\mathbb{L M}$. Vessel properties of large arteries in uncomplicated IDDM. Diabetes Care 1995; 18:618-624.

22. Mangoni AA, Mircoli L, Giannattasio C, Ferrari AU, Mancia G. Heart ratedependence of arterial distensibility in vivo. J Hypertens 1996;14:897-901. 


\section{Chapter 8}

Summary 


\section{Summary}

Cardiovascular complications are the main source of morbidity and mortality in hemodialysis patients. Cardiac disease in hemodialysis patients usually results from systolic failure, Left Ventricular Hypertrophy (LVH) with diastolic dysfunction, or ischemic disease. LVH appears to be an important, independent, determinant of survival in uremic patients. The elastic properties of the venous and arterial vessels are found to be decreased in hemodialysis patients. A decreased arterial compliance augments arterial pulse pressure resulting in a decrease in diastolic pressure and an increased systolic pressure. The decreased arterial compliance can contribute to LVH in hemodialysis patients.

Hypertension is found to be the most important risk factor for cardiovascular complications and is a major pathogenetic factor in $\mathrm{LVH}$ and decreased vascular compliance in hemodialysis patients.

The incidence of hypertension is high, and most dialysis patients are using antihypertensive drugs in order to control their blood pressure. Defining blood pressure in hemodialysis patients is difficult, for blood pressure is usually measured during the dialysis treatment. In general post-dialytic blood pressure may underestimate average blood pressure, whereas pre-dialytic blood pressure may lead to overestimation of average blood pressure. A better way to determine blood pressure level in hemodialysis patients is a continuous interdialtic blood pressure recording as can be obtained with ambulatory blood pressure monitors. Such measurements have a greater predictive value on the incidence of cardiovascular complications than a casual blood pressure reading. Using ambulatory blood pressure monitoring in hemodialysis patients, the normal physiological night-time blood pressure fall is found to be reduced. In non-uremic patients a blunted daynight blood pressure profille has been associated with cardiac damage.

The pathogenesis of hypertension in hemodialysis patients is complex and not completely understood. Hydration status, elevated vasoactive hormones, increased sympathetic activity, and structural vascular changes all play a role. Hypervolemia has always been considered the main cause of hypertension in dialysis patients. However, inter-dialytic weight gain does not correlate with inter-dialytic blood pressure changes. Although most nephrologists try to control blood pressure by ultra-filtration and lowering dry weight, the incidence of hypertension remains high. In contrast to most dialysis centers in Europe and the USA, blood pressure is remarkably well controlled in most patients in the Tassin dialysis center in France. 95\% Of their patients have an adequate blood pressure control without the use of antihypertensive medication. They treat their patients with long-treatment-time dialysis 3 times a week 8 hours, in contrast with short-treatment-time dialysis 3 times a week $3-5$ hours as is usual in most other dialysis centers. The long dialysis 
makes it possible to ultra-filtrate fluid excess more gradual with a better plasma volume preservation, which reduces the chance of intradialytic hypotension. They claim that a lower dry weight can be reached with this type of conventional dialysis as compared to short term dialysis. However, during the long dialysis sessions, patients are also more efficiently dialyzed in terms of removing small and middle molecular toxins which could have an effect on blood pressure controll too.

The main goal of this study was to investigate possible pathogenetic mechanisms that influences inter-dialytic blood pressure regulation with special focus on fluid status and dialysis dose.

Diurnal blood pressure variation is attenuated in dialysis patients. In chapter 2 we studied diurnal blood pressure variation in normotensive and hypertensive hemodialysis patients, CAPD patients, and non-uremic controls who were not receiving antihypertensive medication. Day-time and night-time blood pressure was measured during a 3-day inter-dialytic period in normotensive- and hypertensive hemodialysis patients using Spacelabs 90207 monitors. Ambulatory blood pressure was also measured during $24 \mathrm{~h}$ in normotensive- and, hypertensive CAPD patients, and in normotensive- and hypertensive control patients with a normal renal function. Although in the dialysis patients and controls a significant nocturnal blood pressure reduction was found, day-night blood pressure difference in dialysis patients was blunted when compared with control patients. No significant differences in diurnal blood pressure variation was found between the normotensive and the hypertensive patients. Day-night blood pressure differences in the hemodialysis patients did not change during the 3-day inter-dialytic period. Also the more stable fluid state of the CAPD patients was not associated with a significant different diurnal blood pressure variation compared to the hemodialysis patients. From this study we conclude that factors other than changes in extracellular fluid volume, are responsible for a blunted day-night blood pressure difference in dialysis patients.

In chapter 3 we studied the influence of short-term inter-dialytic fluid changes on blood pressure control in normotensive and hypertensive hemodialysis patients. The blood pressure was measured during 2-day and 3-day inter-dialytic periods using ambulatory blood pressure monitors. Although the inter-dialytic weight gain in the normotensive and hypertensive patients was greater during the 3-day than during the 2-day inter-dialytic period, the inter-dialytic systolic and diastolic blood pressure changes were not greater during the 3-day period. Also the inter-dialytic blood pressure rise did not correlate significantly with weight gain, neither in the normotensive nor in hypertensive patients. No significant inter-dialytic blood pressure changes were found between the normotensive and the hypertensive 
patients. From this study we conclude that fluid overload does not seem to play a major role in inter-dialytic blood pressure control in normotensive and hypertensive hemodialysis patients.

In chapter 4 the influence of hypervolemia on hemodynamics and inter-dialytic blood pressure, was investigated in 10 hemodialysis patients who were not receiving vasoactive medication. All subjects were studied during a relative normovolemic inter-dialytic period (from $1 \mathrm{~kg}$ below dry weight post-dialytic until dry weight pre-dialytic) and a hypervolemic inter-dialytic period (from $1 \mathrm{~kg}$ above dry weight post-dialytic until $3 \mathrm{~kg}$ above dry weight pre-dialytic). Inter-dialytic blood pressure was measured with an ambullatory blood pressure monitor. Cardiac output was echographically measured and systemic vascular resistance calculated post-dialytic, mid-inter-dialytic, and pre-dialytic.

After fluid load an increase in intravascular volume, an increase in caval vein diameter and cardiac output, and a decrease in peripheral resistance was observed. No significant influence of a $3 \mathrm{~L}$ fluid load was found on inter-dialytic blood pressure course comparing the hypervolemic period and the normovolemic period. Sodium and osmolality were similar in the hypervolemic and the normovolemic inter-dialytic period. After fluid load we found a decrease in AVP and Angiotensin II probably contributing to the decreased systemic vascular resistance. Catecholamines were not influenced by fluid load, but increased during the interdialytic period, suggesting accumulation after dialysis. Three of the 10 patients had higher systolic but not diastolic blood pressures after fluid load. No correlation could be found between arterial or venous compliance and blood pressure changes. From this study we concluded that a $3 \mathrm{~L}$ inter-dialytic fluid load does not result in higher blood pressure in most hemodialysis patients.

In chapter 5 we studied if the adequate blood pressure control in the Tassin patients on long-treatment-time dialysis ( 3 times a week $8 \mathrm{~h}$ ) as compared to patients on short-treatment-time dialysis, was associated with a decrease of extracellular fluid volume. 2-Day inter-dialytic ambulatory blood pressure monitoring was performed in non-diabetic patients on long-treatment-time dialysis, in patients on short-treatment-time dialysis matched for the years they had been on dialysis treatment, and during $24 \mathrm{~h}$ in healthy volunteers. Echography of the inferior caval vein was performed to determine fluid state. Cardiac dimensions and stroke index were measured by echocardiography. $73 \%$ of the patients on short dialysis were using antihypertensive medication in contrast to none of the patients on long dialysis. However, blood pressure was significantly lower in patients on long dialysis as compared to patients on short-treatment-time dialysis. Indexed caval vein diameter, left ventricular diameter index, and ANP were not significantly different in patients on long dialysis as compared to patients on short dialysis. Also 
cardiac index was comparable in patients on long and short dialysis. However, systemic vascular resistance index was significantly lower in patients on long dialysis as compared to patients on short diallysis and normal controls. Left ventricular mass index was increased in both patients on long and short dialysis as compared to controls.

From this study we conclude that patients on long-treatment-time dialysis have an adequate blood pressure control which seems mainly to be caused by a low systemic vascular resistance. These data suggests that other factors than a lower fluid state also contribute to the good blood pressure control in patients on longtreatment-time dialysis.

In chapter 6 we tested the hypothesis that by increasing dialysis dose, blood pressure can be better controlled with fewer antihypertensive drugs. The effect of lowering dry weight and increasing dialysis treatment-time on $48 \mathrm{~h}$ inter-dialytic blood pressure was prospectively studied during 3 months in hypertensive hemodialysis patients. Echocardiography was performed to determine cardiac index and left ventricular mass index. Forearm vascular resistance was measured using strain gauge plethysmography. Dialysis treatment-time was increased with 2 hours and dry weight was gradually decreased in group 1. Dialysis treatment-time was increased $2 \mathrm{~h}$ without a change in dry weight in group 2 . Dry weight was gradually lowered without changing the dialysis treatment-time in group 3.

Antihypertensive medication could be reduced in all patients groups by 30 to $60 \%$. Inter-dialytic systolic blood pressure decreased significantly after increasing dialysis treatment-time without changing dry weight. Systolic blood pressure was also lower in the other patient groups, but these differences were not significant. No change in diastolic blood pressure was found. Cardiac index and left ventricular mass did not change significantly. Forearm vascular resistance tended to decrease in the patients on long dialysis in contrast to the patients on short dialysis. No change in serum sodium was found in either of the patients groups. Kt/ $\mathrm{V}$ increased after increasing dialysis treatment-time.

From this study we conclude that dialysis dose influences blood pressure control and blood pressure is better controlled when patients are longer dialyzed.

It is not clear whether decreased arterial compliance in uremic patients is a consequence of longstanding increased mean arterial blood pressure or a consequence of the uremic state. In chapter 7 we studied femoral and carotid artery wall properties in patients on long-treatment-time dialysis who were normotensive for many years, and normal controls matched for mean arterial pressure, age, sex, and body mass index. Arterial distensibility coefficient and compliance coefficient were determined with a vessel wall movement detector system. 
We found no significant differences in mean arterial pressure or pulse pressure between patients and controls. Femoral distensibility coefficient and compliance coefficient were lower in patients as compared to controls. No differences in carotid distensibility coefficient and compliance coefficient were found between patients and controls.

From this study we conclude that patients on long-treatment-time dialysis have an increased stiffening of the muscular femoral artery but not of the more elastic carotid artery. These results suggest that the uremic state itself has a deleterious effect on the elastic properties of the muscular femoral artery.

The general conclusion from this thesis is that short-term inter-dialytic fluid changes have no major influence on blood pressure in contrast to long-term(weeksmonths) changes in fluid state. Blood pressure is better controlled by longer dialysis sessions with a higher $\mathrm{Kt} / \mathrm{V}$. When blood pressure in hemodialysis patients is not well controlled despite optimizing dry weight, dialysis treatment-time should be increased in order to increase dialysis dose.

Patients on long-treatment-time dialysis with an adequate blood pressure control for many years, still have an increased left ventricular mass and a decreased arterial compliance. The decreased arterial compliance can contribute to LVH. 


\section{Chapter 9}

\section{Samenvatting}




\section{Samenvatting}

Een toenemend aantal patiënten heeft in verband met nierfalen nierfunctievervangende behandeling nodig. Tengevolge van het niet of onvoldoende functioneren van de nieren ontstaat bij deze patiënten een opeenstapeling van afvalstoffen. Door een verminderde of afwezige urine produktie zal tevens het totale lichaamsvocht toenemen.

Hemodialyse (kunstnier-behandeling) is een vorm van nierfunctie-vervangende behandeling waarbij de nierpatiënten enkele malen per week in een dialysecentrum een kunstnier-behandeling krijgen waarbij het bloed gezuiverd wordt van afvalstoffen en het teveel aan vocht aan het lichaam onttrokken wordt. Bij CAPD (buikvlies-dialyse), een andere vorm van nierfunctie-vervangende behandeling, heeft de patiënt een catheter in de buik waardoor hij in staat is een aantal malen per dag vloeistof in en uit de buik te laten lopen. Het buikvlies fungeert dan als dialyse-membraan, waarover afvalstoffen en overtollig vocht aan het lichaam onttrokken wordt. CAPD is een geleidelijker behandeling dan hemodialyse. De CAPD patiënt dialyseert immers elke dag 24 uren terwijl de hemodialyse patiënt doorgaans 3 maal per week een aantal uren dialyseert.

Bij hemodialyse (en CAPD) patiënten vormen complicaties van hart en bloedvaten de belangrijkste bron van ziekte en sterfte. Hartproblemen bij dialysepatiënten zijn meestal het gevolg van pompfunctie stoornissen, een verdikte hartspierwand ( $L V H$ : linker ventrikel hypertrofie) en kransslagader vernauwing. LVH blijkt een belangrijke, onafhankelijke, factor voor de overleving van nierpatiënten te zijn. De elasticiteit (compliantie) van de aders (venen) en slagaders (arteriën) is bij dialysepatiënten verminderd. Een verminderde arteriële elasticiteit verhoogt de arteriële drukgolf, met als gevolg een lagere onderdruk (diastole) en een hogere bovendruk (systole). De verminderde arteriële compliantie kan door een verhoogde drukbelasting van het hart, LVH bij dialysepatiënten bevorderen.

Hoge bloeddruk (hypertensie) blijkt bij dialysepatiënten de belangrijkste risicofactor voor het ontstaan van hart- en vaatziekten te zijn en vormt tevens een belangrijke oorzakelijke factor voor verminderde bloedvat elasticiteit en het krijgen van LVH.

Hypertensie komt veelvuldig voor en de meeste hemodialysepatiënten hebben bloeddruk verlagende medicamenten nodig. Het bepalen van de juiste bloeddruk bij hemodialysepatiënten is moeilijk, daar de bloeddruk meestal vlak voor, tijdens, of vlak na de dialyse wordt gemeten. Over het algemeen is de bloeddruk gemeten vlak na de dialyse een te lage vaststelling van de gemiddelde bloeddruk van die dag terwijl de bloeddruk gemeten vlak voor de dialyse behandeling dikwijls een te hoge uitkomst geeft van de gemiddelde bloeddruk. Een betere manier om bij hemodialysepatiënten de juiste bloeddruk te bepalen is een continue-bloeddrukmeting met ambulante bloeddrukmeters gedurende de gehele periode tussen twee 
dialysebehandelingen (interdialytische periode). Zulke metingen hebben een grotere voorspellende waarde voor het optreden van hart- en vaatziekten dan een eenmalig gemeten bloeddruk. Onderzoeken bij hemodialysepatiënten met ambulante bloeddrukmeters hebben aangetoond dat de normale nachtelijke bloeddrukdaling verminderd is. Bij patiënten met een normale nierfunctie is een gedempt dag-nacht bloeddrukprofiel geassocieerd met orgaanschade. Of dit ook voor dialysepatiënten geldt is nog niet wetenschappelijk aangetoond.

Het mechanisme van hypertensie bij hemodialysepatiënten is complex en onvoldoende begrepen. Een teveel aan vocht en zout, een teveel aan bloeddrukverhogende-hormonen, verhoogde sympathische activiteit en structurele vaatveranderingen spelen allen een rol. Een teveel aan zout en lichaamsvocht wordt wel als de belangrijkste oorzaak van hypertensie bij dialysepatiënten beschouwd. Bij alle hemodialysepatiënten dient een correct streefgewicht bepaald te worden. Het streefgewicht is het gewicht van de hemodialysepatiënt na een dialyse behandeling waarbij de patiënt een normale hoeveelheid lichaamsvocht heeft. Door de patiënt te wegen voor de dialysebehandeling kan bepaald worden hoeveel vocht er tijdens de dialyse aan het lichaam onttrokken moet worden, namelijk het verschil tussen dit gewicht en het eerder vastgestelde streefgewicht. Dit geschiedt meestal op basis van klinische gegevens, waaronder het normaliseren van de bloeddruk door vochtonttrekking.

De meeste nefrologen trachten de bloeddruk dan ook te reguleren door het streefgewicht van hun dialysepatiënten te verlagen en zo het totale lichaamsvocht te verminderen. Desondanks hebben veel dialysepatiënten hypertensie. Tevens blijkt de interdialytische gewichtstoename (en dus vochttoename) niet gecorreleerd te zijn aan interdialytische bloeddrukveranderingen. Mogelijk spelen andere factoren dan water en zout regulatie een belangrijke rol.

Bij het merendeel van de patiënten in het Tassin dialysecentrum in Frankrijk is de bloeddruk goed gereguleerd, dit in tegenstelling tot de patiënten behandeld in de meeste Europese en Amerikaanse dialysecentra. 95\% Van deze patiënten heeft een normale bloeddruk zonder dat zij hiervoor medicamenten nodig hebben. $\mathrm{Zij}$ worden in dit centrum behandeld met langdurige dialyse 3 maal per week 8 uren, in tegenstelling tot kortere dialyse 3 maal per week 3-5 uren hetgeen gebruikelijk is in de meeste andere dialysecentra. De langdurige dialyse sessies maken het mogelijk om een teveel aan vocht meer geleidelijk aan het lichaam te onttrekken met minder kans op grote dalingen van het bloedvolume met als gevolg bloeddrukdalingen. Dit Franse dialysecentrum claimt dat zij met hun langdurige dialysebehandelingen in staat zijn een lager streefgewicht (en lichaamswocht) te bereiken vergeleken met de meer gebruikelijke korte dialyse. De patiënten die behandeld worden met langdurige dialyse worden tevens efficiënter gedialyseerd in termen van het 
verwijderen van afvalstoffen wat weer van invloed kan zijn op de bloeddrukregulatie.

Het voornaamste doel van dit proefschrift was de mogelijke mechanismen van hypertensie bij hemodialysepatiënten te onderzoeken, met speciale aandacht voor de vochtstatus en de dialyse effectiviteit (dialysedosis).

Het dag-nacht bloeddruk-ritme is gedempt bij dialysepatiënten. In hoofdstuk 2 onderzochten wij de dag-nacht bloeddrukvariatie bij normotensieve (normale bloeddruk) en hypertensieve hemodialysepatiënten, CAPD patiënten en patiënten met een normale nierfunctie zonder medicamenten tegen hoge bloeddruk. De dag en nacht bloeddruk werd gedurende een driedaagse interdialytische periode continu gemeten met ambulante bloeddrukmeters. Ambulante bloeddrukmetingen werden ook verricht gedurende 24 uren bij de CAPD patiënten en controlepatiënten. Alhoewel zowel de dialysepatiënten als de controle patiënten een significante nachtelijke bloeddrukdaling hadden, was het dag-nacht bloeddruk verschil bij de dialysepatiënten gedempt ten opzichte van de controlepatiënten. Er werden tussen de normotensieve en hypertensieve patiënten geen significante verschillen in dagnacht bloeddruk variatie gevonden. Het dag-nacht bloeddrukverschil bij de hemodialysepatiënten veranderde niet gedurende de driedaagse interdialytische periode. Ook bleek de stabielere vochtstatus bij CAPD patiënten ten opzichte van hemodialysepatiënten niet te resulteren in een ander dag-nacht bloeddrukverschil.

Uit deze studie concluderen wij dat andere factoren dan veranderingen in het lichaamsvocht verantwoordelijk zijn voor het gedempte dag-nacht bloeddruk ritme bij dialysepatiënten.

In hoofdstuk 3 onderzochten wij de invloed van korte-termijn interdialytische veranderingen in het lichaamsvocht op de bloeddrukregulatie bij normotensieve en hypertensieve hemodialysepatiënten. Met ambulante bloeddrukmeters werd de bloeddruk gemeten gedurende een tweedaagse en driedaagse interdialytische periode. Alhoewel de interdialytische gewichtstoename (en toename van het lichaamswater) het grootst was gedurende de driedaagse periode, resulteerde dit niet in een grotere interdialytische bloeddruk stijging gedurende de driedaagse periode ten opzichte van de tweedaagse periode. Ook bleek de interdialytische bloeddrukstijging niet gecorreleerd te zijn aan de interdialytische gewichtstoename. Dit gold zowel voor de hypertensieve patiënten als voor de normotensieve patiënten. De interdialytische bloeddrukveranderingen bij de normotensieve patiënten was overeenkomstig de interdialytische bloeddruk veranderingen bij de hypertensieve patiënten.

Uit deze studie concluderen wij dat een teveel aan lichaamsvocht geen belangrijke rol speelt bij de interdialytische bloeddrukregulatie bij normotensieve en 
hypertensieve dialysepatiënten.

In hoofdstuk 4 werd de invloed van een teveel aan lichaamsvocht op de circulatie en interdialytische bloeddruk regulatie prospectief onderzocht bij 10 hemodialysepatiênten zonder bloeddruk-medicamenten. Alle patiënten werden onderzocht gedurende een relatieve "droge" interdialytische periode (normovolemisch: van $1 \mathrm{~kg}$ onder het streefgewicht na de dialyse tot op het streefgewicht vlak voor de volgende dialyse) en gedurende een relatief "natte" interdialytische periode (kypervolemisch: van $1 \mathrm{~kg}$ boven het streefgewicht na de dialyse tot $3 \mathrm{~kg}$ boven het streefgewicht vlak voor de volgende dialyse). De interdialytische bloeddruk werd gemeten met behulp van ambulante bloeddrukmeters. De cardiac output (de hoeveelheid bloed die per minuut door het hart wordt uitgepompt) werd gemeten met een echoapparaat en de totale (bloed)vaatweerstand werd uitgerekend vlak na de dialyse, tussen twee dialyses in en vlak voor de volgende dialyse.

Na vochtbelasting zagen wij een toename van het bloedvolume, een toename van de vena cava diameter (grote holle lichaamsader), een toename van de cardiac output en een afname van de vaatweerstand. Er werd geen significante invloed van 3 liter vocht belasting op de interdialytische bloeddruk gevonden wanneer de hypervolemische periode werd vergeleken met de normovolemische periode. Het serum natrium gehalte en de osmolariteit waren vergelijkbaar in de hypervolemisch interdialytische periode en de normovolemisch interdialytische periode. $\mathrm{Na}$ vochtbelasting zagen we een afname van de hormonen AVP en Angiotensine II wat mogelijk een bijdrage levert aan de verminderde vaatweerstand. Adrenaline en noradrenaline werden niet beïnvloed door vocht belasting, maar stegen gedurende de interdialytische periode, wat een accumulatie van deze hormonen na dialyse suggereert. 3 van de 10 patiënten hadden wel een hogere bovendruk na vochtbelasting. Opvallend was dat in deze patiënten de daling van het Angiotensine II minder uitgesproken was dan in de patiënten die niet reageerden met een bloeddrukstijging. Er werd geen relatie tussen de elasticiteit van de bloedvaten en bloeddruk-veranderingen gevonden.

Uit deze studie concluderen wij dat 3 liter vocht belasting niet resulteert in een hogere bloeddruk bij de meeste hemodialysepatiënten.

In hoofdstuk 5 onderzochten wij of de goede bloeddrukregulatie bij de Tassin patiënten die behandeld werden met lange dialyse ( 3 maal per week 8 uren) een lagere vochtstatus hadden dan patiënten op korte dialyse. Ambulante bloeddrukmetingen werden verricht gedurende een tweedaagse interdialytische periode bij patiënten op lange dialyse en korte dialyse en gedurende 24 uur bij gezonde vrijwilligers. De patiënten op korte dialyse en de patiënten op lange dialyse werden een overeenkomstig aantal jaren behandeld met hemodialyse. Om 
de vochtstatus te bepalen werd een echografie van de vena cava verricht. Tevens werd een echo van het hart verricht om de cardiac output en de hartspierwanddikte te meten. $73 \%$ Van de patiënten op korte dialyse gebruikten bloeddruk medicamenten terwijl geen van de patiënten op lange dialyse bloeddruk medicamenten gebruikten. De bloeddruk van de patiënten op lange dialyse bleek echter significant lager te zijn dan de bloeddruk van de patiënten op korte dialyse. De vochtstatus bij de patiënten op lange dialyse bleek niet significant anders te zijn dan de vochtstatus bij de patiënten op korte dialyse, gemeten aan de diameter van de Vena cava en het hormoon ANP. Ook was de cardiac output vergelijkbaar bij de patiënten op lange en korte diallyse. De vaatweerstand bleek echter significant lager te zijn bij de patiënten op lange dialyse in vergelijking tot de patiënten op korte dialyse, terwijl de patiënten op korte dialyse veel bloeddruk-verlagende en vaatverwijdende medicamenten gebruikten. De dikte van de hartspierwand bleek toegenomen ten opzichte van gezonde vrijwilligers zowel bij de patiënten op korte dialyse als bij de patiënten op lange dialyse.

Uit deze studie concluderen wij dat de goede bloeddrukregulatie bij patiënten op lange dialyse voornamelijk veroorzaakt wordt door een lagere vaatweerstand. Deze gegevens suggereren dat ook andere factoren dan een lagere vochtstatus bijdraagt tot de goede bloeddrukregulatie bij patiënten op lange dialyse.

In hoofdstuk 6 testten wij de hypothese dat de bloeddruk beter gereguleerd kan worden met minder bloeddruk-medicamenten door de dialysedosis te verhogen. Wij onderzochten het effect op de interdialytische bloeddruk van een geleidelijke verlaging van het streefgewicht en een verhoging van de dialyse dosis gedurende een periode van 3 maanden. Er werd een echografie van het hart gemaakt om de cardiac output en de hartspierwanddikte te meten. De vaatweerstand in de onderarm werd direct gemeten met behulp van een plethysmograaf met een kwikdraad. De patiënten werden ingedeeld in 3 groepen. In groep 1 werd de dialysedosis verhoogd door de dialyseduur met twee uren te verlengen. Tevens werd het lichaamsvocht verlaagd door gelejdelijk het streefgewicht te verlagen. In groep 2 werd alleen de dialysedosis verhoogd door de dialyseduur met twee uren te verlengen zonder dat het streefgewicht werd verandert. In groep 3 werd alleen het lichaamsvocht verlaagd door het streefgewicht geleidelijk te verlagen zonder de dialyseduur te veranderen.

De bloeddruk-medicamenten konden met 30 tot $60 \%$ worden verminderd bij alle patiëntengroepen. Na drie maanden bleek ondanks minder bloeddruk medicatie de bloeddruk significant lager bij de patiënten waar de dialyseduur was verlengd zonder dat het streefgewicht was veranderd. De systolische bloeddruk daalde ook bij de andere patiëntengroepen maar deze verschillen bleken niet significant. Er werden geen veranderingen in diastolische bloeddruk gevonden. De cardiac output en hartspierwanddikte veranderden niet. De vaatweerstand in de onderarm had een 
calende tendens bij patiënten na varlenging van de dialyseduur in tegenstelling tot patiënten zonder verandering in dialyseduur. Het serum natrium veranderde in geen wan de patiẻnten groepen. De $K t / V$ (een maat voor de dialysedosis) steeg na verlenging van de dialyseduur.

Uit deze studie concluderen wij clat de bloeddrukregulatie beïnvloed wordt door de dialysedosis en dat de bloeddruk verbeterd kan worden door de dialyseduur te verlengen.

Het is niet duidelijk of de verminderde elasticiteit van de arteriën bij hemodialysepatiënten het gevolg is van een verhoogde bloeddruk of het gevolg is wan nierfalen. In hoofdstuk 7 bestudeerden wij de elastische vaateigenschappen van de liesslagader (arteria femoralis) en de halsslagader (arteria carotis) bij patiënten op lange dialyse die reeds vele jaren een normale bloeddruk hadden. De dialysepatiënten werden vergeleken met gezonde vrijwilligers met een overeenkomstige bloeddruk, leeftijd, lichaamsgewicht-index en sekse. Met een vaatwand-bewegings-detector-systeem werden de arteriële distensibiliteitscoëfficiënt en compliantie bepaald.

De liesslagader bleek bij dialysepatiënten stijver te zijn dan bij gezonde vrijwilligers. Er werden geen verschillen in elasticiteit gevonden van de halsslagader tussen dialysepatiënten en gezonde controles.

Uit deze studie concluderen wij dat patiënten die behandeld worden met lange dialyse een verminderde elasticiteit hebben van de liesslagader maar niet van de halsslagader. De liesslagader bevat meer gladspierweefsel dan de halsslagader. Deze gegevens suggereren dat nierfalen met name een negatief effect heeft op de elasticiteit van gladspiercel-bevattende liesslagaders.

De eindconclusie van dit proefschrift is dat korte termijn interdialytische veranderingen in de vochtstatus van dialysepatiënten geen belangrijke invloed heeft op de bloeddruk in tegenstelling tot meer langdurige (weken tot maanden) veranderingen in de vochtstatus. De bloeddruk is beter gereguleerd bij patiënten met langere dialyse behandelingen met een hogere dialysedosis $(\mathrm{Kt} / \mathrm{V})$. Wanneer de bloeddruk bij hemodialysepatiënten niet goed is gereguleerd ondanks een correcte bepaling van het streefgewicht, dient de dialyseduur verlengd te worden om zo de dialysedosis te verhogen.

Patiënten die behandeld worden met lange dialyse en die gedurende vele jaren een normale bloeddruk hebben, blijken toch nog een verdikte hartspierwand en stijvere slagaders te hebben. De verminderde arteriële compliantie bevordert de LVH bij dialysepatiënten. 


\section{Chapter 10}

\section{General discussion}

In part published: Editorial Comments; Hypertension in haemodialysis patients: is it only hypervolemia? AJ Luik, JP Kooman, KML Leunissen. Nephrol Dial Transpl 1997;12:1557-1560. 


\section{General discussion}

Cardiovascular complications remain the leading cause of death in hemodialysis patients ${ }^{1}$. Hypertension predisposes to structural abnormalities of the cardiovascular system and is identified as an important risk factor for cardiovascular disease in this population ${ }^{1,2}$. Therefore, adequate diagnosis and treatment of hypertension in hemodialysis patients is a logical step in the prevention of cardiovascular morbidity and mortality in this population.

\section{Inter-dialytic blood pressure variation}

Some problems arise with the diagnosis and definition of hypertension in hemodialysis patients. Pre-dialytic values may be higher than inter-dialytic blood pressure because of factors such as volume overload or the accumulation of vasoactive factors in the inter-dialytic period, whereas post-dialytic blood pressure may be influenced by the dialysis procedure itself. The sole use of pre-dialytic values may lead to overestimation of the incidence of hypertension, whereas postdialytic blood pressure may lead to an underestimation of inter-dialytic blood pressure because of intravascular under filling. Therefore, inter-dialytic ambulatory blood pressure measurements may be helpful. Moreover, ambulatory blood pressure measurements also inform us about the day-night blood pressure rhythm, which is often disturbed in uremic patients ${ }^{3}$. In patients with essentiall hypertension, ambulatory blood pressure measurements are correlated better with end-organ damage than office blood pressure ${ }^{4}$. A blunted day-night blood pressure difference is associated with an increased incidence of left ventricular hypertrophy ${ }^{5}$, and hence could lead to more cardiovascular complications. If this also holds true for dialysis patients remains to be elucidated. We found diurnal blood pressure variation to be attenuated to the same extent in hypertensive and normotensive hemodialysis and CAPD patients. Furthermore diurnal blood pressure variations were found not to be modified by inter-dialytic fluid changes. So other factors than changes in extracellular fluid volume seems to be responsible for the blunted day-night blood pressure difference. Probably the duration of renal insufficiency and the development of autonomic neuropathy influences diurnal blood pressure variation in dialysis patients ${ }^{6}$. Also the elevated sympathetic activity could explain the disturbed diurnal blood pressure variation. Because of their high basal level of sympathetic neural and humoral activity, dialysis patients could have an impaired response on day-time sympathetic activation, resulting in a blunted diurnal blood pressure profille?

\section{The role of volume overload}

Undoubtably, a major role in the pathogenesis of hypertension in hemodialysis 
patients is played by fluid retention, as the majority of the hemodialysis patients become normotensive after dialysis treatment is initiated and the excess volume is removed. However, the relationship between volume overload and hypertension is certainly not clear in all patients. In studies in non-díalyzed uremic patients, no significant relationship was observed between volume status and blood pressure levels.9. Moreover, a significant proportion of hemodialysis patients remain hypertensive despite the fact that 'dry weight' is reached ${ }^{10,11}$. We found no relationship between inter-dialytic weight gain and inter-dialytic blood pressure changes. Also other studies fail to find a clear relationship between inter-dialytic fluid changes and blood pressure variation ${ }^{3,12,13}$.

From a hemodynamic point of view, volume overload leads to an increase in blood pressure when the vascular tone does not adjust to the volume excess. In other words, for hypertension to occur, peripheral vascular resistance has to be increased. Indeed, differences in blood pressure in uremic patients appear to be mainly accompanied with differences in vascular resistance ${ }^{14-17}$. Whereas a local myogenic response (serving to autoregulate tissue blood flow) may contribute to this increase in vascular resistance ${ }^{18}$, abundant evidence has emerged that also supports a role for activated vasopressor systems in the pathogenesis of hypertension in hemodialysis patients. We found after inter-dialytic fluid loading an increased intravascular volume, and an increased cardiac output but a decreased systemic vascular resistance resulting in no change in inter-dialytic blood pressure. Autoregulation of systemic blood flow as postulated by Guyton ${ }^{19}$ does not appear to be applicable for short-term inter-dialytic fluid changes. However, long-term changes in volume status and exchangeable sodium could have a different effect on blood pressure control compared to short-term inter-dialytic fluid changes. We were able to reduce antihypertensive medication without increasing inter-dialytic blood pressure after slowly reducing volume status during a three months period.

\section{The role of pressor systems}

In healthy subjects, the renin-angiotensin system is suppressed in response to volume loading. However, in uremic patients, the renin-angiotensin system appears to be inappropriately activated in relationship to the volume status, which may result in an inappropriate increase in systemic vascular resistance ${ }^{14.20}$. Moreover, a correlation between blood pressure and plasma renin activity has been observed in patients with chronic renal failure ${ }^{3}$. Still, the renin-angiotensin system is not activated in all uremic patients. In our study three out of ten patients responded with an increase in blood pressure after inter-dialytic fluid loading. Whereas renin and angiotensin levels decreased significantly during inter-dialytic fluid load, this decrease was less pronounced in volume responders as compared to volume nonresponders.

Recent evidence suggests an important role for the endothelium in blood pressure 
regulation. Increased levels of endothelium-derived vasopressor factors, like endothelin- 1 are observed in hemodialysis patients, which might be due to a decreased renal clearance or to endothelial cell damage. Endothelin-1 could increase blood pressure by augmenting peripheral vasoconstriction. However, the role of endothelin- 1 in the pathogenesis of hypertension in uremic patients is still obscure, as endothelin levels were also found to be increased in normotensive hemodialysis patients ${ }^{2 x}$. In recent studies, an increase in endothelin-1 and a decrease in endothelium-dependant vasodilation was observed after administration of erythropoietin, suggesting a role for increased levels endothelium-dependant vasoactive factors in the pathogenesis of rHuEPO-related hypertension ${ }^{22.23}$.

Another mechanism leading to the increased vascular resistance in uremic patients might be a reduced endothelium-dependent vasodilatation by accumulation of endogenous inhibitors of nitric oxide, like asymmetric dimethyl arginine (1ADMA) ${ }^{24}$. However, this remains a controversial subject, as it is not clear whether 1-ADMA levels are indeed significantly elevated in the dialysis population ${ }^{25}$.

Recent studies by Converse et al., have suggested an important role for the sympathetic system in the pathogenesis of hypertension in dialysis patients ${ }^{26}$. Using micro-electrodes to assess sympathetic nerve discharge, they observed an increased sympathetic activity in hemodialysis patients (most of them being hypertensive) in comparison with healthy subjects. This sympathetic overactivity appears to be related to the diseased kidney, as in dialysis patients who had a bilateral nephrectomy, sympathetic nerve discharge equaled that of healthy controls. The mechanism behind the increased sympathetic nerve activity in dialysis patients remains as yet speculative. Possibly, uremic toxins or ischemic metabolites stimulate renal afferent nerves, either directly or via renal chemoreceptors, leading to an increase in sympathetic nerve activity through central nervous pathways ${ }^{27}$. Indeed, in rats with experimentally induced renal failure, an increased turnover of norepinephrine was observed in the locus coeruleus and posterior hypothalamic nuclei, which play an important role in the regulation of sympathetic nerve activity $^{28}$. All these data prompt further research towards the role of an increased sympathetic activity in the pathogenesis of hypertension in hemodialysis patients.

\section{The effect of hemodialysis treatment on long-term control of blood pressure}

An adequate blood pressure control with an incidence of hypertension below $5 \%$ was achieved by long-treatment-time dialysis (three times a week $8 \mathrm{~h}$ ), as performed in the Tassin center ${ }^{29}$. The long dialysis makes it possible to ultra filtrate fluid excess more gradual with a better plasma volume preservation which reduces the chance of intradialytic hypotension. During the long dialysis sessions, patients are also more efficiently dialyzed in terms of removing small and middle molecular toxins. We found that blood pressure levels in the Tassin dialysis patients were even lower compared to healthy controls. Furthermore we compared the volume 
status of patients on long-treatment-time dialysis with that of patients on shorttreatment-time dialysis (three times a week $4 \mathrm{~h}$ ). Only small and non-significant differences in volume status (assessed by echocardiography, alpha-ANP, and echography of the inferior caval vein) were observed, whereas the incidence of hypertension was manyfold higher in the group treated with shorter dialysis. The main hemodynamic finding in the patients treated with long dialysis was a reduced peripheral vascular resistance. The influence of both an increased volume removal and an increased dialysis treatment-time was studied independently. It appeared that both a decrease in dry weight without a change in dialysis treatment-time and an increase in dialysis time without a change in dry weight, lead to a significant improvement in blood pressure control. Could indeed an increased removal of uremic toxins, implicated in sympathetic overactivity, play a role in the blood pressure lowering effect of long dialysis? A role for middle molecules is suggested by the decreased incidence of hypertension with the use of hemofiltration, as found by Quelhorst et al ${ }^{30}$ It certainly appears worthwhile to address these important physiologic questions in further research.

\section{Hypertension and left ventricular hypertrophy (LVH)}

With respect to cardiovascular disease, LVH has been shown the most predominant structural finding in patients with endstage renal disease ${ }^{31.32}$. Generally, LVH progresses with time ${ }^{33}$. LVH has been shown to be an important independent determinant of survival in dialysis patients ${ }^{34}$. LVH is a physiological adaptation in response to increased pressure or volume overload. In concentric and septal hypertrophy, cardiac wall and septum are increased by chronic pressure overload due to hypertension or increased stiffening of the arterial systemic vasculature. Eccentric LVH results from chronic volume load due to hypervolemia, anemia, and arteriovenous fistula. Other factors contributing to $\mathrm{LVH}$ are age, hyperparathyroidism, and perhaps uremic toxins ${ }^{35}$. Hypertension plays a central role in the occurrence of $\mathrm{LVH}^{31}$. Control of blood pressure seems to be an important goal in reducing LVH. Canella et al. showed that long-term (24 months) treatment of hypertension with ACE inhibitors, beta-blockers and calcium antagonists resulted in a decline of the interventricular septum thickness and left ventricular mass to a degree observed in spontaneous normotensive uremic patients ${ }^{36}$.

Dialysis patients of the Tassin center on long-treatment-time dialysis have an adequate blood pressure control and less cardiovascular morbidity and mortality as compared to patients on more usual short-treatment-time dialysis ${ }^{29}$. Although blood pressure was adequately controlled for many years, LVH was still present in the Tassin patients. Left ventricular mass did not correlate with blood pressure. However, a significant correlation was found with hemoglobin concentration, suggesting anemia to be an important factor in LVH. An other important factor in 
the occurrence of LVH in the Tassin population is an increased stiffening of the arterial system, leading to an increased systolic pressure load. We found especially the distensibility of the muscular femoral arteries to be reduced in the Tassin patients on long-treatment-time dialysis, as compared to normal controls.

\section{Treatment of hypertension in hemodialysis patients}

What should be our target blood pressure in the treatment of hypertension in dialysis patients? Until now, this cannot be elucidated from present studies. However, it is probably advisable to be aggressive in the treatment of hypertension in dialysis patients, as in a recent study is was shown that patients with a mean arterial pressure below $99 \mathrm{mmHg}$ had a significantly better survival compared with patients with higher blood pressure levels ${ }^{29}$.

Furthermore, we think that it is desirable to look at the relationship between hypertension and the impact of antihypertensive treatment on end-organ damage, as a clear relationship exist, e.g. between echocardiographic abnormalities (left ventricular mass and volume) and long-term prognosis of dialysis patients ${ }^{37}$. In our clinic, we perform echocardiography once a year in our dialysis population.

How should hypertension be treated in hemodialysis patients? First, fluid and salt restriction is of utmost importance. The patients should be ultra-filtrated until optimal dry weight, preferably assessed with the help of an objective method, such as echography of the inferior caval vein (not to be performed immediately after dialysis) or bio-impedance measurements. Short and rapid ultra-filtration should be avoided, as this may lead to blood pressure drops and therefore, inadequate volume removal. In patients in whom ultra-filtration is difficult because of massive interdialytic weight gain or cardiac problems, certain manoeuvres may be of value, such as fluid removal by isolated ultra-filtration, sodium modeling or the use of intradialytic blood volume measurements. One should be very careful with excessive lowering of dry weight, as this may result in serious intradialytic morbidity and even in cerebrovascular and coronary ischemia.

When patients remain hypertensive, adjunctive treatment with antihypertensive agents should be initiated. Until now, there are few controlled data that suggest the use of any agent as first line treatment in dialysis patients. However, converting. enzyme inhibitors are often very effective, which is in line with the activated reninangiotensin system in uremic patients. Moreover, in a recent randomized study in patients with end-stage renal disease it was shown that, in contrast to a dihydropyridine calcium antagonist, the use of ACE-inhibitor resulted in a significant decrease in left ventricular dimensions ${ }^{38}$. Whether this will result in decreased cardiovascular morbidity or mortality remains to be elucidated. When despite multi-drug antihypertensive therapy the patient still remains hypertensive. increased dialysis treatment-time might be an option.

In conclusion, hypertension in the dialysis population is not a simple phenomenon, 
but has a complex and intriguing pathophysiology. Further research should provide more insight into the complex role of volume and vasopressor systems in the pathogenesis of hypertension in dialysis patients, and should address the role of blood pressure control in reduction of cardiovascular morbidity and mortality in dialysis patients. 


\section{References}

1. Degoulet $P$, Legrain M, Reach I, Aime F, Devries C, Rojas P, Jacobs C. Mortality risk factors in patients treated by chronic hemodialysis. Nehpron $1982 ; 31: 103-110$.

2. Lima JJG, Abensur $H$, Bernardes-Silva $H$, Bellotti $G$, Pileggi F. Role of arterial hypertension in left ventricular hypertrophy in hemodialysis patients: an echocardiographic study. Cardiology 1992;80:161-167.

3. Kooman JP, Gladziwa U, Bocker $G$, Wijnen JAG, van Bortel $L$, Luik AJ, de Leeuw PW, van Hooff JP, Leunissen KML. Representative blood pressure in haemodialysis patients by 48-hour ambulatory blood pressure monitoring. Nephrol Dial Transpl 1992;7:917-923.

4. Clement DL, de Buyzere M, Duprez D. Prognostic value of ambulatory blood pressure monitoring. J Hypertens 1994;12:857-864.

5. Verdecchia P, Schillaci G, Guerrieri $M$, Gatteschi $C$, Benemio $G$, Boldrini $F$, Porcellati $\mathrm{C}$. Circadian blood pressure changes and left ventricular hypertrophy in essential hypertension. Circulation 1990;81:528-536.

6. Campese VM, Romoff MS, Levitan D, Lane $\mathbb{K}$, Massry S. Mechanisms of autonomous nervous system dysfunction in uremia. Kidney Int 1981;20:246-253.

7. Bergström J. Catechoamines and control of blood pressure in hemodialysis and hemofiltration. Kidney Int 1988;34(suppl.25): S110-S114.

8. Wilkinson R, Scott DF, Uldal』 PR, Kerr DNS, Swinney J. Plasma renin and exchangeable sodium in the hypertension of chronic renal failure. $Q J$ Med $1969 ; 39: 377-394$.

9. Schultze G, Piefke S, Molzahn M. Blood pressure in terminal renal failure. Nephron 1980;25:15-24.

10. Vertes $\mathrm{V}$, Cangiano $\mathrm{K}$, Berman LB: Hypertension in end stage renal disease. $\mathrm{N}$ Engl J Med 1969;280:978-981.

11. Klooker P, Bommer J, Ritz E. Treatment of hypertension in dialysis patients. Blood Purif $1985 ; 3: 15-26$.

12. Battistella P, De Cornelissen F, De Gaudemaris R, Contard S, Janin G. Profil tensionnel ambulatoire de 48 heures chez l'hemodialyse chronique. Arch Mal Coeur $1990 ; 83: 1223-1227$.

13. Chazot C, Charra B, Laurent G., Didier C, Vo Van C, Terrat JC, Calemard E, Vanel $T$, Ruffet M. Interdialysis blood pressure control by long hemodiallysis sessions. Nephrol Dial Transpl 1995; 10:831-837.

14. Kim KE, Onesti G, Del Guerico ET, Fernandes M, Eidellson B, Swartz C. Sequential hemodynamic changes in end-stage renal disease and the anephric state during volume expansion. Hypertension 1980;2:102-110.

15. Cangiano JL, Ramirez-Muxo $O$, Ramirez-Gonzalez $R$, Trevino A, Campos JA. Normal renin uremic hypertension. Study of cardiac hemodynamics, plasma volume, extracellular fluid volume, and the renin-angiotensin system. Arch Intern Med 1976;136:17-23. 
16. Tuckman $\mathrm{J}$, Benninger $\mathrm{JL}$, Reubi $\mathrm{F}$. Haemodynamic and blood volume studies in long-term haemodialysis patients and in patients with successfully transplanted kidneys. Clin Sci Mol Med 1973;45(suppl 1):155-157.

17. de Leeuw PW. Pathophysiology of hypertension in patients on renal replacement therapy. Blood Purif 1994;12:245-251.

18. MacAllister RJ, Vallance P. Systemic vascular adaptations to increases in blood volume: The role of the blood vessel wall. Nephrol Dial transpl 1996;11:231-240.

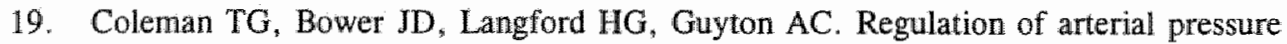
in the anephric state. Circulation 1970;42:509-514.

20. Weideman P, Baretta-Piccoli C, Steffen F, Blumberg A, Reubi C. Hypertension in chronic renal failure. Kidney Int 1976;9:294-301.

21. Takashia $K$, Totsune $K$, Mouri $T$. Endothelium in chronic renal failure. Nephron 1994;66:373-379.

22. Wada $Y$, Matsuoka H, Tamai O, Kohno $K$, Nishida H, Imaizumi T. Erythropoietin attenuates endothelium-dependent wasodilation in human forearm vessels. JASN 1996; 7:1557.

23. Kang DH, Choi KB, Yoon KI. Changes in plasma concentration of proendothelin-1 and endothelin-1 after recombinant human erythropoietin administartion in hemodialysis patients: A possible role of the activity of endothelin converting enzyme in rHuEpo-induced hypertension. JASN 1996;7:1551.

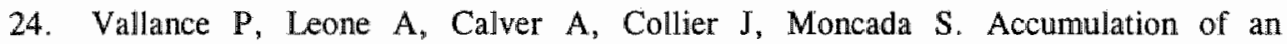
endogenous inhibitor of nitric oxide synthesis in chronic renal failure. Lancet 1992;339:572-575.

25. Anderstam $B$, Katzarski $\mathrm{K}$, Bergström J. Methylarginines in uremia. JASN $1994 ; 5: 572$.

26. Converse RL, Jacobsen TN, Toto RD, Jost CJ, Cosentino F, Fouad-Tarazi DOF, Victor RG. Sympathetic overactivity in patients with chronic renal failure. New Eng I Ned 1992;327:1912-1918.

27. Campese WM. Neurogenic factors in hypertensive patients with chronic renal failure and on dialysis. Semin Dial 1996;9:390-391.

28. Bigazzi R, Kogosov E, Campese VM. Altered norepinephrine turnover in the brain of rats with chronic renal failure. JASN 1994;4:1901-1907.

29. Charra B, Calemard E, Ruffet M, Chazot C, Terrat JC, Vanel T, Laurent G. Survival as an index of adequacy of dialysis. Kidney Int 1992;41:1286-1291.

30. Quelhorst E, Schuenemann B, Hildebrand U, Neumann W. Hypertension and haemofiltration. Contrib Nephrol 1982;32:46-55.

31. Harnett JD, Parfrey PS, Griffith SM, Gault MH, Barre P, Guttmann RD. Left ventricular hypertrophy in end-stage renal disease. Nephron 1988;48:107-115.

32. Foley RN, Parfrey PS, Harnett JD, Kent GM, Martin CJ, Murray DC, Barre PE. Clinical and echographic disease in patients starting with end-stage renal disease therapy. Kidney Int 1995;47:186-192.

33. Parfrey PS, Harnett JD, Griffiths SM, Taylor R, Hand J, King A, Barre PE. The clinical course of left ventricular hypertrophy in dialysis patients. Nephron 1990;55:114-120. 
34. Silberberg JS, Barre PE, Prichard SS, Sniderman AD. Impact of left ventricular hypertrophy on survival in end-stage renal disease. Kidney Int 1989;36:286-290.

35. London GM, Guerin AP, Marchais SI. Pathophysiology of left ventricular hypertrophy in dialysis patients. Blood purif 1994;12:277-283.

36. Canella $G$, Paoletti $E$, Delfino $R$, Peloso $G$, Molinari $S$, Traverso GB. Regression of left ventricular hyperthrophy in hypertensive uremic patients on long-1erm antihypertensive therapy. Kidney Int 1993;44:881-886.

37 Foley RN, Parfrey PS, Harnett JD, Kent GM, Murray DC, Barre DE. The prognostic importance of LV geometry in uremic cardiomyopathy. JASN $1995 ; 5: 2024-2031$.

38 London GM, Pannier B, Guerin AP, Marchais SJ, Safar ME, Cuche IL. Cardiac hypertrophy, aortic compliance, peripheral resistance and wave reflection in endstage renal disease. Comparative effects of ACE inhibition and calcium channel blockade. Circulation 1994;90:2786-2796. 


\section{Dankwoord}




\section{Dankwoord}

Een proefschrift maak je niet alleen. Het is de inspanning van velen die het mogellik maken een dergelijk werk te voltooien. In de eerste plaats zijn het natuurlijk de vele dialysepatienten die hun medewerking hebben verleend. Hen wil ik in de eerste plaats bedanken voor de inspanning die zij hebben geleverd. Metname de langdurige studies vragen veel van de betrokkenen. Het is bijvoorbeeld niet niks on gedurende 3 maanden 3 maal per week 2 uur langer gedialyseerd te worden. Dit proefschrift is een poging dialysepatienten beter te kunnen behandelen. De patiënten die hebben meegewerkt aan dit onderzoek hebben dit ook metname gedaan voor hun medepatiënten. Ik hoop dan ook dat dit proefschrift aan de verwachting voldoet.

Voorts will ik mijn copromotor en begeleider Dr KML Leunissen bedanken. Beste Karel, jij bent altijd de stimulerende en enthousiasmerende factor geweest met dit proefschrift als resultaat. Ik hoop dat we in de toekomst nog gezamenlijk het nodige wetenschappelijke werk op het gebied van hypertensie bij dialysepatienten kunnen verrichten. Ook wil ik mijn promotor en opleider in het aandachtsgebied Nefrologie Prof dr JP van Hooff bijzonder bedanken. Beste Hans, de bijna zes jaren die ik op de afdeling Nefrologie in het azM heb gewerkt heb ik altijd als zeer plezierig ervaren. Jij bent daar een belangrijke factor in geweest wat voornamelijk ook komt door de prettige samenwerking die ik heb ondervonden. Ik ben dan ook blij dat ik vanuit het st Maartensgasthuis deze samenwerking kan continueren door de affiliatieovereenkomst die wij onlangs met het azM hebben geslloten.

In het azM ben ik veelvuldig bijgestaan door verschillende collega's. Zelden deed ik vergeefs een beroep op hen. Ik wil dan ook speciaal Frank van de Sande, Jeroen Kooman, Petra Draaijer en Willy van Kuijk bedanken. Dit proefschrift is alleen maar mogelijk geweest door de medewerking van velen. Janneke Spek en Dr LMAB van Bortel van de vakgroep Farmacologie van de UM wil ik hier hartelijk voor danken. Luc van Bortell wil ik tevens danken voor het feit dat hij zitting heeft willen nemen in de beoordelingscommissie. Janneke Spek heeft de moed gehad om mij ook tijdens het onderzoek in Frankrijk te begeleiden. Janneke, ook hiervoor mijn dank. Dr EC Cheriex en Jos Habets van de vakgroep cardiologie wil ik eveneens bedanken voor de bereidwilligheid de belangrijkste cardiologische evaluaties te verzorgen. Jos Habets heeft hiervoor wel een bijzonder offer gebracht toen hij mij zelfs tijdens carnaval vergezelde tijdens onze studie in Frankrijk. Speciale steun kreeg ik van de mensen van het lab Claudia, Timo, Monique, Paul van Es en Paul Schiffers. Bedankt allen.

Het onderzoek werd verricht op verschillende dialyseafdelingen. Ik wil daarom de dialyseverpleging van azM, maar ook de dialyseverpleging van Roermond, Sittard, het AMC, en Tassin bedanken. Wim Grave en Joris Wirtz nefrologen in Roermond hartelijk dank voor de samenwerking. Ook Cees Doorenbosch en Frans de Heer nefrologen in Sittard en Deventer, bedankt. Dick Struijk en Rudolf van Olden Nefrologen in het AMC wil ik danken voor hun medewerking aan de studie bij CAPD patiënten. Prof H Mann, Dr U Gladziwa, Dr P Weideman, und Frau Stiller von dem Kuratorium für Heimdialyse will ich danken für die Zusammenarbeit und die Gastfreiheit, die es möglich gemacht 
haben, ein wichtigen Tell der wissenschafthchen arbeit zu vollbringen. I want to bring my special thanks to Dr Bernard Charra and Dr Guy Laurent from the Tassin dialysis center in France. You have given us twice the possibility to study your dialysis patients who are unique in terms of dialysis treatment. I will always think with delight at that time. I want to thank Dr Krassmir Katzarski and Prof dr J Bergström of the Karolinska Institute Hudinge Sweden for their participation to our collaborative study at the Tassin dialysis center. Krassimir I really enjoyed as well our work at Tassin as the time we've spend in Lyon after the work was done. Thank You.

Dr PCA Menheere en Prof PW de Leeuw wil ik danken voor de bijdrage die zij hebben geleverd.

De leden van de beoordelingscommissie die ik nog niet heb genoemd wil ik bedanken voor de bereidwilligheid mee te werken aan dit proefschrift. Prof Dr PJEM Kitselaar wil ik danken voor het feit dat hij voorzitter van de beoordelingscommissie wil zijn. Ook dank aan Prof Dr ir APG Hoeks die waardevolle opmerkingen m.b.t. dit proefschrift heeft gegeven. Prof Dr GK van der Hem wil ik nog eens extra bedanken. U was het die mij indertijd in Groningen mijn interesse in de nefrologie heeft weten te wekken. Prof Dr GM London, thank you for your participation in this thesis. It is a privilege to have you in the board as a specialist in the field of hypertension in dialysis patients.

Tiny Wouters wil ik danken voor de tijd en inspanning die zij heeft geleverd voor het drukkJaar maken van dit proefschrift. Dick de Reus dank ik voor de gramaticale correcties. Max Gaasbeek dank ik voor het ontwerpen van de cover. De collega's van mijn maatschap Dr Jos Mattousch, Herman Scheerder, Vic Verstappen, Dr Jan Vreeswijk en Loek van Wilderen will ik danken voor de prettige samenwerking en goede sfeer waarin ik dagelijks werk.

Eveneens wil ik bedanken mijn opleiders algemene interne geneeskunde aan de VU in Amsterdam Prof Dr C van der Meer en later Prof Dr $J$ van der Meer.

Mijn speciale dank gaan uit naar mijn ouders die mij voor het belangrijkste deel hebben gevormd en de mogelijkheid hebben gegeven om te studeren.

Eveneens gaat mijn speciale dank uit naar mijn kinderen Lucas, Sophie, en Philine aan wie ik dit proefschrift heb opgedragen. Zij moesten hun Papa vaak missen, niet alleen voor dit proefschrift maar ook voor zijn werkzaamheden in het st Maartens Gasthuis. Ik hoop dit toch na 15 januari weer goed te maken. Ten slotte wil ik mijn lieve vrouw Marijke danken voor de steun die ze mij heeft gegeven en geeft. Ik weet dat je dit onzin vind maar zonder jou was dit werk nooit tot stand gekomen. 
Curriculum Vitae 


\section{Curriculum Vitae}

The author of this thesis was born on August 6, 1959 in Steenwijk, the Netherlands. He graduated in 1978 from the Dr Nassau College (Atheneum B) in Assen. From 1978 he studied at the Medical Faculty of the University of Groningen where he received his doctoral degree in 1983, and his medical degree in 1985. In 1985 he started his Internal Medicine specialist training at the Free University Hospital Amsterdam (head Prof $\mathrm{C}$ van der Meer, later Prof $J$ van der Meer). In 1989 he married Marijke S Koop. He was registered as an Internist in 1990 . From 1990 until 1995 he worked as a staff member at the Department of Nephrology of the University Hospital Maastricht (head Prof JP van Hooff). In that period his three children were born (Lucas 1990, Sophie 1992, Philine 1994). In 1991 he was registered as a Nephrologist. Since 1995 he is working as an Internist-Nephrologist at the Department of Internal Medicine of the st Maartensgasthuis Venlo. 